Cómo citar este artículo / How to cite this article: Morillo Cerdán, Á., Durán Cabello, R., Martín Hernández E., y Rodríguez Martín, G. (2022). El complejo militar romano republicano del Pedrosillo (Casas de Reina, Badajoz). ¿Un escenario de las Guerras Lusitanas? Lucentum, Online First, 1-32. https://doi.org/10.14198/LVCENTVM.20197

\title{
El complejo militar romano republicano del Pedrosillo (Casas de Reina, Badajoz). ¿Un escenario de las Guerras Lusitanas?
}

\author{
The republican roman military complex of El Pedrosillo (Casas de Reina, \\ Badajoz). A battlefield of the Lusitanian Wars?
}

\begin{abstract}
Ángel Morillo Cerdán, amorillo@ucm.es, https://orcid.org/0000-0003-2139-0346, Universidad Complutense de Madrid, España Rosalía Durán Cabello, roduran@ucm.es, https://orcid.org/0000-0002-9896-7716, Universidad Complutense de Madrid, España Esperanza Martín Hernández, dolabra@dolabra.es, https://orcid.org/0000-0003-1718-7281, Investigadora independiente, España Germán Rodríguez Martín, germanroma@gmail.com, https://orcid.org/0000-0003-3909-4019, Investigador independiente, España
\end{abstract}

\section{Resumen}

Las intervenciones arqueológicas desarrolladas en el yacimiento del Pedrosillo (Casas de Reina, Badajoz) entre los años 2004 y 2010 pusieron de manifiesto la existencia de un complejo militar romano de época republicana, formado por dos recintos campamentales poligonales, además de numerosos recintos circulares y cuadrangulares y defensas complementarias como muros de piedra aislados (tituli). Las evidencias se extendían a lo largo de unas 50 ha, ocupando ambas riberas del arroyo Pedrosillo y las dos laderas que bajan con cierta pendiente hacia el mismo, justo donde se encuentran tanto un manantial como un vado natural. Presentamos en estas líneas los resultados del análisis edilicio y arquitectónico de las estructuras de dicho conjunto. A pesar de sus diferencias en cuanto a dimensiones y planta, las estructuras comparten la misma técnica y sistema edilicio: un doble paramento realizado con bloques de piedra regularizados en sus caras exteriores y un núcleo de piedras de mediano y pequeño tamaño compactado con tierra. Más que ante murallas estamos ante parapetos de 1,30-1,40 $\mathrm{m}$ de altura y unos 1,80 $\mathrm{m}$ de anchura. Para su construcción se amortizan intencionadamente las ruinas de varias estructuras de época calcolítica.

Se presentan asimismo las evidencias materiales tanto numismáticas como de militaria (glandes, pila catapultaria), además de utillaje militar (piquetas de tienda) y objetos de adorno personal (pasador en "T", amuleto de forma fálica) localizados a través de la prospección con detector de metales. Los hallazgos romano-republicanos se concentran en el interior de los dos campamentos, lo que confirma su identificación como objetos perdidos durante la ocupación romana. Se han localizado

\begin{abstract}
Archaeological fieldwork and excavations carried out between 2004 and 2010 in the Roman settlement of Pedrosillo (Casas de Reina, Badajoz) revealed a late Republican Roman military complex formed by two polygonal camps, circular redoubts and an associated system of defence in the shape of isolated walls (tituli). The archaeological remains cover about 50 ha, occupying both banks of the Pedrosillo stream and the two slopes that descend toward the area where there are both a spring and a natural ford. The analysis of the physical form of this complex is presented in this discussion. Despite there being differences in dimensions and layout, the structures have the same construction technique: a facing wall of regular stone blocks on either side and a compacted inner core of small and medium-sized stones and earth. These remains can be interpreted as parapets/ramparts 1,30-1,40 $\mathrm{m}$ high and about 1,80 $\mathrm{m}$ wide. Their construction process intentionally levelled several Chalcolithic structures.

The archaeological artefacts that were recovered from metal detector surveys are also discussed. These objects included coins, militaria (iron spears, lead slingshots), military tools (iron tent pegs) and personal objects (T-shaped fibulae, lead phallic amulet). The Roman Republican finds are concentrated inside the two camps, confirming their identification as lost objects during the Roman Republican period. Several tent pegs made out of iron were even found in situ, allowing reconstruction of the position and the modular layout of the leather tents.

The site appears to be of strategic significance, controlling and protecting a stream ford with circular forts and linear fortifications. Therefore, we hypothesize that the space may have been
\end{abstract}

Financiación: Este trabajo se inscribe dentro del Proyecto de Investigación "Paisaje y territorio militarizado en la Hispania romana: movilidad y transferencia cultural (ss. II a. C.-IV d. C.)" (I+D HAR2017-85929-P), concedido por el Ministerio de Economía, Industria y Competitividad (MINECO), la Agencia Estatal de Investigación (AEI) y el Fondo Europeo de Desarrollo Regional (FEDER), dirigido por Á. Morillo y C. Blázquez Cerrato. 
incluso varias clavijas in situ que permiten reconstruir la posición y el módulo de las tiendas de campaña.

El yacimiento parece constituir un dispositivo táctico para controlar y proteger un vado del arroyo mediante fortines circulares y fortificaciones lineales, por lo que se plantea la hipótesis de que el espacio fue adecuado como un campo de batalla. La documentación arqueológica permite proponer una datación para este conjunto centrada en la segunda mitad del siglo II a. C., tal vez en relación con las Guerras Lusitanas.

Palabras clave. Lusitania; República romana; Guerras Lusitanas; castrametación; campamentos; campo de batalla; monedas; militaria; balas de honda de plomo. prepared as a potential battlefield. Archaeological data (coins) allows us to propose the second half of the 2 nd century $\mathrm{BC}$ as the potential period of use of this complex, perhaps in relation with the Lusitanian War.

Key Words. Lusitanian; Roman Republic; Lusitanian War; castrametation; Roman Camps; battlefield; coins; Militaria; lead slingshots.

\section{DESCRIPCIÓN GEOGRÁFICA Y TOPOGRÁ- FICA DEL YACIMIENTO DEL PEDROSILLO}

El yacimiento de El Pedrosillo se localiza en la provincia de Badajoz, junto a las ultimas estribaciones de Sierra Morena y próximo a un paso natural de la Cordillera, a unos $7 \mathrm{~km}$ al noreste de la actual ciudad de Llerena, precisamente donde se encuentran los términos municipales de Llerena, Higuera de Llerena y Casas de Reina, municipio al que pertenecen las estructuras constructivas más destacadas. El yacimiento se desarrolla a lo largo de una extensa superficie, si bien la parte principal ocupa unas 50 ha y se concentra a ambos lados del vado del paso del arroyo denominado Pedrosillo, afluente del arroyo Conejo, que vierte aguas en el embalse de Llerena, dando así nombre al yacimiento ${ }^{1}$. El riachuelo discurre en esta zona en la cota 577-575 m s.n.m., a partir de la cual el terreno asciende por las dos orillas con una ligera pendiente, hasta alcanzar una altitud máxima de $602 \mathrm{~m}$, lo que permite un buen control visual del territorio circundante (Fig. 1).

Desde el punto de vista geológico y morfológico, toda esta región corresponde a una penillanura que desciende suavemente desde Sierra Morena en dirección norte. Los materiales pertenecen al antiguo zócalo herciniano (Periodos Precámbrico y Cámbrico). Sus testimonios se pueden apreciar en el lecho de la corriente del arroyo en la denominada localmente "piedra jabaluna", haciendo referencia al aspecto jabonoso de la roca erosionada. El resto del yacimiento afecta una zona de material tectónico más reciente, de finales del Terciario o del Cuaternario inferior (Plioceno o Pleistoceno), con afloramientos en superficie de esquisto de color gris-azulado o verdoso, roca silícea de grano fino y superficie satinada, que retiene el agua fácilmente incluso durante el verano. La naturaleza del terreno y la abundancia de afloramientos rocosos y piedras aisladas

1. Los topónimos "El Pedrosillo" y "Las Matas del Pedrosillo" aparecen reflejados en este lugar, un islote de tierras incultas rodeado de campos de labranza, en el mapa de escala 1:50000 de 1946. Sin embargo, en las ediciones más modernas del IGC (1987 y 2002) se ha colocado más al oeste, en una zona donde no hay ningún indicio en el terreno que pueda justificar dicho topónimo. en superficie, empleados como material constructivo para el hábitat humano, han determinado que estas tierras permanecieran sin cultivar hasta principios de este siglo, dedicadas a pastos, pero manteniendo manchas aisladas de encina y carrasca y matorral (retama). En los últimos 20 años, el empleo de maquinaria agrícola para la adecuación de estas tierras para el cultivo ha supuesto el desmantelamiento y la deformación de buena parte de las estructuras del yacimiento, tal y como se puede apreciar con una simple comparativa de las fotografías aéreas del Vuelo Americano de 1956 con las imágenes obtenidas a partir del año 2003 (Fig. 2).

\section{LA IDENTIFICACIÓN DEL ASENTAMIENTO Y LAS INTERVENCIONES ARQUEOLÓGICAS (2006-2010)}

En el año 2003, dentro del Programa Marco Cuatrianual de Investigación de la Casa de Velázquez, destinado al estudio del territorio de la ciudad romana de Regina (Casas de Reina, Badajoz), J.-G. Gorges y F. G. Rodríguez Martín localizaron este yacimiento. En el lugar se conocía la presencia de "túmulos" de época calcolítica, en los que se realizaron algunos sondeos durante los años ochenta del siglo XX. Los resultados de dichas intervenciones arqueológicas nunca fueron entregados ni publicados. Fue la presencia de varios recintos anómalos construidos en piedra seca, así como un importante número de antiguos majanos perfectamente alineados en el terreno lo que llamó la atención de los mencionados investigadores, que acometieron durante los años 2003 y 2004 una prospección superficial intensiva, en particular de toda el área meridional del complejo, que concentra los recintos más significativos y se extiende a lo largo de unas 90 ha. Los resultados de dichas investigaciones se dieron a conocer en varios trabajos (Gorges y Rodríguez Martín, 2004; 2006) (Fig. 3). A la vista de su posible identificación como un conjunto de estructuras militares de época romana, a partir de 2005 se configuró un nuevo equipo investigador, incorporando a A. Morillo, R. Durán Cabello y E. Martín Hernández, con los que han colaborado puntualmente otros investigadores como F. Morales Hernández y J. Salido. 


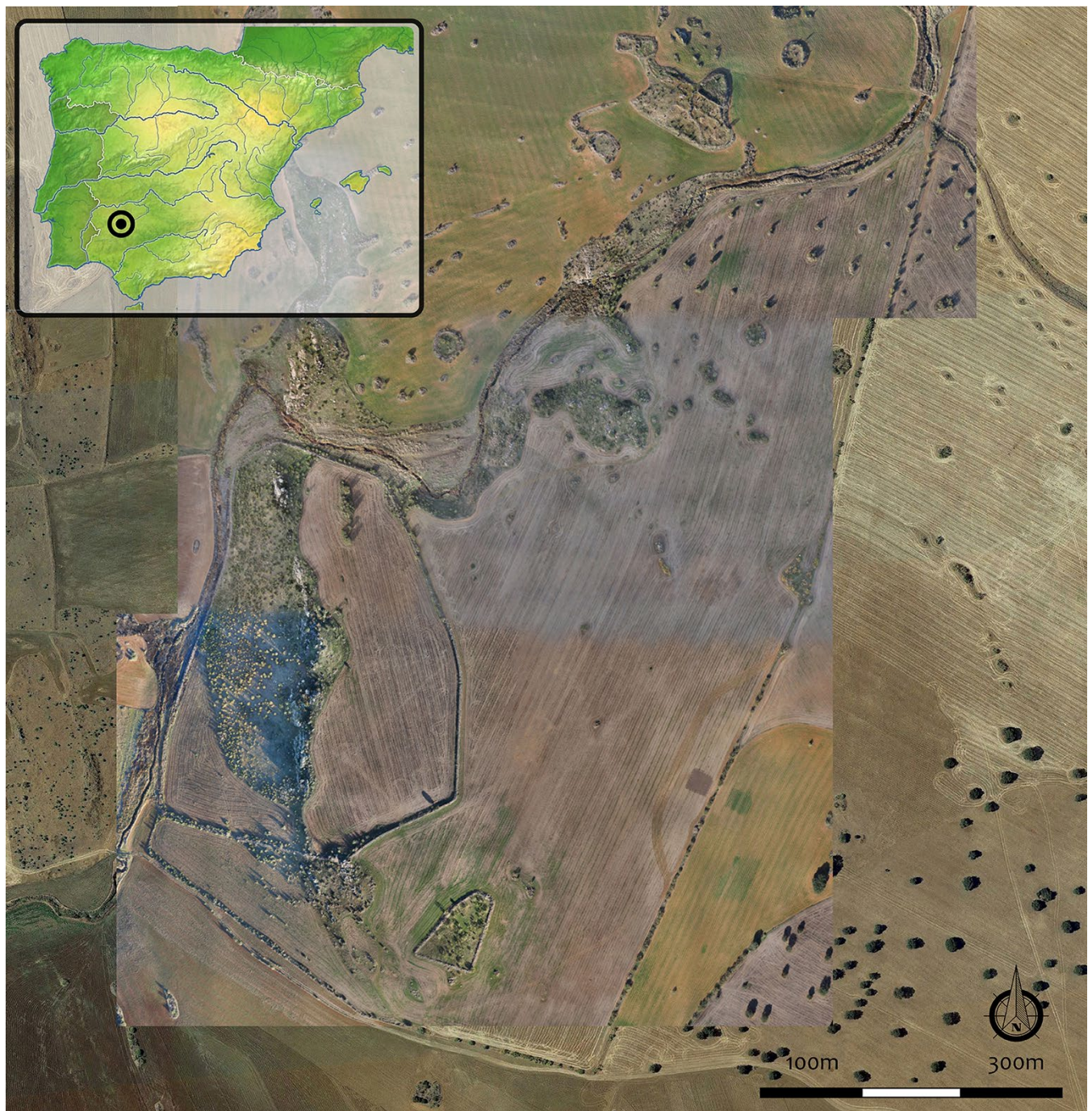

Figura 1: Localización del yacimiento del Pedrosillo y ortofotografía elaborada por el CAI de Geografía e Historia de la Universidad Complutense de Madrid, orientación norte (octubre 2015)

La primera campaña de excavación, acometida en el año 2006 bajo la dirección científica de J-G. Gorges, Á. Morillo, y F. G. Rodríguez Martín, con el apoyo económico de la Casa de Velázquez de Madrid y de la Universidad de Toulouse, estuvo encaminada a confirmar las hipótesis planteadas a partir de las prospecciones anteriores. Se acometieron 8 sondeos. Tres de ellos, el Sondeo 2006/1 (10 x 5 m), el 2006/5 $(5,50 \times 2,25 \mathrm{~m})$ y el 2006/6 (6 × $3 \mathrm{~m})$ se llevaron a cabo en las cercanías del recinto poligonal de menor tamaño, que se denominó $\mathrm{C} 2 \mathrm{a}^{2}$, a fin de determinar la existencia de un posible asentamiento anterior que parecía intuirse a través de la fotografía aérea. Esta hipótesis que se descartó por completo gracias a las

2. En este trabajo hemos mantenido la denominación alfanumérica que asignaron J-G. Gorges y F. G. Rodríguez Martín (2006: 666, fig. 5) a las diferentes estructuras, aunque algunas de las identificadas en su día ya no resultan reconocibles en la actualidad e incluso otras puedan reinterpretarse después de una documentación exhaustiva. intervenciones, comprobándose en su lugar la presencia de estructuras prehistóricas. La prospección intensiva del pequeño recinto permitió documentar in situ varios clavos largos de hierro todavía hincados en el suelo a intervalos regulares, de los que nos ocuparemos más adelante. El recinto grande (C2) fue objeto de otros 4 sondeos, a fin de comprobar el sistema constructivo de sus defensas (Sondeo 2006/2, de 2 × 6 intramuros y 8 x 2 m extramuros, y Sondeo 2006/4, de 4 x 2 m) y descartar la presencia de estructuras interiores (Sondeos 2006/7 y 2006/8 de 1 x $1 \mathrm{~m}$, acometidos a 10 y $20 \mathrm{~m}$ del muro oriental). Finalmente, el Sondeo 2006/3 (3 x $2 \mathrm{~m}$ ) se llevó a cabo en un pequeño regato de dirección sureste-noroeste, que claramente delimitaba el espacio por el este, desaguando en el arroyo Pedrosillo, aproximadamente a unos $200 \mathrm{~m}$ de su intersección con aquel. Aunque el sondeo puso en evidencia una canaleta abierta a mano en el lecho del riachuelo, no se pudo comprobar la antigüedad de la obra.

Más allá de algunas hipótesis de trabajo sobre la interpretación funcional y adscripción cultural al periodo romano de este yacimiento, esta campaña no 


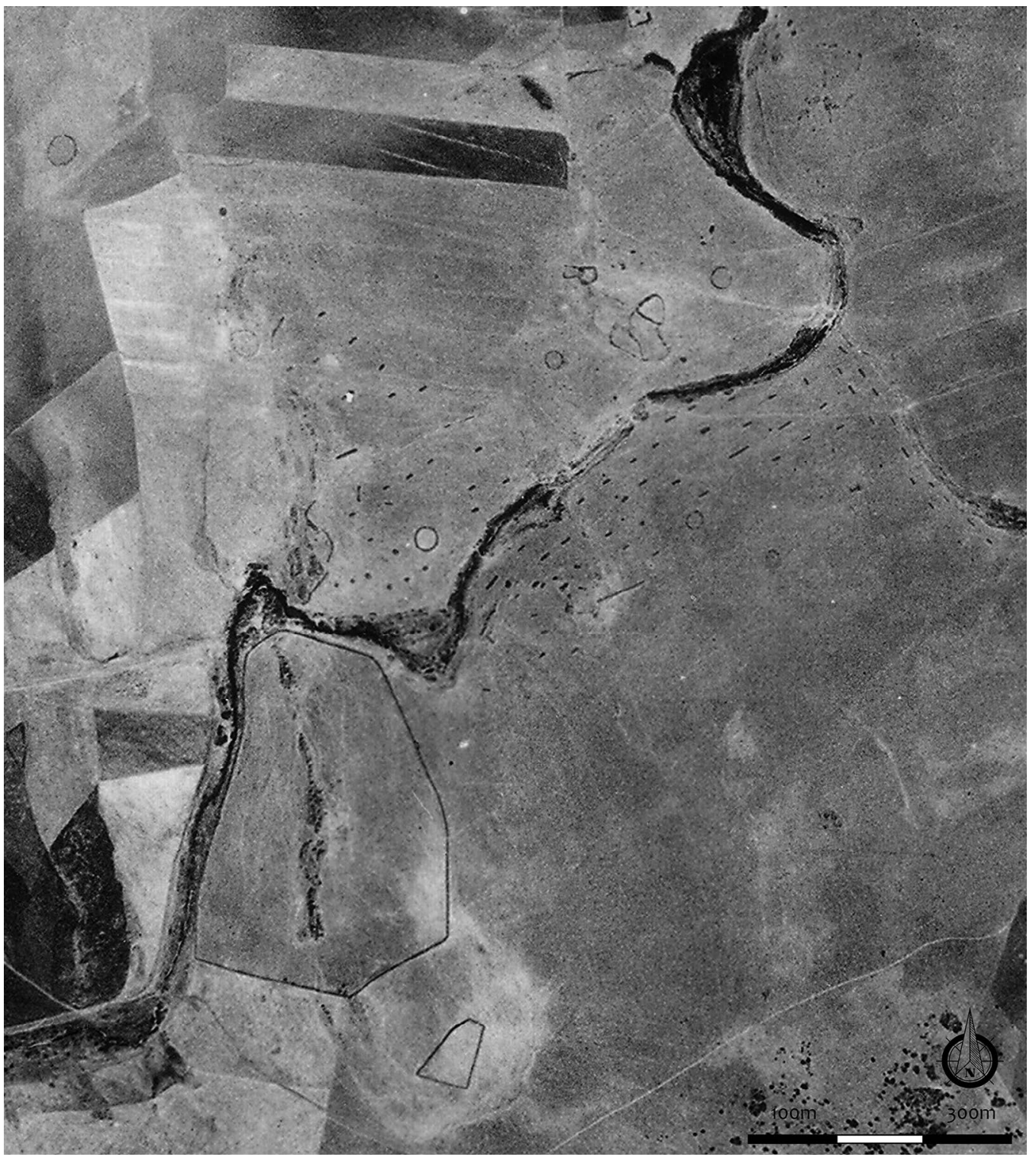

Figura 2: Vista de la parte principal del complejo arqueológico del Pedrosillo a partir de la fotografía aérea vertical del Vuelo Americano de 1956, orientación norte (Fotografía 19028, rollo 193, fecha: 5 de agosto de 1956)

proporcionó ningún elemento de datación. Los resultados científicos de las excavaciones se dieron a conocer en 2009 (Gorges et al., 2009).

La segunda intervención arqueológica se llevó a cabo durante el mes de octubre de 2007 bajo la dirección científica de Á. Morillo, J-G. Gorges y F. G. Rodríguez Martín. En esta ocasión se contó con el apoyo económico de la Casa de Velázquez de Madrid, la Universidad de León y la empresa Arquex S. L. Los trabajos de excavación (Morillo et al., 2011), consistieron en la realización de 7 sondeos en diferentes puntos del complejo. Asimismo, se acometió una prospección empleando un detector de metales.

Buena parte de los trabajos de excavación se concentraron en el campamento más grande $(\mathrm{C} 2)$, a fin de completar su documentación arqueológica, ya iniciada durante la campaña anterior. El Sondeo 2007/2 (9 x 7 m extramuros y 2,5 x 2 intramuros), el Sondeo 2007/3
$(3 \times 2,25 \mathrm{~m})$ y el Sondeo $2007 / 7(1,3 \times 1,2 \mathrm{~m})$ tuvieron como objetivo comprobar el sistema constructivo de las defensas en el ángulo sudoriental y sus laterales meridional y occidental respectivamente. La homogeneidad del planteamiento y la obra quedo perfectamente constatada, así como la amortización intencionada en la zona sudoriental de las estructuras calcolíticas, que ya se habían registrado en la campaña anterior. La Cata 2007/1, ubicada en el punto culminante del espolón rocoso central del recinto grande, confirmó la escasa potencia arqueológica $(20-30 \mathrm{~cm})$ y corroboró la ausencia de construcciones interiores (Morillo et al., 2011: 62-64).

El resto de las intervenciones (Sondeos 2007/4, $2007 / 5$ y 2007/6) se efectuaron en otros sectores del yacimiento. El Sondeo 2007/4 se acometió en uno de los recintos circulares mejor conservados, ubicado en la ribera izquierda del arroyo (c5). Desde dicha 


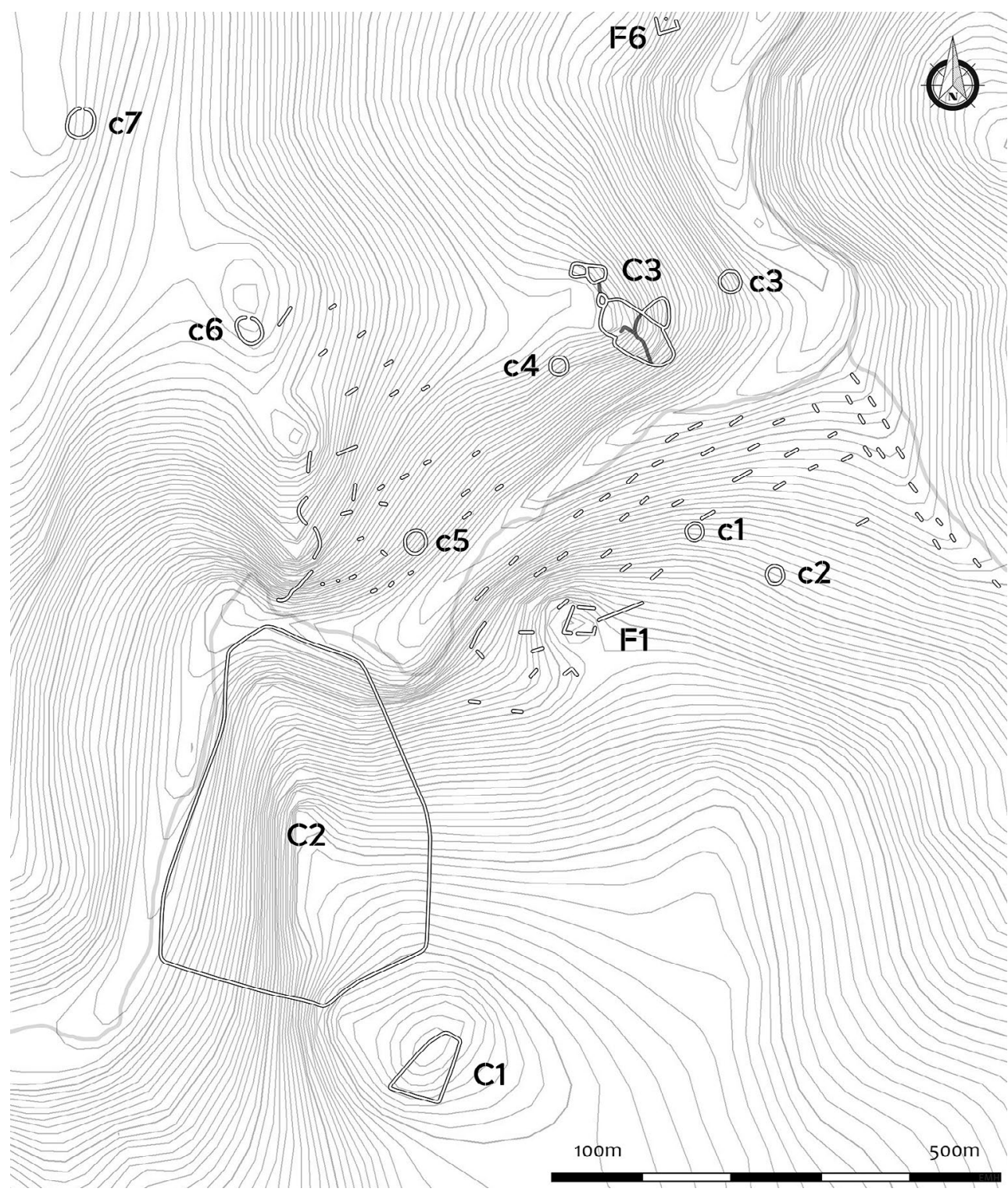

Figura 3: Esquema del complejo arqueológico del Pedrosillo con numeración de las estructuras identificadas (a partir de Gorges y Rodríguez Martín, 2006: 666, con modificaciones)

estructura, que ha continuado en uso hasta nuestros días como encerradero de ganado, se domina perfectamente todo el flanco nororiental del campamento, así como el vado y las dos orillas del regato. Dicha área (2007/4) se dividió en 4 catas: la 4a, a ambos lados de la puerta de acceso $(6 \times 2,5 \mathrm{~m})$; la $4 \mathrm{~b}(2 \times 2 \mathrm{~m})$, en el centro geométrico del recinto; la $4 \mathrm{c}(2,5 \times 2,5 \mathrm{~m})$ y la $4 \mathrm{~d}(2,5 \times 2 \mathrm{~m})$ a ambos lados del muro septentrional que conforma la estructura. Se pudo constatar que el patrón constructivo es idéntico al documentado en los recintos principales.

Los Sondeos 2007/6a (3 x 1,5 m) y 2007/6b (2,5 x $1,5 \mathrm{~m})$ sirvieron para comprobar el sistema constructivo y la potencia arqueológica de uno de los fortines poligonales, en este caso el situado en una prominencia del terreno frente al campamento grande, controlando ambas riberas del arroyo. También en este caso se confirmó que la anchura del muro perimetral y su técnica edilicia resultaban completamente idénticas a los del resto de estructuras del complejo (Morillo et al., 2011: 64).

Uno de los elementos más espectaculares del conjunto es, incuestionablemente, el constituido por varias decenas de amontonamientos o majanos de piedras colocadas en seco, que llamaban la atención por su regularidad en las dimensiones y su disposición en líneas paralelas, ocupando la parte media y baja de la ladera. Su documentación arqueológica fue el objetivo del sondeo 2007/5. Se eligió una de las estructuras de este tipo más grandes y mejor conservadas, situada justamente frente al arroyo, entre el campamento grande y el recinto poligonal donde se realizó el sondeo 6 . Mediante una cata de 21,5 x $5 \mathrm{~m}$ se exhumó la estructura completa, rectangular y de $20 \mathrm{~m}$ de longitud $\mathrm{x}$ entre 1,7 y $2,2 \mathrm{~m}$ de anchura, y con el mismo sistema constructivo que el resto de edificaciones (Morillo et al., 2011: 64-65, figs. 6 y 7). 
Con la finalidad de encontrar posibles evidencias arqueológicas de cara a la datación e interpretación del conjunto, se procedió a efectuar una prospección georreferenciada mediante detector de metales. El método empleado fue la realización de transectos de $1 \mathrm{~m}$ de separación, cubriendo toda la superficie del recinto pequeño $\mathrm{C} 2 \mathrm{a}$, y algo menos de la mitad oriental del gran recinto $\mathrm{C} 2$. Asimismo, se prospectaron intensivamente las construcciones en las que se habían practicado catas. Dichas labores proporcionaron diversos hallazgos metálicos que aportaron las primeras pruebas documentales relativas a la datación tardorrrepublicana del conjunto y a su vinculación con el ejército romano (Morillo et al., 2011: 66-68, figs. 9-13).

La intervención del año 2010, realizada entre los meses de septiembre y octubre bajo la dirección científica de Á. Morillo, F. G. Rodríguez Martín y E. Martín Hernández, y financiada por Grupo de Investigación Complutense "Ciudades Romanas" (CIR), se centró en tratar de delimitar la extensión del yacimiento a partir de los hallazgos, señalar las áreas con mayor densidad de ocupación, así como en tratar de precisar aún más la cronología del asentamiento. Los resultados de dicha campaña han sido recientemente publicados (Morillo et al., 2021).

Con los objetivos enunciados continuaron las labores de prospección magnética georreferenciada empleando detector de metales, combinándola con una prospección en superficie, que abarcó unas 80 ha. Para llevarlos a cabo se emplearon 3 aparatos de detección (Garret ACE 250) graduados a intensidad media, sin discriminar el material metálico a identificar. Sin embargo, se regularon a una profundidad variable entre 0 y $25 \mathrm{~cm}$, con vistas a identificar preferentemente objetos de hierro y bronce. El sistema de muestreo consistía en una prospección sistemática mediante transectos lineales de $2 \mathrm{~m}$ de separación, empleando los surcos del arado como guía. Se definieron así unidades de documentación artificiales (Unidades de Muestreo o UMs) pero con módulos regulares, de forma cuadrangular/rectangular, de $2 \mathrm{~m}$ de anchura por una longitud variable. Una vez detectadas las anomalías mediante el aparato, la extracción de materiales se realizó rigurosamente marcando un rectángulo de $25 \times 25 \mathrm{~cm}$ que era excavado por capas de 2 a $4 \mathrm{~cm}$, profundizándose de 2 a $15 \mathrm{~cm}$. Solo excepcionalmente se ha llegado a $20 \mathrm{~cm}$. Una vez recuperado el objeto éste era descrito y tomadas las coordenadas con GPS, georreferenciando así todos los hallazgos sobre base cartográfica vectorial para posteriormente reflejarlos en el plano. Para apoyar esta metodología se contó en todo momento con una estación total Leica TCR307, que permitió, además, elaborar una planimetría tridimensional incluyendo los materiales detectados. Toda la información obtenida se ha trasladado a la base cartográfica y digital disponible para su tratamiento y procesado informático a través de un Sistema de Información Geográfica (SIG).

La topografía accidentada y la presencia de elementos geográficos diferenciados (arroyos, pendientes) en el área de estudio, propició la división del yacimiento en diversas áreas. Las prospecciones cubrieron toda la mitad oriental del gran recinto poligonal C2, mientras todo el sector occidental del mismo se dejó sin revisar debido a la vegetación cerrada de retamas, configurando un espacio en reserva para futuras prospecciones. Se volvió a trabajar en el pequeño recinto $\mathrm{C} 2 \mathrm{a}$ para completar su documentación. Finalmente, se prospectó también todo espacio situado entre el límite oriental del campamento grande y el límite del arroyo y el área situada en la ribera derecha del arroyo, centrándonos en algunas estructuras constructivas de este sector.

Se localizaron mediante detector de metales varias decenas de objetos metálicos de hierro, bronce y plomo, buena parte de los cuales son de difícil identificación, aunque también se han recuperado fragmentos cerámicos a través de prospección tradicional (Morillo et al., 2021: 114)

Con el fin de completar la documentación gráfica del yacimiento, en octubre de 2015 se llevó a cabo un vuelo de dron (Modelo MD4 1000) por parte del Centro de Apoyo a la Investigación de Arqueometría y Análisis Arqueológico de la UCM, con el que se ha elaborado una ortofotografía completa. Se ha realizado asimismo un modelo digital de terreno (MDT) para análisis de superficie.

\section{DESCRIPCIÓN DE LAS ESTRUCTURAS CONSTRUCTIVAS}

Las prospecciones y sondeos desarrollados a lo largo de casi una década en el yacimiento del Pedrosillo han puesto de manifiesto que estamos ante un conjunto de construcciones formado por varios recintos de diferentes tamaños y plantas (poligonales, circulares), además de estructuras lineales aisladas en el paisaje, todos ellos extraordinariamente adaptados a la topografía del terreno. El análisis de la fotografía aérea del Vuelo Americano de 1956 revelaba un magnífico estado de conservación de todo el complejo en aquel momento, situación que se mantuvo hasta hace 20 años aproximadamente, cuando se adecuó todo este sector para el cultivo (v. Fig. 2). De hecho, la pervivencia de dichas estructuras casi intactas fue uno de los elementos que hicieron dudar al comienzo de las labores de investigación de la posibilidad de una datación romana para el conjunto. Vamos a ir analizando por separado las características de cada una de ellas.

\subsection{EL RECINTO GRANDE (C2)}

Las construcciones más sobresalientes de todo el conjunto, que fueron las que llamaron inmediatamente la atención durante las primeras labores de prospección, se localizan en la pendiente que desciende suavemente hasta la orilla derecha del arroyo Pedrosillo, controlando el vado de paso. Se trataba de dos recintos de 


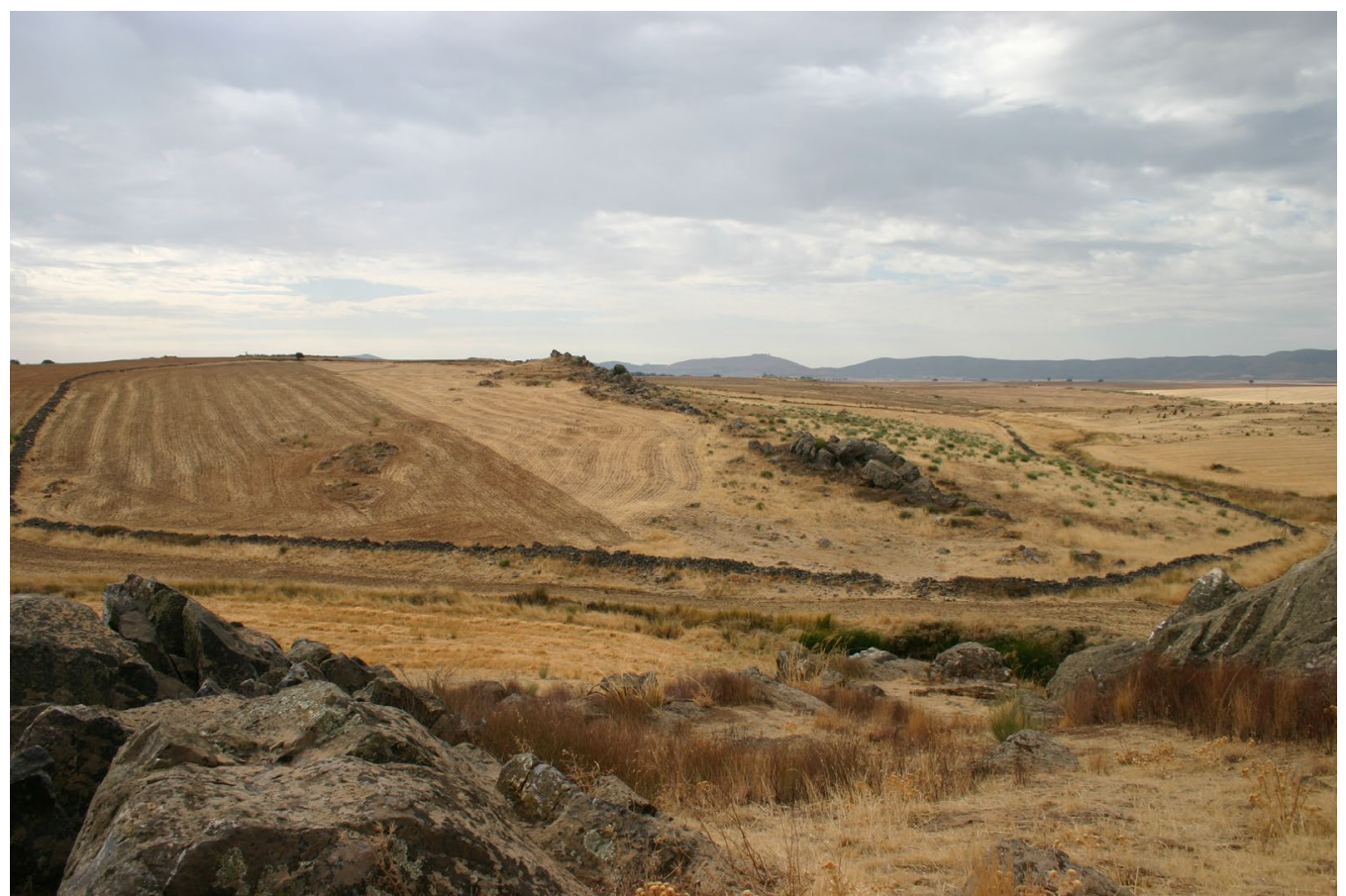

Figura 4: Vista general del recinto C2 desde el norte. En primer término, se aprecia el arroyo Pedrosillo (octubre de 2005)

forma poligonal y tamaño muy diferente delimitados por muros de piedras colocadas en seco. El más grande es de forma trapezoidal y se sitúa entre las cotas 595 y $578 \mathrm{~m}$ s.n.m. A partir de las intervenciones de 2006, fue denominado C2 (v. Figs. 2 y 3). Está situado sobre un quiebro que describe el arroyo, cuyo cauce le sirvió de foso natural por sus lados $\mathrm{N}$ y W. En la parte más baja, al norte, linda con dos puntos importantes del arroyo Pedrosillo: por un lado, un afloramiento de agua que mana de forma permanente, incluso en verano, conocido por los lugareños con el nombre de "Charca de Ruiz Pérez"; por otro, un vado de paso contiguo que garantiza el cruce entre ambas orillas. En el interior del recinto, una alineación rocosa que parece haber sido retallada y nivelada intencionadamente y con una dirección aproximada N-S divide, a modo de espina dorsal, el recinto en dos mitades: la oriental, con un desnivel más suave (4\%) hacia el Norte, y la occidental, con una pendiente más fuerte hacia el $\mathrm{W}$, también en dirección al arroyo $(8,6 \%)$ (Fig. 4).

El muro de delimitación se extiende a lo largo de $1226 \mathrm{~m}$, con ejes máximos de unos $440 \mathrm{~m}(\mathrm{~N}-\mathrm{S})$ x 300 $\mathrm{m}$ (E-W), englobando una superficie de 9,80 ha. Las intervenciones arqueológicas desarrolladas en 2006 (Sondeos 2 y 4) y 2007 (Sondeos 2, 3 y 7) permitieron constatar la homogeneidad del muro en cuanto a sus dimensiones a lo largo de todo su perímetro. La anchura media se encontraba entre 1,80 y $2 \mathrm{~m}$, aunque se ensanchaba hasta los 2,5 $\mathrm{m}$ en los puntos más vulnerables, como las esquinas. El muro sigue un trazado irregular, con tramos rectilíneos, con una ligera inflexión de pocos grados para adaptarse convenientemente a la topografía del terreno, y esquinas con ángulos biselados (Fig. 5). Su técnica constructiva es muy homogénea. La muralla se asentó directamente sobre el terreno natural sin zanja de cimentación alguna, enterrándose tan sólo unos $15-20 \mathrm{~cm}$ la primera hilada de piedra respecto al suelo actual, que no debe encontrarse a cota muy diferente respecto al suelo de uso original, representado por la UE 37 del Sondeo 2007/2 (Fig. 6: A).

El alzado (UEM 34) presenta dos paramentos realizados con bloques de esquisto de diferente tamaño, colocados aparentemente en seco, careados y con los bordes regularizados en la parte vista, con algunos calzos, de tal manera que la superficie exterior ofrece una gran regularidad y verticalidad a la manera de una mampostería regularizada. El cuidado en el tratamiento y encaje de los bloques pétreos está sin duda motivado por la necesidad de asentar lo mejor posible sobre el terreno una estructura que carece de cimentación. Los bloques en los que se asientan ambos paramentos son más grandes (aproximadamente 50-60 cm de longitud x $25 \mathrm{~cm}$ de anchura), reduciendo su tamaño a partir de la segunda hilada y a medida que gana altura la construcción. El relleno interior se realiza a base de piedra menuda. Aunque hoy en día no se aprecia la tierra que debía trabar el núcleo interior debido a la escorrentía de la lluvia sobre el muro, las intervenciones en el Sondeo 2007/2b permitieron identificar una interfaz (UE 36) de escasos centímetros, formada por materia vegetal, ligada a los procesos deposicionales naturales derivados del arrastre de la tierra que trababa el núcleo del muro con parte de los elementos, que motivaron su concentración en la base del mismo (Fig. 6: B).

La totalidad del perímetro amurallado conserva una altura muy regular, entre 1,20 y $1,30 \mathrm{~m}$. Si bien el paramento exterior está perfectamente aplomado, la disposición del lateral interior del muro no es vertical, 


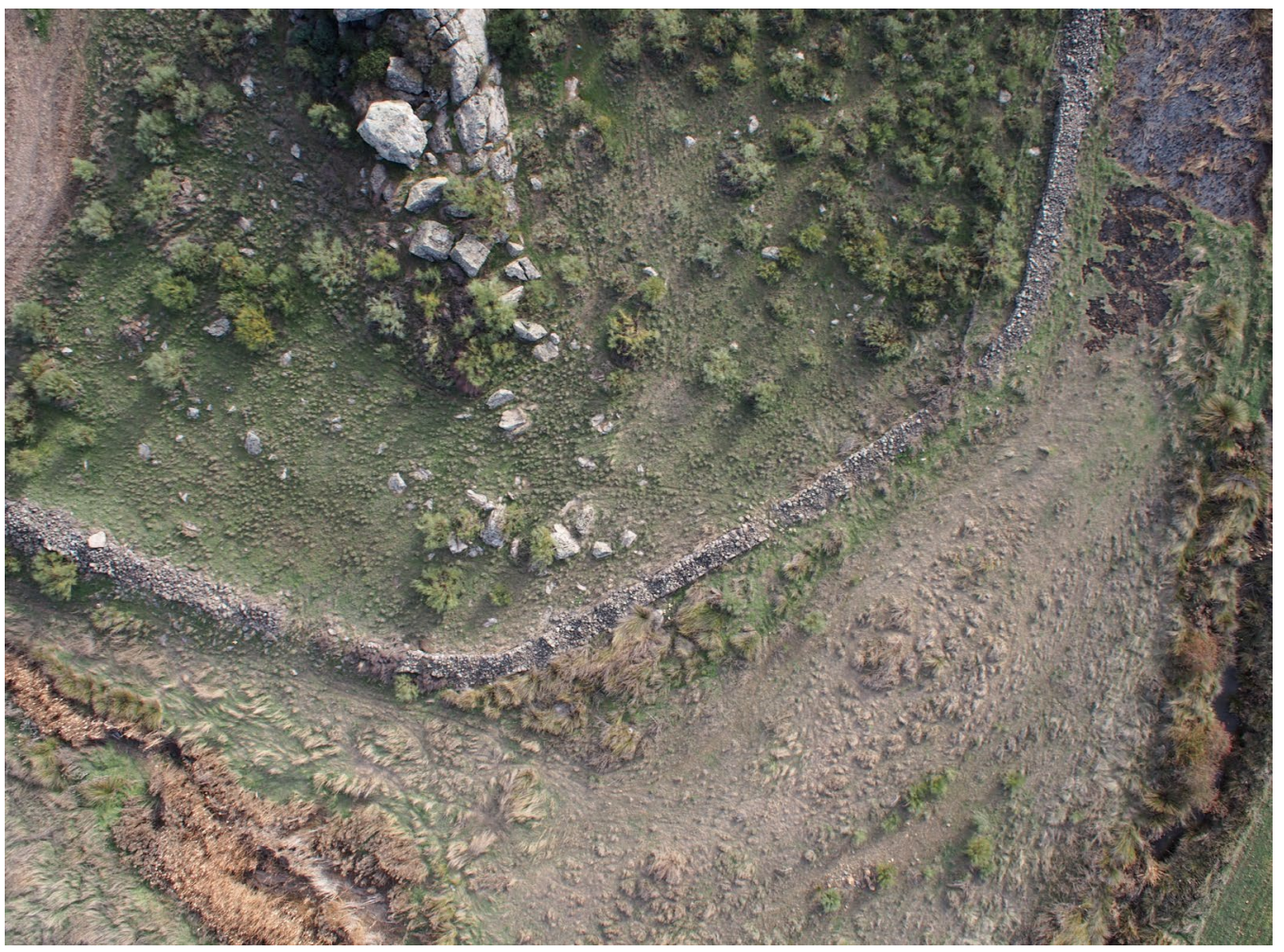

Figura 5: Vista cenital realizada con dron del ángulo noroeste del gran recinto C2 donde se aprecia su trazado a partir de tramos rectilíneos adaptados a la topografía en el sector en el que el arroyo Pedrosillo describe una fuerte curva para tomar una dirección sureste

sino levemente inclinada, unos $17^{\circ}$ respecto al eje vertical. El coronamiento del muro parece concebido asimismo como un plano inclinado, ya que en todos los puntos el paramento interno es siempre más alto (unos $0,30 \mathrm{~cm}$ ) que el paramento exterior (Gorges et al., 2009: 270-273; Morillo et al., 2011: 62-63).

Solamente se ha verificado la existencia de un pequeño vano de acceso al recinto, de aproximadamente $0,70 \mathrm{~m}$ de anchura, abierto en el muro oriental (Gorges et al., 2009: 270) (Fig. 7). La adecuación del interior del recinto para el cultivo a comienzos de este siglo conllevó la necesidad de romper el muro en varios puntos para practicar aberturas de unos $3 \mathrm{~m}$ por las que

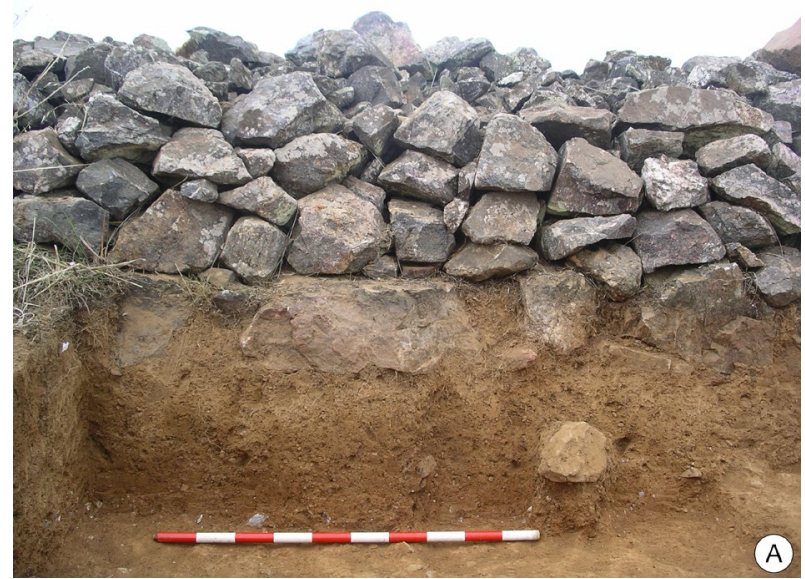

poder introducir la maquinaria. Estas se localizan en la zona meridional, cerca del acceso desde el camino rural a la parcela.

Las intervenciones del año 2007 en este recinto C2 (Sondeo 2007/2) permitieron comprobar que en el ángulo sureste, donde el terreno desciende con un suave declive E-W, el muro perimetral se asentó sobre una gran estructura prehistórica de tendencia circular y de unos $6 \mathrm{~m}$ de diámetro (T1). Estaba realizada mediante dos paramentos de grandes piedras sin trabar de entre 1,4 y 1,5 $\mathrm{m}$ de espesor, asentadas en una zanja de cimentación (UE 11) de unos $25 \mathrm{~cm}$ de profundidad, donde se encaja la primera hilada de piedras. $\mathrm{La}$

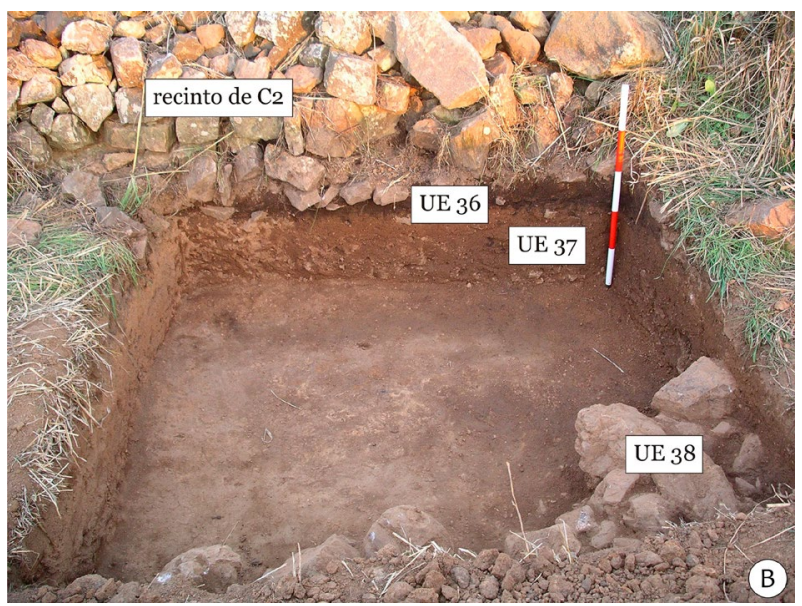

Figura 6: Recinto C2: A. Sondeo 2007/2a: Paramento exterior del muro perimetral oriental; B. Sondeo 2007/2b: Paramento interior del muro perimetral oriental 


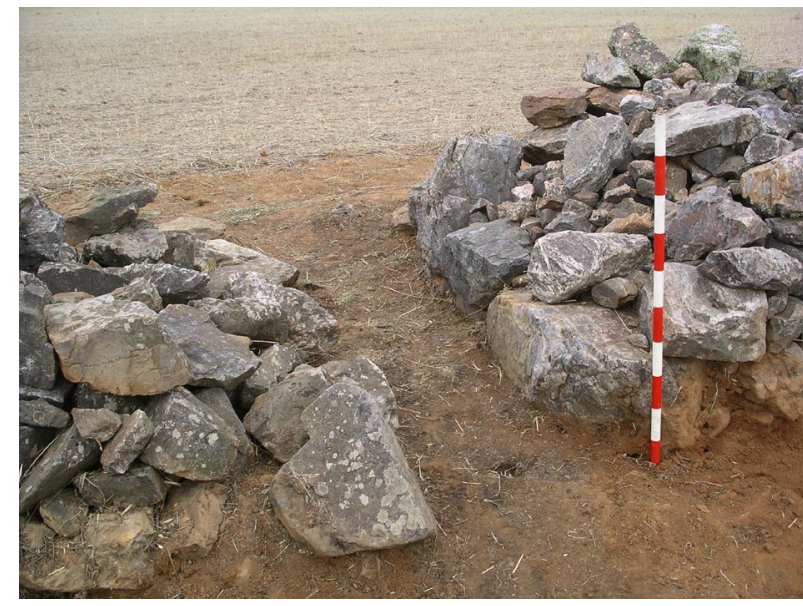

Figura 7: Recinto C2. Vano de acceso abierto en el muro perimetral oriental (octubre de 2006)

segunda hilada corresponde al alzado conservado del zócalo de dicha estructura doméstica. El suelo de uso (UE 39) es de unos $25 \mathrm{~cm}$ de espesor, de tierra batida con abundantes restos de cerámica en la parte superior. Sobre éste (UE 10) se identificaron numerosos fragmentos de cerámica reductora bruñida, que podemos adscribir al periodo Calcolítico/Edad del Bronce (Morillo et al., 2011: 62-63).

Esta cabaña prehistórica se encontraba en la cota más elevada del terreno. Sus ruinas (en realidad parte de su zócalo pétreo que debía estar parcialmente en pie) fueron completamente desmanteladas de forma intencionada y sincrónica, como demostró la disposición del nivel de derrumbe documentado hacia el este (UE 6). A nuestro juicio este derribo a cota regularizada coincide con la construcción del recinto poligonal C2 del que estamos hablando, probablemente para crear una zona despejada delante de su muro. La forma en que tuvo lugar el desmantelamiento obedece a la propia morfología natural del terreno, que presenta un desnivel de unos $60 \mathrm{~cm}$ hacia el este, lo que fue aprovechado para derribar el alzado de la edificación prehistórica y permitir así una visibilidad completa (Fig. 8). Buena parte del material pétreo de estas construcciones previas, seleccionado y regularizado, debió emplearse para la erección del muro del recinto C2 (Gorges et al., 2009: 270-273; Morillo et al., 2011: 62-63). En el Sondeo 2006/2, muy cercano al anterior, se constató también la presencia de cerámicas calcolíticas.

Por otra parte, en ambos sondeos (2006/2 y 2007/2) se comprobó que el espacio interior inmediato al muro perimetral había sido despejado completamente de piedras, creando una superficie de circulación con tierra rojiza muy compactada, que corresponde con la UE 37 del Sondeo 2007/2, que en este caso afloraba inmediatamente por debajo de la capa superficial (UE 1). Dicho espacio de paso tiene unos 1,20-1,30 m de anchura y quedaba $20-30 \mathrm{~cm}$ sobreelevada respecto a la cimentación del muro (Gorges et al., 2009: 271; Morillo et al., 2011: 63).

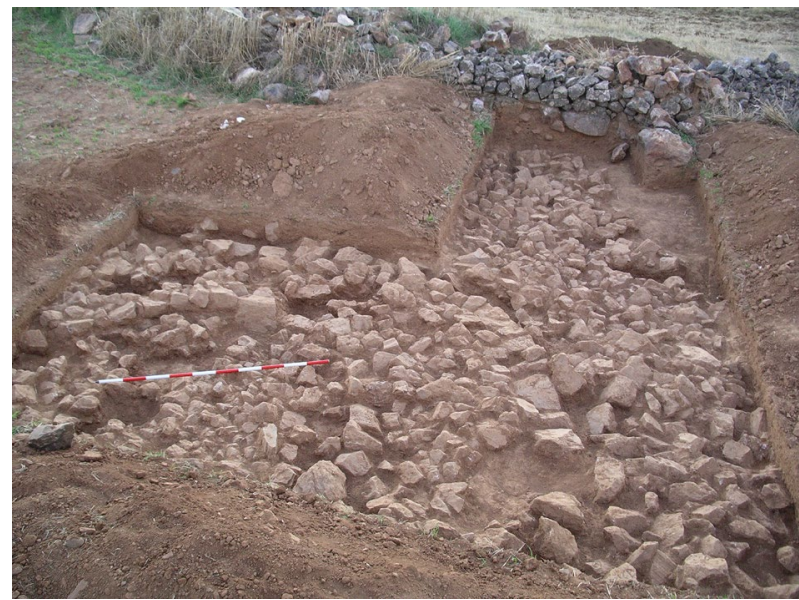

Figura 8: Recinto C2. Sondeo 2007/2a. Estructuras prehistóricas de carácter doméstico desmanteladas intencionadamente y enrasadas

\subsection{El RECINTO PEQUEÑo (C2A)}

El recinto menor (C2a) se sitúa en una cota algo más elevada que el anterior, de entre 599 y 602 m s.n.m., en un otero situado al SE, que domina buena parte del declive que desciende hacia el arroyo, así como la orilla opuesta, aunque la corriente de agua propiamente dicha no resulta visible (v. Figs. 2 y 3). Presenta una forma trapezoidal, con el lado más largo orientado en dirección NE. Los laterales E y S forman un ángulo recto, mientras los otros dos se adaptan a la topografía describiendo varios quiebros. El interior del recinto, que ocupa una superficie de 3,45 ha, está enteramente aterrazado y presenta una pendiente muy suave (Gorges y Rodríguez Martín, 2006: 661) (Fig. 9).

El sistema constructivo del muro perimetral de este recinto (UEM 50) es idéntico al anterior en dimensiones, materiales y técnica, aunque se encuentra algo peor conservado debido a su utilización como encerradero de ganado. También al igual que en el $\mathrm{C} 2$, el único acceso lo constituye asimismo un vano de 0,70 $\mathrm{m}$ abierto igualmente en el lado E (Gorges y Rodríguez Martín, 2006: 661). En este caso no se llevó a cabo ningún sondeo en su interior, aunque en el año 2006 se limpió un buen sector del recinto, junto a la cara interna del muro oriental y cerca de la esquina SE. Durante los

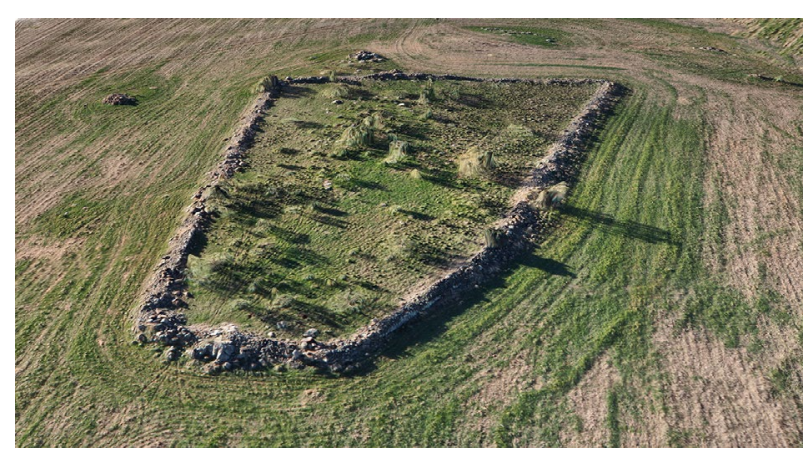

Figura 9: Recinto C2a. Imagen obtenida a partir del vuelo del dron (octubre de 2015) tomada desde el norte 
trabajos de desbroce quedaron al descubierto varios clavos de hierro aún hincados en el terreno a distancias regulares (Gorges et al., 2009: 574-576).

En las fotografías aéreas se apreciaba que el recinto C2a está inscrito en la parte central de una plataforma se elevaba unos $60 \mathrm{~cm}$ respecto al terreno circundante y que buzaba hacia el este, creando un talud artificial cuyos límites se prolongan hacia el NW hasta el recinto grande (C2). Esto parecía indicar la presencia de una estructura negativa interpretada como una posible estructura defensiva en tierra y madera (Gorges y Rodríguez Martín, 2006: 661-662). Las excavaciones de 2006 (Sondeos 2006/1, 2006/5 y 2006/6) permitieron descartar por completo esta hipótesis, revelando que se trata de una estructura morfológica natural. El Sondeo 2006/1, abierto junto al muro oriental del recinto $\mathrm{C} 2 \mathrm{a}$, reveló también en este sector la presencia de las grandes construcciones domesticas prehistóricas (H1) que se habían hallado bajo el lienzo sureste del recinto grande. Tanto sus dimensiones y técnica edilicia, como los materiales asociados coincidían en todo con los de la estructura T1, hallada como ya hemos apuntado bajo el muro oriental del recinto $\mathrm{C} 2$. En este caso se pudo constatar que la obra, sin duda un zócalo, estaba reforzada mediante postes adosados al muro exterior (UE 9), en relación con el sistema de cubrimiento. La construcción prehistórica se ubicaba al borde de la plataforma rocosa natural. Esta circunstancia motivó que cuando se acometió en aquella ocasión el desmantelamiento intencionado de los restos de esta cabaña, coincidiendo con la edificación del recinto $\mathrm{C} 2 \mathrm{a}$, todo el derrumbe cayera hacia el este, depositándose de manera escalonada a lo largo de $3 \mathrm{~m}$ y siguiendo la inclinación natural del terreno en declive. De esta manera se despejó espacial y visualmente las inmediaciones del nuevo recinto erigido (Gorges et al., 2009: 272-274, fig. 3a). Tal y como hemos descrito más arriba, este sistema fue el mismo que se empleó en el ángulo SE del vecino ámbito $\mathrm{C} 2$ lo que indica una acción sincrónica de derribo de las ruinas del antiguo poblado calcolítico ubicado en esta plataforma rocosa natural.

\subsection{El POSIBLE RECINTO C3}

En la orilla opuesta a los recintos poligonales que acabamos de describir, entre los recintos circulares c3 y c4, y bajo el recinto cuadrangular F2 el fotograma del Vuelo Americano de 1956 dibujada una estructura o un conjunto de estructuras aparentemente si forma definida y muy modificados por la presencia de varios encerraderos de ganados modernos. La comprobación sobre el terreno, realizada durante las campañas de 2007 y 2010 resultó muy compleja debido a la presencia de una vegetación muy cerrada. Aunque no hubo tiempo de realizar intervenciones, el sistema constructivo resulta muy semejante al del resto de los recintos. En sus inmediaciones se hallaron también diferentes restos metálicos. Por el momento no podemos aportar más datos sobre esta compleja estructura (v. Figs. 2 y 3 ).

\subsection{LOS RECINTOS POLIGONALES O CUADRANGULARES DE PEQUEÑO TAMAÑO}

Al norte del recinto más grande, a ambos lados del arroyo, se disponen otras construcciones complementarias, de dimensiones y morfología muy diferente a la de los recintos anteriores ( $\mathrm{C} 2$ y $\mathrm{C} 2 \mathrm{a})$, lo que indica una funcionalidad distinta, que en algunos casos es difícil de interpretar. Los más complejos sin duda son recintos que responden a una planta cuadrangular. Se han detectado varios de este tipo (v. Figs. 2 y 3), todos ellos, a excepción de uno (F1), en la ribera izquierda del arroyo. No tienen una disposición regularizada, sino que se localizan en puntos topográficos concretos, caracterizados por su dominio del terreno circundante. La mayoría presenta dimensiones de unos 30-35 m de lado, aunque los hay más grandes, como el F5, hoy prácticamente desaparecido. Presentan muros perimetrales del mismo tipo, módulo y técnica constructiva que los recintos más grandes ( $\mathrm{C} 2$ y $\mathrm{C} 2 \mathrm{a})$. Alguno de ellos todavía se apreciaba relativamente bien en la fotografía del Vuelo Americano de 1956, pero en la actualidad están completamente deformados y desmantelados por su utilización como refugio para cazadores y por las labores agrícolas desarrolladas desde hace 20 años (Gorges y Rodríguez Martín, 2006: 663).

A fin de comprobar las características constructivas de dichas estructuras, durante 2007 se llevó a cabo una cata en uno de ellos (F1), situado en una prominencia del terreno frente al recinto grande $\mathrm{C} 2$, controlando ambas riberas del arroyo. El Sondeo 2007/6 sirvió para comprobar su sistema constructivo y la potencia arqueológica. Su utilización como refugio de caza había deformado por completo todo el sector de acceso a este espacio. También en este caso se confirmó que la anchura del muro perimetral (aproximadamente 1,60 m) era muy semejante a la del resto de estructuras del complejo, mientras que su sistema constructivo resultaba idéntico (Morillo et al., 2011: 64).

Sería preciso documentar arqueológicamente mediante intervenciones puntuales cada uno de ellos para completar su conocimiento y avanzar en su interpretación.

\subsection{LOS RECINTOS CIRCULARES}

Una red de recintos de planta circular se extiende por toda la parte septentrional del complejo, concentrándose en la margen izquierda del arroyo, lo que parece indicar una relación directa con él. El resto, en la margen derecha, están aislados en eminencias del terreno. En el fotograma del Vuelo Americano de 1956 únicamente se aprecian dos en la orilla derecha, al este del recinto grande (C2) (v. Figs. 2 y 3). En cuanto a la forma, generalmente se aproximan mucho al círculo, aunque a veces pueden ser ligeramente ovalados. Su diámetro oscila entre los 15 y $20 \mathrm{~m}$, llegando a alcanzar los $30 \mathrm{~m}$ (c6, c7), o incluso los 50 m (c8) (Gorges y Rodríguez 
Martín, 2006: 663) (Fig. 10). Se localizaron 15 a través de la fotografía aérea y la prospección, dos de ellos ya casi un $\mathrm{km}$ al norte de los recintos poligonales.

Todos ellos comparten las mismas características edilicias que los recintos ya descritos. A fin de comprobarlo se escogió para excavar uno de los mejor conservados (c5), situado en la margen izquierda del arroyo (Sondeo 2007/4). Desde dicha estructura se domina perfectamente todo el flanco NE del gran recinto poligonal $\mathrm{C} 2$, así como el riachuelo. Este recinto ha continuado en uso hasta época actual, que es empleado como refugio del ganado lanar que se pastoreaba en la zona hasta su reconversión en tierras de cultivo. Se encuentra en buenas condiciones de conservación, aunque en la parte superior de los muros los labriegos han ido acumulando grandes bloques de cuarcita que dificultaban las labores agrícolas, cuya procedencia se distingue por su coloración rosada, muy diferente al aspecto grisáceo derivado de la exposición a la intemperie de los elementos constructivos aún in situ. La planta del fortín es ligeramente ovalada, siendo sus dimensiones $26,05 \times 24,4 \mathrm{~m}$.

El patrón constructivo es el mismo que el empleado en los recintos principales. La anchura del muro (UEM 13) está entre 1,77 y $1,93 \mathrm{~m}$ y su máxima elevación es de $1,40 \mathrm{~m}$. De nuevo nos encontramos ante dos paramentos de mampuestos careados de gran y mediado tamaño y un relleno interior de piedra menor. El alzado exterior manifiesta asimismo una inclinación hacia el interior. Se constata que el muro se adapta a la topografía del terreno, apoyándose directamente en el mismo (UE 19=UE 20=UE 24), sin zanja de cimentación. El

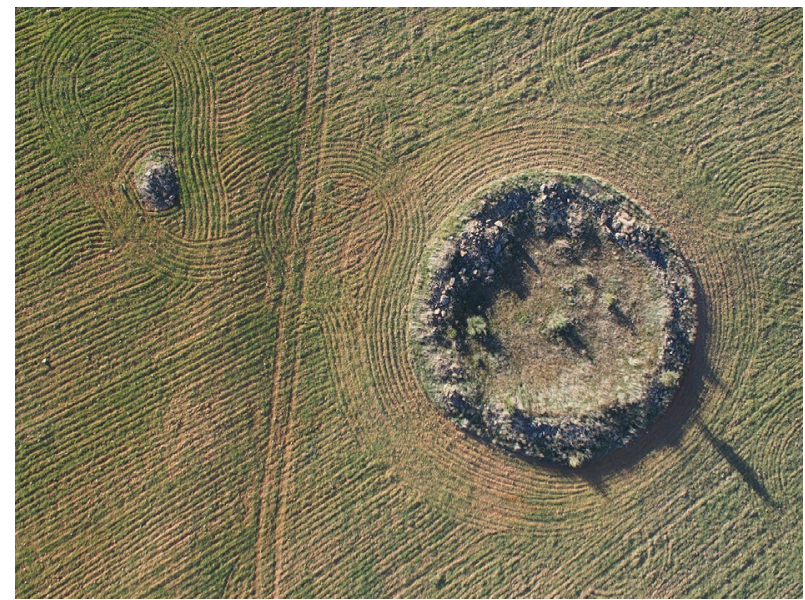

Figura 10: Recinto circular c3. Imagen obtenida a partir del vuelo del dron (octubre de 2015)

vano de acceso, orientado al SW, mirando al recinto C2, mide $0,55 \mathrm{~m}$ (Fig. 11). Se detectaron las evidencias estratigráficas del comienzo de la ruina del recinto (UE 13=UE 18=UE 25). La presencia de manchas cenicientas con manchas de carbones y arcillas rubefactadas cerca del vano de acceso (UE 16, UE 17 y UE 40) en el interior del recinto confirma su uso reiterado como lugar de combustión de numerosas hogueras en un momento muy cercano al presente. Asociado a este uso se procedió a enlosar el vano de acceso mediante un pavimento realizado a base de grandes piedras dispuestas por su lado más plano a modo de enlosado rústico (UE 21), soportado por piedras menores destinadas a nivelar el anterior (UE 22).
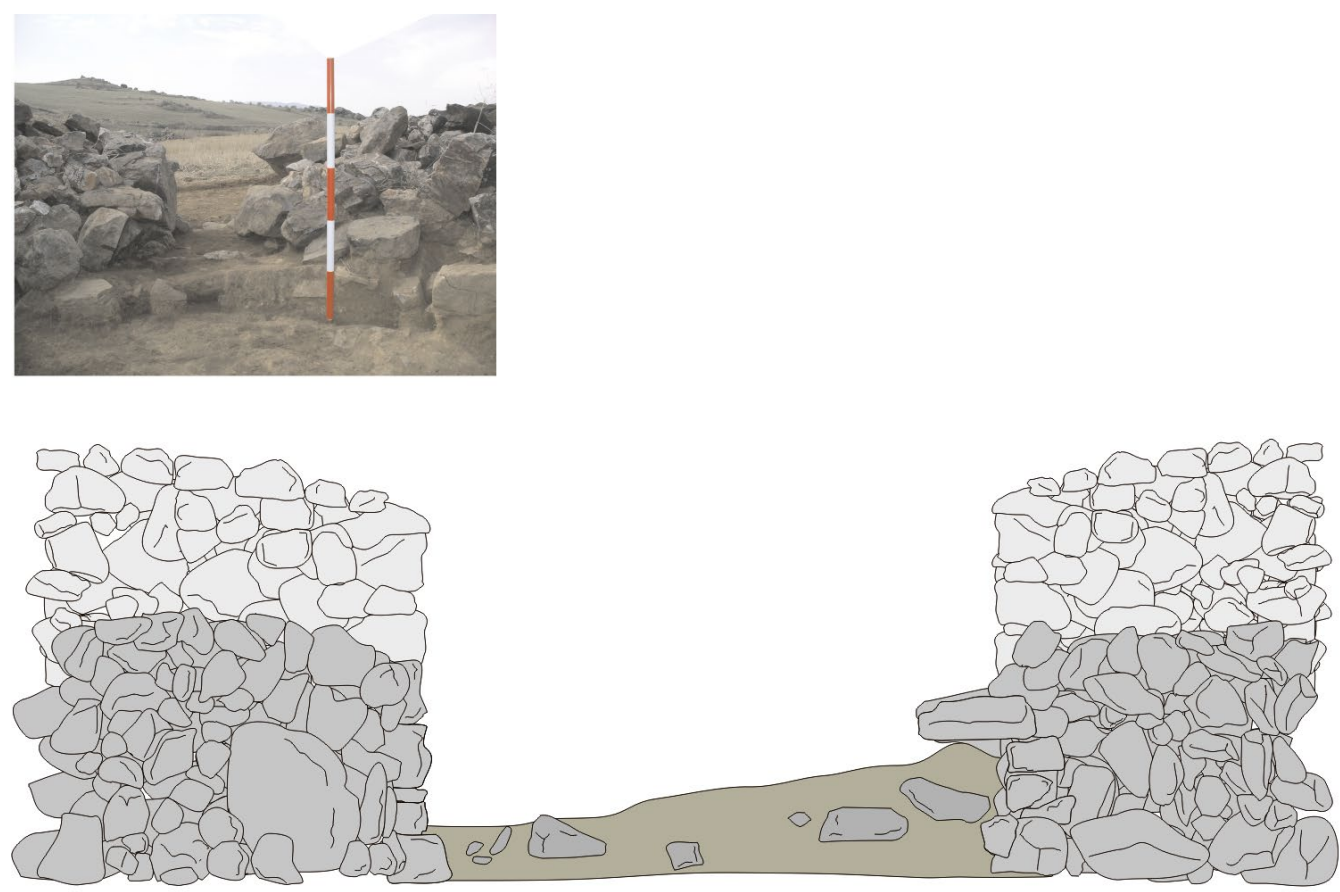

Figura 11: Recinto circular c5. Vano de acceso. Fotografía y sección 
No se constataron estructuras interiores. A una cota muy próxima al nivel de paso actual afloraba el paleosuelo (UE 19) (Morillo et al., 2011: 63-64, figs. 3-5).

\subsection{LOS MUROS RECTILÍNEOS AISLADOS}

Uno de los elementos que más llamaba la atención del complejo del Pedrosillo en el fotograma del Vuelo Americano de 1956 era la presencia de más de un centenar de secciones aisladas de muros de piedra, alineadas y dispuestas en filas paralelas al tresbolillo, de tal manera que cada sección de muro corresponde al medio de los huecos entre ellos de la fila inmediata. Se colocan en la parte media y baja de la ladera que desciende hacia la orilla derecha del arroyo, y alineadas en 4 filas paralelas en la misma dirección que el riachuelo en este tramo (suroeste-noreste), justo en el sector que comienza tras el vado de paso y la charca, aguas abajo del recinto grande $(\mathrm{C} 2)$. Un poco más hacia el NE, su disposición gira $90^{\circ}$ para alinearse en dos hileras paralelas, en este caso siguiendo la dirección de un pequeño afluente del arroyo Pedrosillo desde un tramo antes de su confluencia. En la zona alta de la ladera, por encima de los muros aislados se disponen dos de los recintos circulares (c1 y c2) (v. Figs. 2 y 3 ).

Justo al otro lado del vado y la charca, y justo frente al recinto grande $\mathrm{C} 2$, se dispone otro conjunto de muros aislados del mismo tipo. También en este caso siguen la misma dirección que el arroyo, pero, a diferencia con los anteriores su número se reduce y la separación entre hileras (de las que se reconocen 7) es mucho más amplia, mientras aumenta la distancia que los separa. Se encuentran asimismo asociados a varios recintos circulares (c4, c5 y c6) (Gorges y Rodríguez Martín, 2006: 664-665) (Fig. 12). Aguas abajo, en esta misma ladera se disponen varios fortines circulares (c4 y c3) y el complejo recinto $\mathrm{C} 3$, afrontados al conjunto de muros aislados de la ribera contraria.

Morfológicamente ya hemos apuntado que son secciones aisladas de muros de piedra construidos con la misma técnica atestiguada en el resto del conjunto. Presentan unas medidas que oscilan entre los 10 y 30 $\mathrm{m}$ de largo y 1,5-3 $\mathrm{m}$ de anchura. Una simple comparativa de la imagen del Vuelo Americano de 1956 con las fotografías aéreas posteriores al año 2000, cuando se empezó a poner en cultivo esta zona, nos muestra que estas construcciones son las más deformadas de todo el conjunto, ya que han funcionado como depósito de las piedras extraídas del terreno por la maquinaria agrícola, que se han apilado encima de tal manera que ahora mismo a primera vista parecen simples majanos. No obstante, el material pétreo apilado recientemente se distingue claramente por su coloración rosada respecto a los bloques en posición primaria, grisáceos debido a su exposición prolongada a los agentes atmosféricos.

La documentación arqueológica de estos elementos fue el objetivo del Sondeo 5 de 2007. Se eligió uno de los más grandes y mejor conservados, situado en la ribera derecha justamente frente al arroyo, entre el recinto grande (C2) y el recinto poligonal (F1), donde

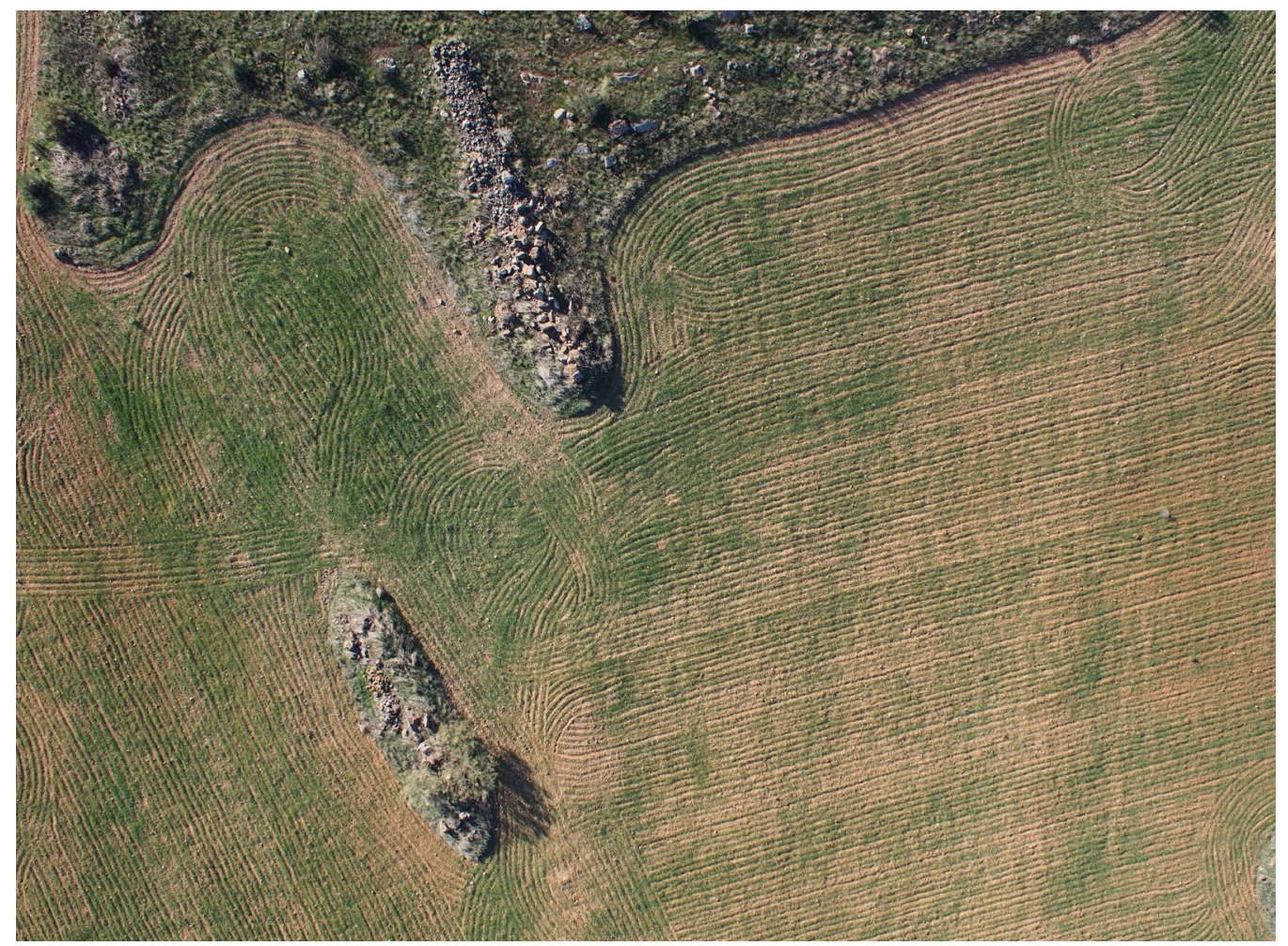

Figura 12: Muros rectilíneos aislados en la vertiente izquierda del arroyo Pedrosillo. Imagen obtenida a partir del vuelo del dron (octubre de 2015) 


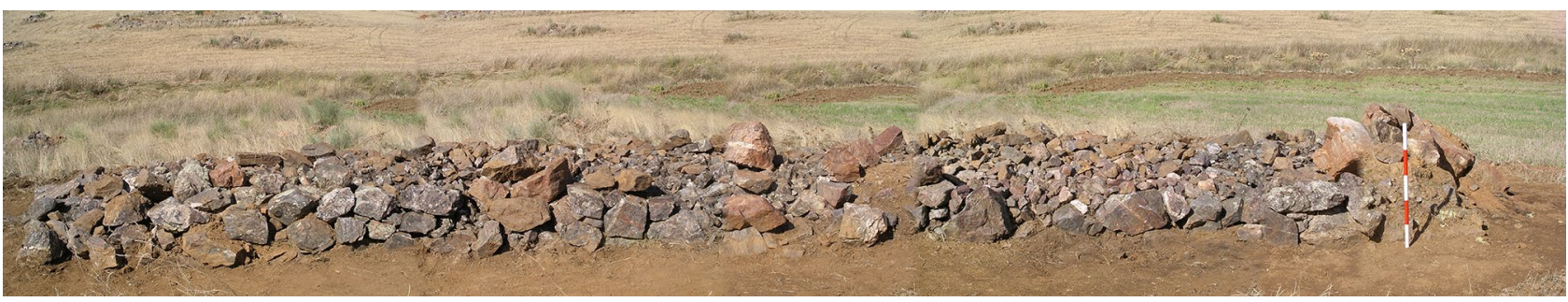

Figura 13: Muro rectilíneo aislado (titulum). Sondeo 2007/5. Fotografía panorámica

se realizó el Sondeo 6. El aspecto original de la estructura objeto de estudio se encuentra bastante alterado.

La excavación comprendió un área de un metro alrededor de toda la estructura (UEM 26). Su longitud alcanzaba los $20 \mathrm{~m}$, mientras su anchura oscilaba entre los 1,7 y 2,2 m (Figs. 13 y 14). El alzado original parece ser en este caso más reducido que el de los muros de los recintos anteriormente descritos, ya que conserva una altura de $1 \mathrm{~m}$, siendo todos los bloques que se encuentran por encima de esta cota es material apilado en los últimos años. La intervención arqueológica permitió identificar el nivel natural (UE 29), que fue ligeramente modificado para asentar los grandes bloques pétreos que constituyen la base del muro. Dicho nivel se encuentra a una profundidad de $0,28 \mathrm{~m}$ respecto a la cota actual, ya que la propia estructura constructiva ha actuado como muro de contención contra la que se han acumulado algunos estratos sedimentarios poco potentes (UE 28, UE 27 y UE 1) que buzan siguiendo la dirección sureste-noroeste de la pendiente hacia el arroyo, de en torno a un 10\% (Morillo et al., 2011: 64-65, figs. 6 y 7).

Se pudo constatar que su construcción era muy regular. Presenta sus cuatro caras perfectamente trabajadas con esquinas trabadas en ángulo recto y realizadas mediante piedras bien careadas. Sobre el terreno natural se asentaron las grandes piedras de tamaño grande y mediano, que definieron los cuatro paramentos del muro, disponiendo la cara mejor escuadrada para constituir la parte vista del muro y conseguir de este modo una superficie tendente a la verticalidad. El relleno interior está constituido por piedra de menor tamaño

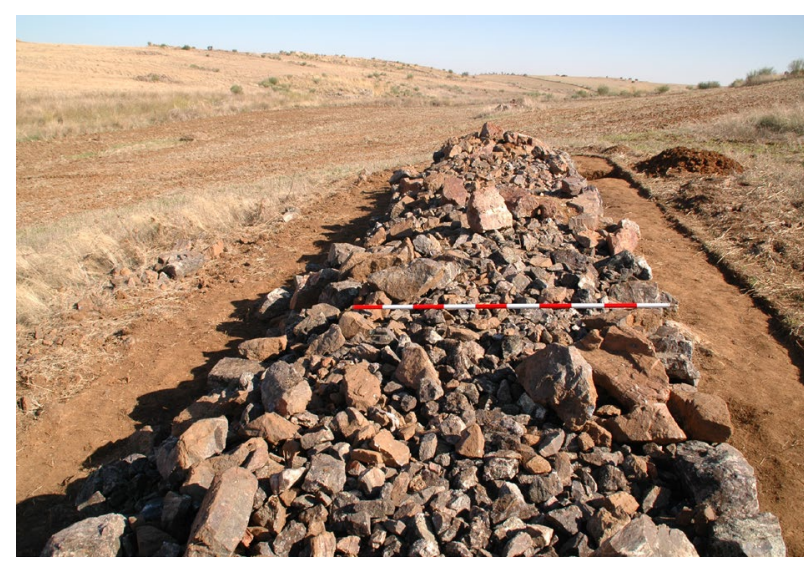

Figura 14: Muro rectilíneo aislado (titulum). Sondeo 2007/5. Vista superior
(Morillo et al., 2011: 64-65, figs. 6 y 7). A diferencia del resto de los recintos poligonales o circulares, en este caso los 4 paramentos que configuran la estructura son verticales y se encuentran perfectamente aplomados, evidencia del carácter exento de estas estructuras.

\subsection{OTRAS CONSTRUCCIONES}

Junto a los elementos que hemos descrito, existen otras construcciones vinculadas espacialmente a las anteriores en el sector septentrional, pero cuyas características constructivas son menos homogéneas y se encuentran mucho más deformadas, habiendo desaparecido algunas que sí se encontraban en la fotografía del Vuelo Americano de 1956 y que recibieron numeración en las primeras publicaciones (Gorges y Rodríguez Martín, 2006: 665-666). Queda pendiente su documentación arqueológica en detalle.

\section{TIPOLOGÍA CONSTRUCTIVA E INTER- PRETACIÓN ARQUITECTÓNICA DE LAS ESTRUCTURAS}

Ya hemos señalado más arriba que, a pesar de sus diferencias en cuanto a dimensiones y planta, las estructuras descritas comparten la misma técnica y sistema edilicio. Este consiste en un doble paramento realizado con bloques de esquisto de diferente tamaño (más grandes en la parte inferior y medianos y más pequeños conforme gana altura la construcción), regularizados en sus caras exteriores para dar mayor estabilidad y con un núcleo de piedras de mediano y pequeño tamaño compactado con tierra, cuya presencia ha podido ser detectada gracias a las intervenciones arqueológicas. La apariencia exterior sería de una mampostería regularizada (Fig. 15).

Desde el punto de vista del análisis edilicio, los paramentos se asemejan a las técnicas de gran aparejo en piedra, concretamente al denominado opus siliceum o aparejo poligonal según G. Lugli (1957: 66-165). Esta categoría recoge una serie de técnicas constructivas, de clara raíz helenística, que se emplean durante el periodo republicano en suelo itálico (Quilici y Quilici Gigli, 2001). La sencillez del aparejo, de piedras de tamaños muy desiguales, dispuestas en seco y apenas desbastadas, lo convirtió en un sistema muy habitual en Hispania para obras principalmente defensivas (Asensio Esteban, 


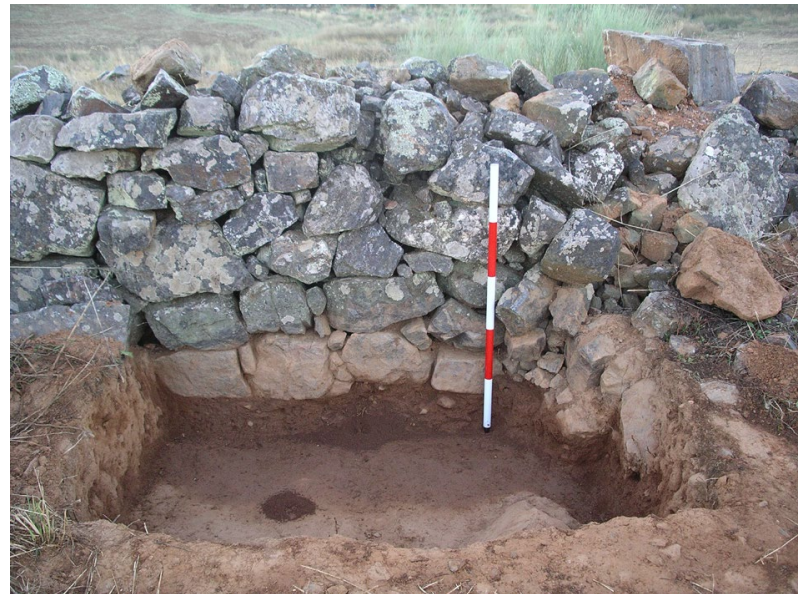

Figura 15: Recinto circular c5. Sondeo 2007/4c. Paramento interior de mampostería regularizada (opus siliceum)

2006: 119-121). Sin embargo, a pesar de que tipológicamente las fábricas presentan grandes similitudes, su variabilidad provoca que resulte muy difícil encuadrarlas dentro de los tipos concretos (maniere) definidos en su momento por G. Lugli. Esto ha llevado incluso a que algunos autores hayan cuestionado la validez de la clasificación del investigador italiano en razón de su rigidez y la dificultad que implica para distinguir uno u otro estilo (Adam, 1996: 111-114, 128, nota 5; cf. Asensio Esteban, 2006: 121, nota 19).

Recientemente J. A. Asensio Esteban ha cuestionado la asimilación e identificación con los modelos de G. Lugli de los aparejos empleados en los establecimientos militares romanos contemporáneos a las murallas urbanas, especialmente en razón de su técnica apresurada y poco definida (2006: 123), Sin embargo, este autor reconoce que son modelos importados de la tradición romana o helenística precisamente en bases del ejército romano de las áreas costeras mediterráneas hispanas, lo que vincularía su adopción con los ingenieros militares (Asensio Esteban, 2006: 125 y 153). Es lógico pensar que dicha experiencia se hiciera extensiva al ámbito de

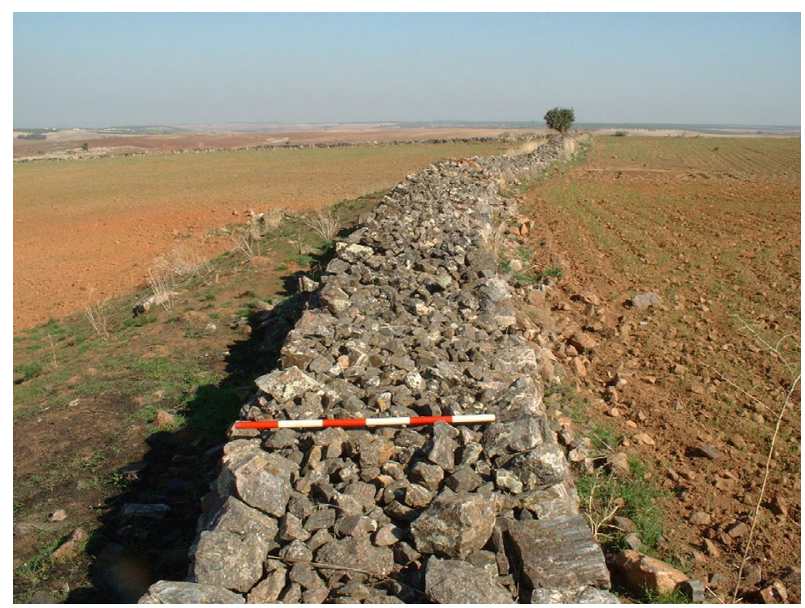

Figura 16: Recinto C2. Muro perimetral oriental en el que se aprecia el doble paramento con relleno interior la castrametación militar, como confirma además un análisis detallado de los acantonamientos.

En el caso concreto del Pedrosillo nos encontraríamos ante una técnica constructiva muy semejante a la del Estilo I de Lugli (bloques escasamente careados o informes, de gran o mediano tamaño, colocados de forma tosca sin mortero y con algunas cuñas), la más sencilla de todas, si bien a veces es muy difícil distinguir esta "Manera" respecto al Estilo II, observación que se hace extensiva incluso a murallas urbanas de los siglos II-I a. C. en el interior de la Península (Asensio Esteban, 2006: 124).

Desgraciadamente, buena parte de las investigaciones sobre edilicia romana se limitan a una lectura de paramentos, debido a la imposibilidad de intervenir en obras como las murallas, que conservan buena parte de su alzado. El conocimiento de los núcleos de las mismas, salvo en casos excepcionales como el de la fortificación de Tarraco (Hauschild, 1984-85; Aquilué et al., 1991; Menchon y Masso, 1999: 15-35) nos priva de un rasgo básico para su caracterización tipológica y constructiva. Solo cuando podemos analizar una obra de este tipo de forma integral, normalmente a través de intervenciones arqueológicas, es posible avanzar en su conocimiento y clasificación.

En los recintos del Pedrosillo ha sido posible documentar la structura completa del muro, de entre 1,80 y $2,00 \mathrm{~m}$. Entre los dos paramentos aparece un relleno interno de piedra menuda y tierra. De cara a su interpretación funcional es preciso reflexionar sobre algunos aspectos de la morfología del muro. El primero hace referencia a su alzado, conservado hasta una altura de 1,20-1,30 m en muchos puntos de los recintos descritos. En ningún caso supera esta altura (Fig. 16). Esto nos lleva a considerar que su altura originaria no debía encontrase muy lejos, posiblemente 1,30-1,40 m (Gorges y Rodríguez Martín, 2006: 659-660; Morillo, 2016: 22), cifra esta última que se aproxima a los 5 pies itálicos. Llamativo es también que la parte superior de la estructura presenta un perfil biselado de dentro afuera, ya que el paramento externo termina en todos los casos a unos $30 \mathrm{~cm}$ por debajo del interno. El perfil de esta cara interior del muro es asimismo inclinado, desviado unos $17^{\circ}$ respecto a la vertical (Morillo, 2016: 22) (Fig. 17). Curiosamente esta misma inclinación se verifica en el sector del muro de la circumvallatio numantina comprendido entre el campamento de Peña Redonda y el río Merdancho ${ }^{3}$. Esta característica se repite en todos los recintos del Pedrosillo, salvo en las secciones de muros rectilíneos aislados, que son construcciones exentas (Fig. 18).

Las características que acabamos de describir nos llevaron a plantear la hipótesis de que más que ante murallas propiamente dichas nos encontramos ante parapetos defensivos de 1,20-1,40 de altura, destinados

3. Agradecemos a Fernando Morales Hernández esta información inédita. 


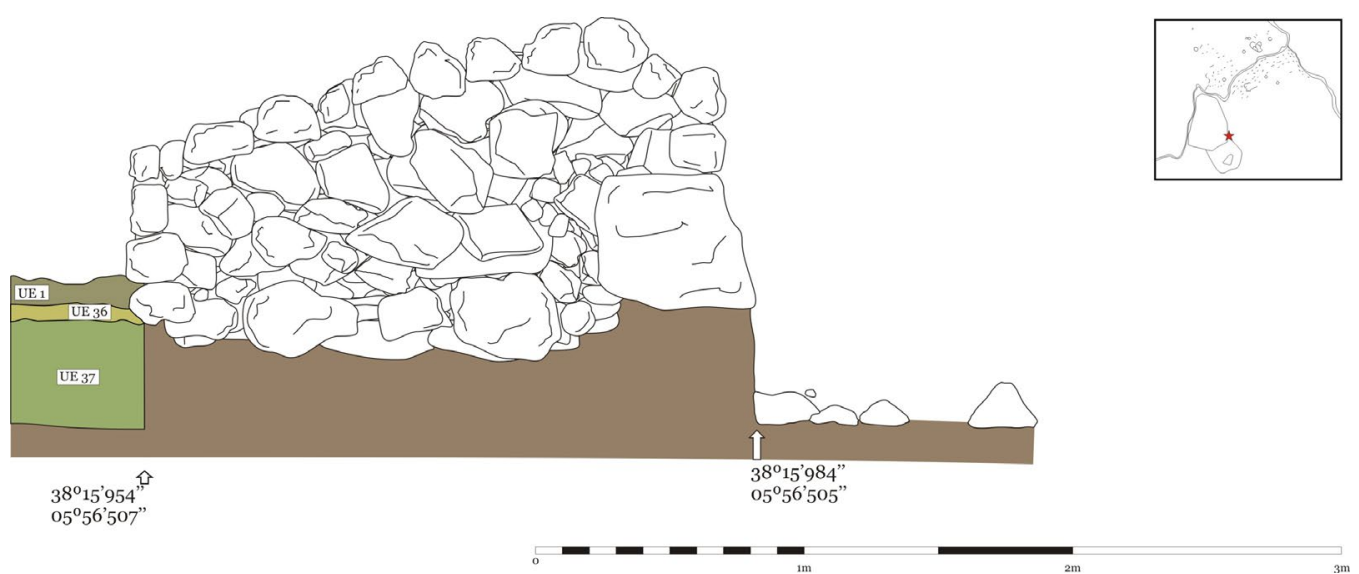

Figura 17: Recinto C2, Sondeo 2007/2a-b. Sección del muro perimetral con UEs asociadas. Se aprecia el perfil desviado unos $17^{\circ}$ respecto a la vertical
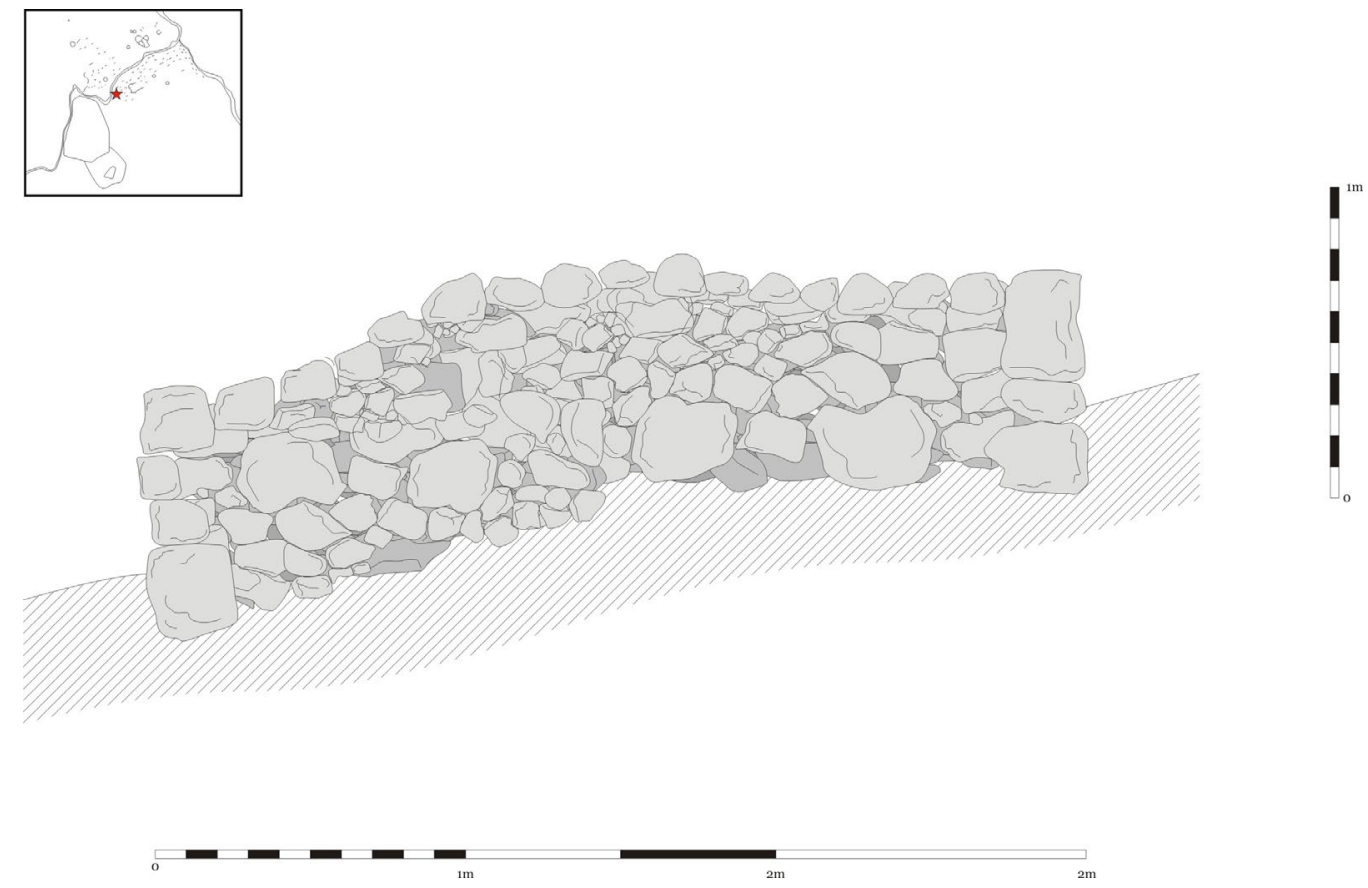

Figura 18: Sección del titulum excavado (Sondeo 2007/5), en el que se aprecia en este caso los perfiles rectos

a proporcionar una magnífica visibilidad respecto al terreno circundante, a la vez que protegen a quienes se encuentran en su interior y facilitan el lanzamiento de proyectiles (Morillo, 2016: 22) (Fig. 19). Dichas construcciones recuerdan por su propia concepción a los sistemas defensivos más sencillos de los campamentos romanos de campaña realizados en tierra y madera, compuestos por foso, terraplén y empalizada (sistema de agger), elemento este último que actúa como parapeto. Higinio, también llamado Pseudo Higinio por los problemas de autoría, en su obra de munitionibus castrorum $(49)^{4}$ hace referencia a terraplenes de 6 pies de

4. Sobre este autor y los problemas de autoría v. Dobson, 2008: 5 , nota 3 y Campbell, 2018. Traducción de D. B. Campbell, Fortifying a Roman Camp. The Liber de munitionibus altura y 8 pies de ancho (aproximadamente 1,70 x 2,30 $\mathrm{m})$, mientras Vegecio (I, 24) relata que tendrían 3 o 4 pies de altura $(0,9-1,2 \mathrm{~m})$ en razón de cada escenario concreto ${ }^{5}$.

Según Higinio (50), el agger se realiza además en materiales muy diversos (tapines, bloques de piedra o piedra "con caemento" $"$ ), como atestiguan numerosos ejemplos en Britannia (Jones, 2012: 80). Pero no cabe duda que el último tipo referenciado por Higinio alude a una fábrica realizada mediante dos paramentos pétreos y un relleno interior de piedra menuda (caementa)

castrorum of Hyginus, Glasgow: Bocca della Verità, 2018.

5. Traducción de D. Paniagua Aguilar, Flavio Vegecio Renato, Compendio de técnica militar, Madrid: Cátedra, 2006.

6. "... cespite aut lapide, saxo sive caemento". 


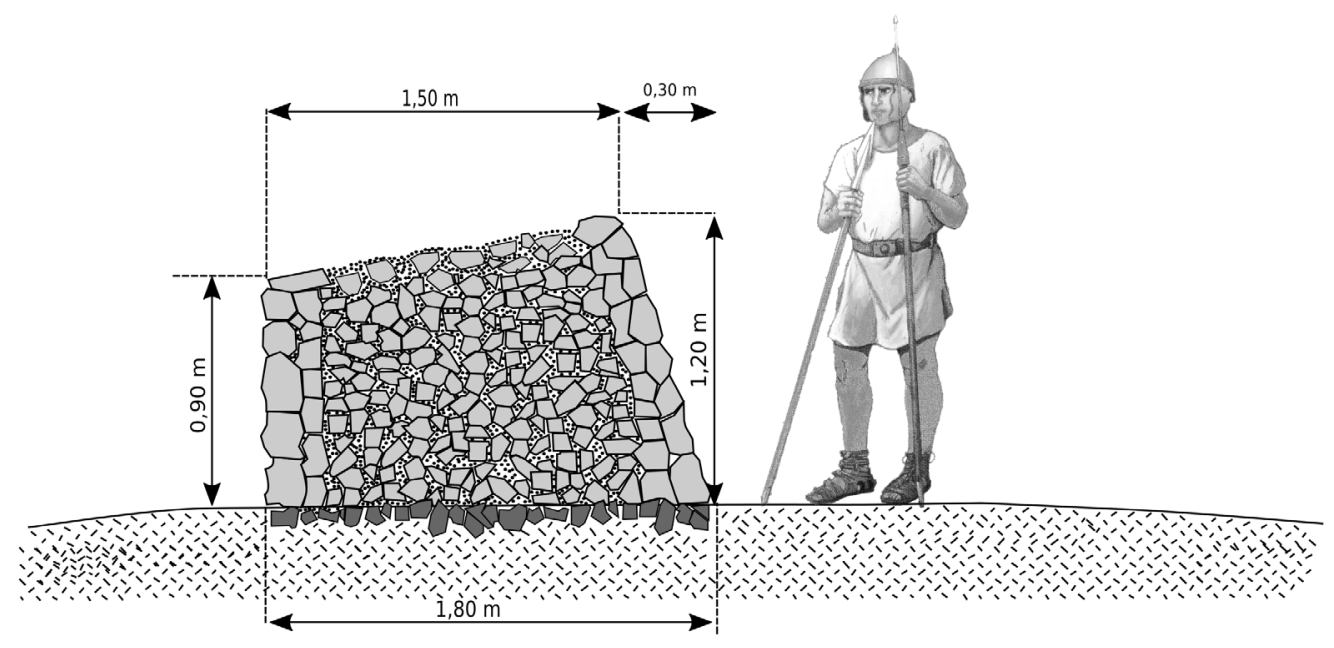

Figura 19: Recreación de los muros perimetrales de los recintos campamentales C2 y C2a, así como de los recintos circulares y poligonales, en relación con la escala humana, donde se aprecia su concepción como parapetos (a partir de Gorges y Rodríguez Martín, 2009 : 363, fig. 6, con modificaciones). Soldado republicano tomado de F. Sala Sellés (2016)

trabada con tierra o barro. Esta es precisamente la descripción que Vitrubio (II, 8, 7) y Plinio (XXXVI, 171) dan del emplecton griego empleado en Roma, menos cuidado en su ejecución, pero más rápido (Braconi, 2001: 108-109). Precisamente por estas diferencias, los expertos prefieren reservar la denominación emplecton para las estructuras que encajan con la tipología helenística propiamente dicha. No es preciso abundar más en la semejanza de esta descripción con la técnica constructiva de las estructuras del Pedrosillo que acabamos de describir.

A partir de M. G. Matherat se ha difundido en la bibliografía el término "agger petrosus" denominación acuñada por dicho autor (1943: 96), que no recoge César en los pasajes aludidos (de Bello Gallico VIII, 9). Se ha descrito como una obra con una base de grandes piedras, alzado con piedra de menor tamaño y con un recubrimiento de tierra.

Los terraplenes, elemento fundamental de la defensa de los campamentos de campaña, suelen ir acompañados de fosos antepuestos, circunstancia que no siempre se verifica, tal y como atestiguan tanto los textos (Higinio, 49; Vegecio, III, 8), como la evidencia arqueológica (Jones, 2012: 81-82; Morillo et al., 2017: 193). Su presencia y características dependen de su finalidad y de la naturaleza del terreno. Ninguno de los recintos del Pedrosillo presenta elementos de este tipo.

Tal y como ya hemos apuntado con anterioridad (Morillo et al., 2017: 193), soluciones edilicias muy semejantes a las que encontramos en El Pedrosillo, tanto en lo relativo a dimensiones (1,8-2 $\mathrm{m}$ anchura) como a técnica constructiva (doble paramento y relleno interior, ausencia de cimentación) las documentamos en otros recintos militares tardorrepublicanos en la Península
Ibérica. Sería el caso de los campamentos de Renieblas I y II (Schulten, 1929: 27-40; Dobson, 2008: 127-132), los laterales este y sur del Castillejo (Schulten, 1927: 100-103) y Aguilar de Anguita (Schulten, 1929: 191195; Gorgues et al., 2014: 103-107), a los que podría tal vez añadirse el recientemente publicado de La Cabeza del Cid (Hinojosa) (Cerdeño y Gamo, 2016). Ninguna de estas cercas defensivas ha sido objeto de un estudio con metodología moderna y se sigue manteniendo su identificación como "murallas" sin ninguna discusión, a pesar de que su alzado se conserva muy parcialmente y que los rasgos constructivos (ausencia de mortero de cal) no permiten una elevación por encima de 1,80-2 m. La ausencia de fosos, en lo que se apartan de los modelos canónicos del campamento romano, constituye también una pauta común en todos ellos. En los casos de Aguilar de Anguita y Renieblas II se detectaron algunas "torres" interiores, que más bien parecen ser plataformas adosadas, cuya finalidad aún no está aclarada.

Con las mismas características constructivas, pero con un espesor un poco más reducido $(1-1,20 \mathrm{~m})$ se encontraría la fortificación del Puig Castellar (Biosca), que también contó con torres o plataformas interiores (Pera et al., 2019: 31-33). A estos podría añadirse, ya con anchuras superiores y en ambos casos sin torres interiores adosadas al muro, Almazán, en el que el espesor de la obra defensiva está entre 2,5 y 3 m (Gamer y Ortego, 1970: 71), y Ampurias, con 2,80 m de anchura (Castanyer et al., 2015: 113).

Otro modelo en piedra está representado por obras más masivas, de unos 4-5 $\mathrm{m}$ de anchura, pero edificadas con la misma técnica de doble paramento y relleno interior. Este sería el caso de Cáceres el Viejo (Ulbert, 1984; 17-24; Salgado Carmona, 2020), Peña Redonda 
y el lateral septentrional del Castillejo (Schulten, 1927: 100-103 y 191-193), o los recintos III y V de Renieblas (Schulten, 1929: 50-59 y 148-152; Dobson, 2008: 134-140 y 200-206). En Cáceres el Viejo se han documentado los tirantes o muros interiores transversales que traban ambos paramentos, dando solidez a la estructura (Salgado Carmona, 2020). E incluso un muro central paralelo a los paramentos internos, como en el Anexo del campamento de Renieblas III (Morales y Morillo, 2020: 195, 201-202), con idéntica finalidad. Los recintos III y V de Renieblas, al igual que Castillejo, contaron con torres o plataformas interiores. A pesar que se conocen de forma muy sumaria, tal vez el Santo de Valdetorres (Heras Mora, 2009) y El Real (Campo de Criptana) (Martínez Velasco, 2011) puedan adscribirse a este mismo tipo. Entre todos ellos sólo Cáceres el Viejo contaba con fosos.

Estas características nos llevan a plantear que tampoco en este caso los muros defensivos pudieron alzarse a una cota mayor de unos 1,40-1,60 m de altura, en todo caso inferior a los $2 \mathrm{~m}$ de altura, ya que el propio muro se hubiera desmoronado si alcanzaba una altura mayor al carecer de cimientos y hormigón que trabara la obra. En estos casos más masivos, los alzados podrían haberse realizado tal vez en materiales perecederos, como adobe (Morillo, 2016: 22 y 24; Morillo et al., 2017: 193).

El Campamento B del asedio de Alesia (Monnier, 2001: 236-237) presenta algunos segmentos de agger pétreo de este mismo tipo, al igual que las recientes fortificaciones militares atestiguadas en las cercanías de Triestre (Bernardini et al., 2015: 1521-1526).

A pesar de que se trata de recintos posteriores, de época flavia, no podemos dejar de señalar las semejanzas edilicias del recinto del Pedrosillo con los campamentos del asedio de Masada, donde las "murallas", presentan unas dimensiones de 1,50-2,50 $\mathrm{m}$ de anchura por 1,50 $\mathrm{m}$ de altura (Schulten, 1933; Richmond, 1962: 145-146; Parrinello et al., 2017: 11.8); o la muralla del fuerte auxiliar de Hardknott, en Cumbria, al norte de Inglaterra (Blood et al., 1999: 22-25), que se hacen extensivas a sus dimensiones (entre 1,4 y 1,8 de anchura y 1,8 de altura). El empleo de las mismas soluciones constructivas en parámetros temporales muy diferentes, incluso en momentos altoimperiales en los que la planta del campamento es rectangular y perfectamente estandarizada, confirman la gran adaptabilidad de la castrametación romana a las condiciones naturales de cada zona (tipos de suelo y cobertera vegetal) o circunstancias (mayor o menor temporalidad).

Ya hemos expuesto que las medidas de las estructuras siguen una pauta muy regular. La cuestión radica en establecer cuál fue el patrón metrológico empleado, porque comprobar que se trata de una medida romana, abundaría, más aún si cabe, en clarificar su datación. Durante los últimos siglos de la República conviven dos patrones metrológicos principales: el llamado pes italicus (o pes oscus) (27,5 cm) (Peterse, 1984; 1985:
42); y el pes monetalis (29,6 cm) derivado del "pie soloniano" o "pie eginético" (Martin, 1965: 12), que en época augustea pasará a denominarse como pes monumentalis ${ }^{7}$. La hibridación cultural se hace presente asimismo en el ámbito púnico, donde junto al tradicional "codo" fenicio $(50-51 \mathrm{~cm})$, conviven otras medidas como el codo egipcio $(52 \mathrm{~cm})$, que parece tener especial repercusión en el Levante y Mediodía peninsulares, e incluso el pie greco-romano de 29,6 cm, que aparece en Mozia (Prados, 2007: 31; Prados et al., 2020: 972 y 974).

A partir de las medidas en metros se ha podido deducir que en el Pedrosillo el patrón métrico que rigió en todas las construcciones fue el pes italicus de aproximadamente $27,5 \mathrm{~cm}$. La altura de los muros de los recintos, $1,40 \mathrm{~m}$, equivaldría a 5 pies itálicos; su anchura (entre 1,80 y $2 \mathrm{~m}$ ) corresponde a 7 pies itálicos, alcanzando en las zonas más reforzadas $2,5 \mathrm{~m}$ ( 9 pies itálicos). Los vanos de acceso $(0,70 \mathrm{~m})$ serían 2,5 pies itálicos. Dichas medidas además muestran una correlación muy simple: la anchura del vano (2,5 pies itálicos) sería la medida menor (el módulo constructivo), que multiplicada por dos se obtiene la altura ( 5 pies) y, por tres, la anchura (7,5 pies).

No cabe duda que la adopción de un sistema metrológico determinado en una obra constructiva dependía de la existencia de instrumentos de precisión con las medidas oficiales (regulae), de los que conocemos varios ejemplares en diferentes soportes (Prevot, 2008: 328). En el ejército se empleaba la decempeda, una vara de 10 pies de longitud que usaban los centuriones para comprobar el trabajo de su centuria (Vegecio, I, 25, 2 y III, 8, 13). Dichos instrumentos eran portables y se trasladaban de uno a otro lugar. A partir de ellos se tomarían las medidas estándar con cuerdas que, mediante nudos, permitían multiplicar dicha medida y trasladarla a la fábrica propiamente dicha. Este sistema funcionaba tanto en el mundo civil como en el ámbito militar, donde existía un cuerpo de ingenieros especializados (metatores, agrimensores).

La homogeneidad desde el punto de vista de la técnica constructiva en el conjunto de recintos del Pedrosillo se ve acompañada por una diversidad planimétrica. Los recintos $\mathrm{C} 2$ y C2a son los más grandes y destacados. Responden a plantas poligonales, adaptadas a la topografía natural, sin aterrazamientos, que combinan tramos rectilíneos con ángulos biselados. Dichos modelos, de origen claramente helenístico, se verifican en los recintos amurallados de las ciudades itálicas republicanas como Cori, Setia o Norba, por poner tan sólo algunos ejemplos (cf. Quilici y Quilici Gigli, 2001). Pero se hacen extensivos a obras militares como campamentos y fuertes de la misma época. El diseño planimétrico poligonal adaptado a la topografía

\footnotetext{
7. A dicha medidas deberíamos añadir el pes Drusianus, que aparece en un momento cesariano o augusteo (v., entre otros, Duncan-Jones, 1980 y Raepsaet, 2019).
} 
es el diseño utilizado de forma casi generalizada en los recintos republicanos hispanos, como los de la circumvallatio numantina (Schulten, 1927), Renieblas I, II y III (Dobson: 2008; 127-193), Aguilar de Anguita (Schulten, 1929: 191-195; Gorgues et al., 2014: 103), La Cabeza del Cid (Cerdeño y Gamo, 2016: 174), Puig Castellar (Biosca) (Pera et al., 2019: 31-32) y Ampurias (Castanyer et al., 2015: 113). Los dos recintos del Pedrosillo encajarían perfectamente dentro de este conjunto, uno más grande $(\mathrm{C} 2)$, de casi 10 ha, como posible campamento legionario (castra) y otro más reducido (C2a), de 3, 45 ha, un probable castellum o fuerte auxiliar.

Al igual que la edilicia militar, el estudio planimétrico de los campamentos de este periodo requiere de estratigrafías fiables, algo difícil de obtener teniendo en cuenta que la mayoría fueron excavados hace un siglo. A. Schulten, intentando encajar sus hallazgos con los datos de las fuentes, pasó por alto que la propia planta de los recintos era un criterio a tener en cuenta. La principal contradicción de la obra del investigador alemán en este campo fue que la mayoría de los campamentos de la circumvallatio numantina y Renieblas eran poligonales y no encajaban con el modelo cuadrado definido por Polibio para el mismo momento (Hist. VI, 28, 10-VI, 42,6). La evidencia arqueológica confirma una datación del siglo II a. C. para la mayoría de los recintos poligonales allí donde, como en el caso del Pedrosillo, se han realizado intervenciones arqueológicas, lo que nos lleva a concluir que el modelo polibiano era un desideratum, algo que sólo con el tiempo se convertiría en una realidad (Morillo, 2008: 79). De hecho, gracias al avance en el conocimiento arqueológico de la última década en el ámbito de la castrametación tardorrepublicana empezamos a poder definir la evolución de los diseños planimétricos (Morillo, 2016: 16-29). Sin duda, los primeros recintos rectangulares como Cáceres el Viejo o Almazán, aparecen a comienzos del siglo I a. C., durante el conflicto sertoriano, tras las reformas del ejército por parte de C. Mario (Morillo, 2014: 41-42) o tras la Guerra Social $^{8}$. Sin embargo, los modelos poligonales seguirán estando presentes durante esa centuria, como confirmaría Andagoste (Unzueta y Ocharan, 1999) y los campamentos del cerco de Alesia (von Schnurbein, 2001), e incluso en época augustea como Oberaden y Anreppen (Kühlborn, 2008; 2009), por poner tan sólo algunos ejemplos bien conocidos. Sin embargo, ninguno de ellos se realiza en opus siliceum.

El resto de los testimonios arquitectónicos del complejo del Pedrosillo presentan una casuística muy diferente. Los que mejor pueden definirse son los recintos de planta circular y las secciones aisladas de muros rectilíneos, que comparten la misma técnica constructiva que los recintos poligonales, pero que constituyen modelos constructivos casi inéditos dentro de las obras militares

8. Sobre las reformas militares de C. Mario, v. los recientes trabajos de Gauthier (p. e. Gauthier, 2016). romanas. Su propia forma y disposición aportan interesantes pistas sobre su interpretación. Por lo que se refiere a los recintos circulares, la altura $(1,40 \mathrm{~m})$ y disposición (paramento interior retranqueado y coronamiento con desnivel de dentro hacia fuera) de los parapetos, al igual que su propia planta, parecen orientados a controlar desde el interior todo el espacio circundante y de esta manera garantizar la protección y permitir al mismo tiempo que se pueda batir el campo mediante descargas de proyectiles. Su posición en eminencias del terreno, que permiten comunicarse visualmente entre sí y con los recintos mayores, y en relación directa con los muros aislados rectilíneos confirmaría dicha interpretación. Por el contrario, sus reducidas dimensiones (aproximadamente 15-20 m de diámetro) no los convierten en espacios aptos para el hábitat.

Si bien los tratadistas romanos mencionan la existencia de campamentos semicirculares, castra lunata (César, de bellum Africanum, 80) o semirotunda (Vegecio, I, 23), no se alude a recintos de planta circular u oval, aunque la adaptación a las condiciones del terreno y a las circunstancias parecer ser más importante que la forma concreta (Vegecio, I, 23). Sin embargo, la arqueología confirma la existencia de algunas estructuras de planta circular, como algunos puestos fortificados (castella 11, 1315 y 18) establecidos junto a la contravallatio del asedio de Alesia (Reddé et al., 1995; Joly y Barral, 2001: 285-287); o el fuerte del Cantón, establecido durante las guerras cántabras (Peralta, 1999: 205). En ambos casos se trata recintos más grandes, con aggeres terreros y diámetros de unos $100 \mathrm{~m}$, y se les ha aplicado la denominación de castella, terminología que aquí preferimos sustituir (Morillo, 2016: 13-14) por la más aséptica de fortines circulares. De cualquier forma, en ninguno de los casos citados se avanza sobre la función de esta planta circular, que se asocia a las operaciones militares propias de sistemas de asedio y no a un simple lugar de acantonamiento.

Los 8 recintos poligonales o cuadrangulares que se encuentran en diferentes zonas del complejo del Pedrosillo son particularmente enigmáticos, muy difíciles de interpretar mientras no se lleven a cabo nuevos sondeos. En el cerco de Alesia se conocen asimismo construcciones muy similares que también constituyen una incógnita (campamento K, castellum 10) (von Schnurbein, 2001: 507).

Finalmente, debemos considerar los muros rectilíneos aislados en el terreno a ambos lados del arroyo. Ya hemos apuntado que son idénticos en materiales y técnica constructiva al resto de las estructuras del conjunto, diferenciándose tan sólo en la altura, que parece algo menor, en torno a $1 \mathrm{~m}$ y en la carencia de inclinación en uno de sus paramentos, como corresponde a estructuras exentas. Presentan cierta variabilidad de sus dimensiones, que van de 10 a $30 \mathrm{~m}$ de longitud y de 1,5 a $3 \mathrm{~m}$ de anchura.

Dichas secciones aisladas de muros, se alinean por sus lados cortos adaptándose a las curvas de nivel y disponiéndose intercalados en filas paralelas, de tal manera 
que los espacios abiertos entre segmento y segmento coinciden con muros tanto en la fila anterior como en la posterior, lo que obligaría a un recorrido zigzagueante y mucho más lento a cualquier enemigo de caballería o infantería que atravesara este intrincado recorrido, haciéndole más vulnerable además a las descargas de proyectiles.

Estos muros lineales defensivos recuerdan por su propia morfología a los tituli, mencionados por Higinio (49-50) como fosos lineales de unos 60 pies $(18 \mathrm{~m})$ que protegían las puertas de los campamentos militares, habitualmente asociados a terraplenes paralelos a las fossae (Reddé, 1995: 349). A partir de los trabajos de A. Schulten en los campamentos hispanos, el término titulum se aplica por extensión a las secciones de terraplenes o muros que se colocan delante de las entradas a los recintos, aunque no vayan acompañados de fosos. De hecho, los ejemplos más antiguos, datados a mediados del siglo II a. C., como los de Peña Redonda y el Anexo del Campamento III de Renieblas (Renieblas VI) o probablemente a comienzos del I a. C. (Renieblas IV y V, Almazán y La Rasa) (Morillo et al., 2017: 194) son parapetos de escasa altura (no se conservan cotas superiores a un metro) con doble paramento de piedra y relleno interior, con dimensiones muy variables, pero sin foso (Dobson, 2013: 231-232). Queda confirmado, por tanto, que son construcciones muy semejantes a las que encontramos en el Pedrosillo alineadas y agrupadas en hileras paralelas.

En definitiva, estamos ante edificaciones que forman parte de un sistema defensivo complejo y creado ad hoc, que encajarían dentro de las fortificaciones lineales que vamos conociendo poco a poco asociadas a campamentos y campos de batalla (Napoli, 1997: 39-40; Deyber et al., 2018: 27).

\section{HALLAZGOS ARQUEOLÓGICOS A TRAVÉS DE LA PROSPECCIÓN MAGNÉTICA GEORRE- FERENCIADA}

Una vez identificadas las estructuras constructivas del complejo y establecida su interrelación espacial y constructiva era preciso avanzar en lo relativo a su datación e interpretación. Los materiales arqueológicos asociados, en su mayoría recuperados mediante prospección con detector de metales durante las campañas de 2007 y 2010, nos proporcionaron la primera información al respecto, derivada tanto de su datación y características como de su lugar de hallazgo concreto.

Se han localizado casi 80 objetos, la mayoría de ellos metálicos, aunque también se han recuperado algunos fragmentos cerámicos a través de prospección superficial. Cubren un amplio abanico temporal, que se extiende desde la Prehistoria reciente hasta la época contemporánea. Se han detectado fragmentos de cerámica e instrumental del periodo Calcolítico/Edad de Bronce y del siglo VI-V a. C, así como materiales de época romana imperial (cerámica y latericio), bajomedieval (moneda), moderna (restos de sello y cerámica) y contemporánea (moneda, recipientes cerámicos, restos de maquinaria agrícola...). Su dispersión corrobora la existencia del yacimiento Calcolítico que ya habíamos documentado a través de las intervenciones arqueológicas en los dos recintos poligonales C2 y C2a. Y nos permite hablar, por ejemplo, de otras realidades arqueológicas, como un asentamiento prerromano del siglo VI-V a. C. en la orilla izquierda del arroyo, o un establecimiento rústico menor (tugurium) de finales del siglo I-comienzos del II d. C. sobre el antiguo asentamiento del Calcolítico-Edad de Bronce. El resto de materiales nos informa sobre una ocupación residual de carácter temporal, propia de las actividades ganaderas y agrícolas, prolongada desde la Edad Media hasta nuestros días. Por otra parte, hemos prescindido para este análisis de numerosos fragmentos de hierro y plomo, que no podemos identificar ni correlacionar con exactitud desde el punto de vista cronocultural (Morillo et al., 2021: 114-115, fig. 4).

No obstante, la mayoría de los restos identificados asociados a las estructuras que hemos descrito anteriormente son de época romana republicana y una buena parte comparte un indudable carácter militar (Fig. 20). Una primera observación es que todos los restos localizados son metálicos, de hierro, bronce y plomo. Una cuestión que no debemos dejar de mencionar es la ausencia de restos cerámicos atribuibles a este momento, lo que dificulta sin duda el establecimiento de un marco cronológico más ajustado, pero que encajaría con la naturaleza y composición del registro arqueológico de carácter material. Este es un rasgo característico de asentamientos militares de campaña, que deriva del comportamiento del propio ejército romano, que se mueve con rapidez sobre el terreno transportando un ajuar limitado evitando recipientes cerámicos pesados y frágiles a la vez (Morillo, 2008: 89).

El empleo del detector de metales constituye actualmente una herramienta indispensable dentro del protocolo de actuación arqueológica en campamentos de campaña y campos de batalla, habida cuenta de la casuística concreta que presentan este tipo de yacimientos (escasa potencia estratigráfica, ausencia de material cerámico) (Morillo, 2008: 81; Quesada, 2008: 30; Noguera et al., 2015; Morillo et al., 2020: 40). Esta técnica ha demostrado ser muy útil en la identificación de asentamientos republicanos en suelo peninsular, como Andagoste (Ocharan y Unzueta, 2002), La Palma y el Camí del Castellet de Banyoles (Noguera, 2008), Santo Tomé-Baecula (Bellón et al., 2015), La Cabeza del Cid (Hinojosa, Guadalajara) (Cerdeño y Gamo, 2016) o El Cabezo de Alcalá de Azaila (Romeo Marugan, 2021). O fuera de nuestras fronteras, ya en yacimientos altoimperiales como Kalkriese (Harnecker, 2004; Rost y Wilberts-Rost, 2012), Harzhorn (Poppelmann et al., 2013) o Septimer Pass (Rageth et al., 2010; Fassbinder et al., 2014).

Aunque ya en publicaciones anteriores hemos presentado dichos materiales de forma pormenorizada, 


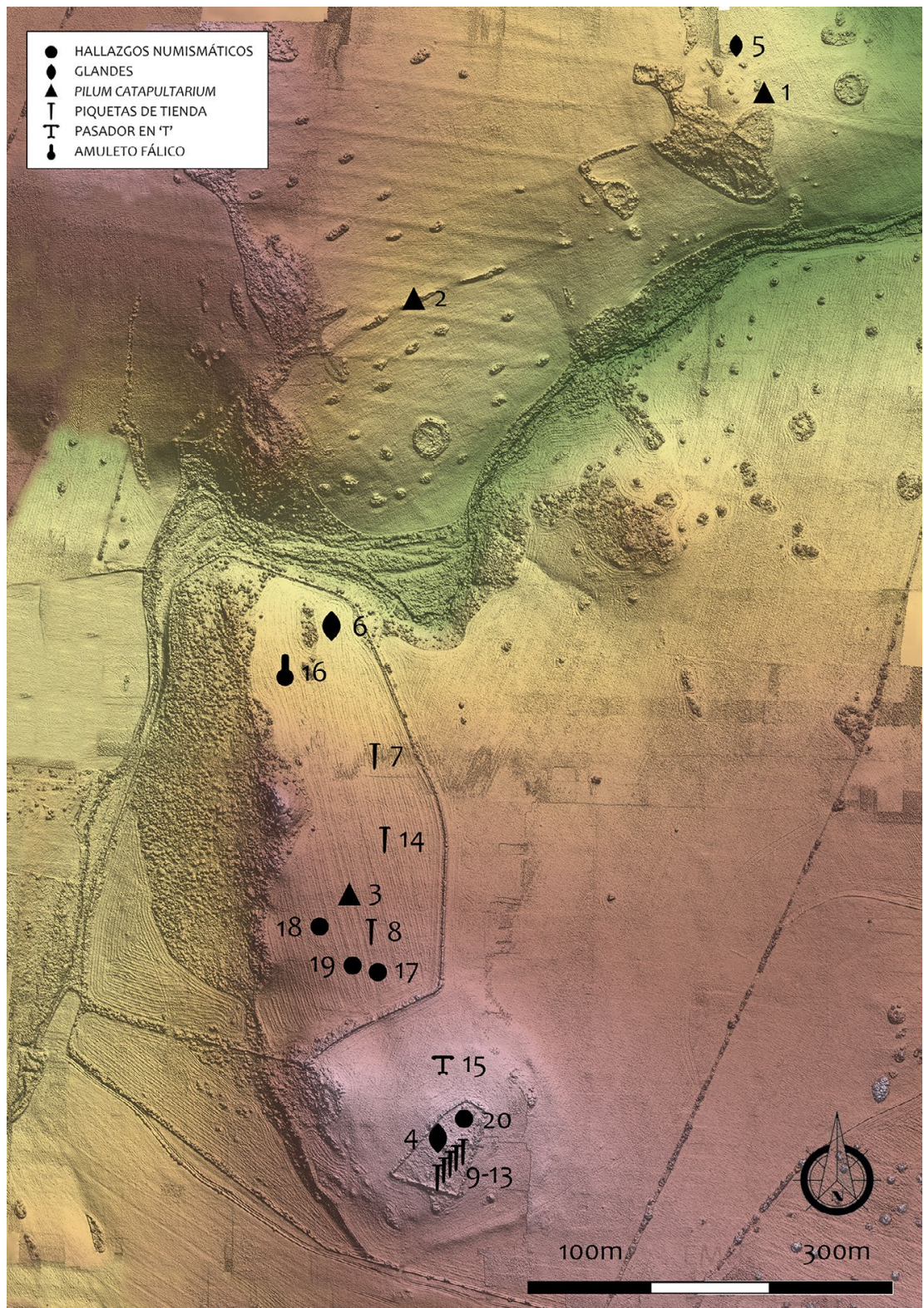

Figura 20: Localización de hallazgos de época romanorrepublicana sobre Modelo Digital de Terreno generado a partir de fotogrametría elaborada por el CAI de Geografía e Historia de la Universidad Complutense de Madrid (octubre 2015)

recogemos aquí los principales datos acerca de los mismos (Gorges et al., 2009: 574-576, fig. 4; Morillo et al., 2011: 66-68, figs. 9-13; Morillo et al., 2021).

Por lo que se refiere al armamento, se han localizado diferentes proyectiles de hierro y plomo. Entre los primeros destacan dos virotes de pilum catapultarium piramidal de sección cuadrangular casi idénticos (Fig. 21: 1 y 2). Sus dimensiones eran $4,30 \mathrm{~cm}$ de longitud y $0,85 \mathrm{~cm}$ de sección mayor, en un caso (Morillo et al., 2011: 67-68, fig. 9), y 5,04 cm de longitud y 1,50 $\mathrm{cm}$ de base (Morillo et al., 2021: 118, fig. 7, n. ${ }^{\circ} 38$ ). Se documenta también un tercer elemento del mismo tipo (Fig. 21:3), en este caso de mayores dimensiones (14,6 $\mathrm{cm}$ de longitud y $1,9 \mathrm{~cm}$ de sección máxima), con sección cuadrangular y vástago de enmangue circular. No se hallaron paralelos exactos para esta pieza (Morillo et al., 2011: 68, fig. 13).
Si bien los ejemplares de pila catapultaria con cabeza piramidal apuntada (de entre 2,4 y $3 \mathrm{~cm}$ ) y enmangue tubular son los más comunes ya desde finales del siglo III a. C. (p. e. Blé, 2012, para el caso hispano), los ejemplares del tipo que aquí reseñamos presentan considerables diferencias respecto a los anteriores, como la mayor longitud de la punta, que es mucho más estilizada, además de que el enmangue se realiza en forma de espiga, lo que les hace asemejarse más a un dardo que a un proyectil de artillería. Esta variante está muy bien atestiguada en contextos militares tardorrepublicanos o vinculados a las guerras cántabras, apareciendo incluso en campamentos imperiales de los siglos I-III (cf. Morillo et al., 2021: 119, con paralelos).

De gran interés de cara a la identidad de las tropas romanas que emplearon estos proyectiles, es que, al menos en época altoimperial, solo las tropas legionarias 


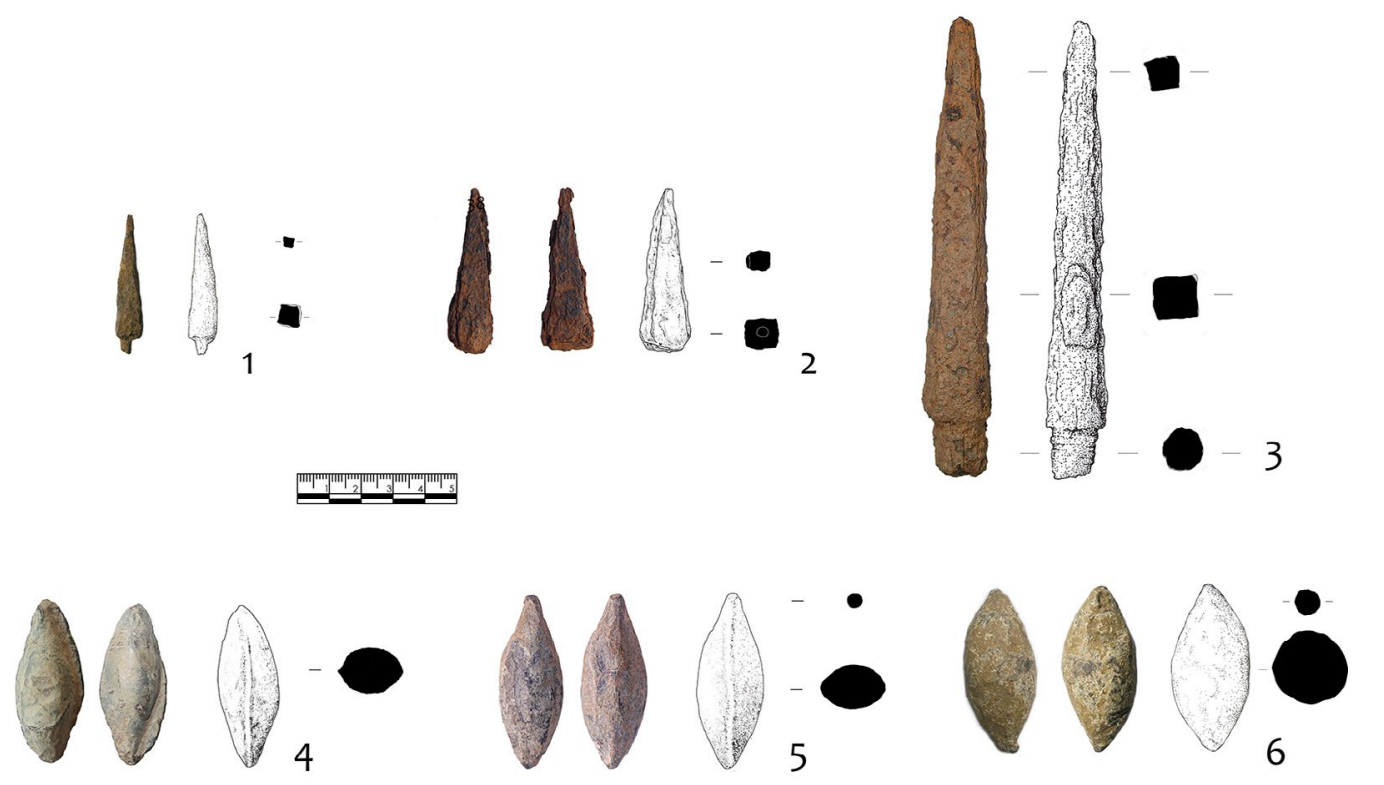

Figura 21: Materiales romanorrepublicanos obtenidos en el transcurso de la prospección: proyectiles: 1-3: pila catapultaría; 4-6: glandes

disponen de este tipo de artillería (Sáez Abad, 2006: 139).

Se han recuperado también 3 proyectiles de plomo para honda. El primero (Fig. 21: 4), fundido en molde bivalvo y con $5,4 \mathrm{~cm}$ de longitud, diámetro máximo de $2,4 \mathrm{~cm}$ y peso de $89 \mathrm{gr}$, se puede clasificar dentro del tipo IIb de Völling (1990), de forma bicónica con rasgos redondeados (Morillo et al., 2011: 67, fig. 10). Otros dos se localizaron en la campaña de 2010 . Uno (Fig. 21: 5) presenta una longitud de 5,2 cm, un diámetro máximo de $2,17 \mathrm{~cm}$ y un peso de $86,71 \mathrm{gr}$ y ha sido fundido en molde bivalvo. La segunda bala (Fig. 21: 6) presenta la misma longitud $(5,2 \mathrm{~cm})$ mientras su diámetro máximo es de $2 \mathrm{~cm}$ y su peso de 86,26 gr. En este caso ha sido elaborado mediante la técnica del martillado. Ambos corresponden al tipo IIa de Völling (bicónicos con extremos afilados) (Morillo et al., 2021: 119-121, fig. 7, n. ${ }^{\text {os }} 1$ y 25 ).

Las balas de plomo, destinadas a barrer al enemigo en campo abierto o durante un asedio constituyen unos de los mejores testimonios de actividad bélica del ejército romano. Recientemente hemos recopilado los abundantes testimonios de su empleo en campos de batalla republicanos, campamentos de campaña y castra estables, asaltos a oppida, e incluso en asentamientos civiles (Morillo et al., 2021: 120).

Una última cuestión sería la relativa al tipo de tropas que empleaba este armamento. Siempre se suelen asociar a la presencia de honderos baleáricos, constatada desde el punto de vista de las fuentes a partir de la última fase de la guerra numantina (Apiano, Iber. 92; Frontino, Strat. 2, 27). Pero también se ha apuntado su posible participación entre las tropas romanas durante la segunda guerra púnica (Quesada et al., 2015: 353354). En este mismo trabajo se apunta que es dudoso el empleo de hondas por parte de los auxiliares hispánicos durante los últimos siglos de la República.
A pesar de los numerosos ejemplares recogidos durante el periodo republicano en la Península Ibérica, la Narbonense y la Galia central, y más tarde en las provincias fronterizas del Imperio, los proyectiles de honda fabricados en plomo presentan no pocos problemas de interpretación, derivados de la variabilidad de módulos, pesos y técnica de elaboración, rasgos propios de una fabricación artesanal, no estandarizada, que depende de circunstancias y decisiones particulares. El único estudio de conjunto es el de Völling, que estableció 6 tipos a partir de la morfología de los hallazgos documentados (1990). Se suele aceptar que las glandes republicanas, de módulo más grande, fueron cambiando hacia tamaños más reducidos (Poux, 2008: 368-370), aunque recientemente Quesada ha propuesto una secuencia evolutiva más completa basada en algunos contextos como Baecula, que plantea que los proyectiles de honda de plomo fueron más pesados (más de 60 gr) a partir de la guerra sertoriana y durante todas las guerras civiles, mientras los anteriores eran más ligeros (Quesada et al., 2015: 351-353, fig. 18). Esta sugerente hipótesis se basa por el momento sólo en el cálculo de los pesos medios y sería necesario ampliar la base documental y los parámetros de comparación, como los mismos autores señalan.

Los ejemplares del Pedrosillo se encuentran entre los más pesados, por encima de 80 gramos, llegando incluso a los 89 gr, lo que los aproxima al valor de tres uncias (onzas), esto es un quadrans o cuarto de libra (82,2 gr). Aunque las glandes de este peso no son las más habituales, abundantes ejemplares con pesos semejantes se encuentran tanto en conjuntos del siglo II a. C., como Chões de Alpompe, Ampurias, Pierredon, Caylus/Puech Boussac o Haltern, como en los del siglo I a. C., como Passet de Segària, Castelo de Juntas, Alto dos Cacos, Cabeça de Vaiamonte o Montemayor (Morillo et al., 2021: 120-121). 

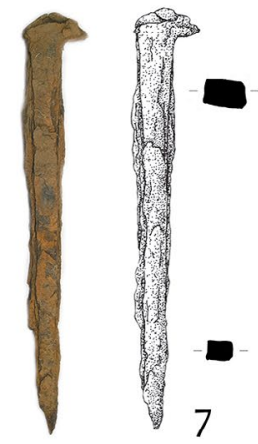

7
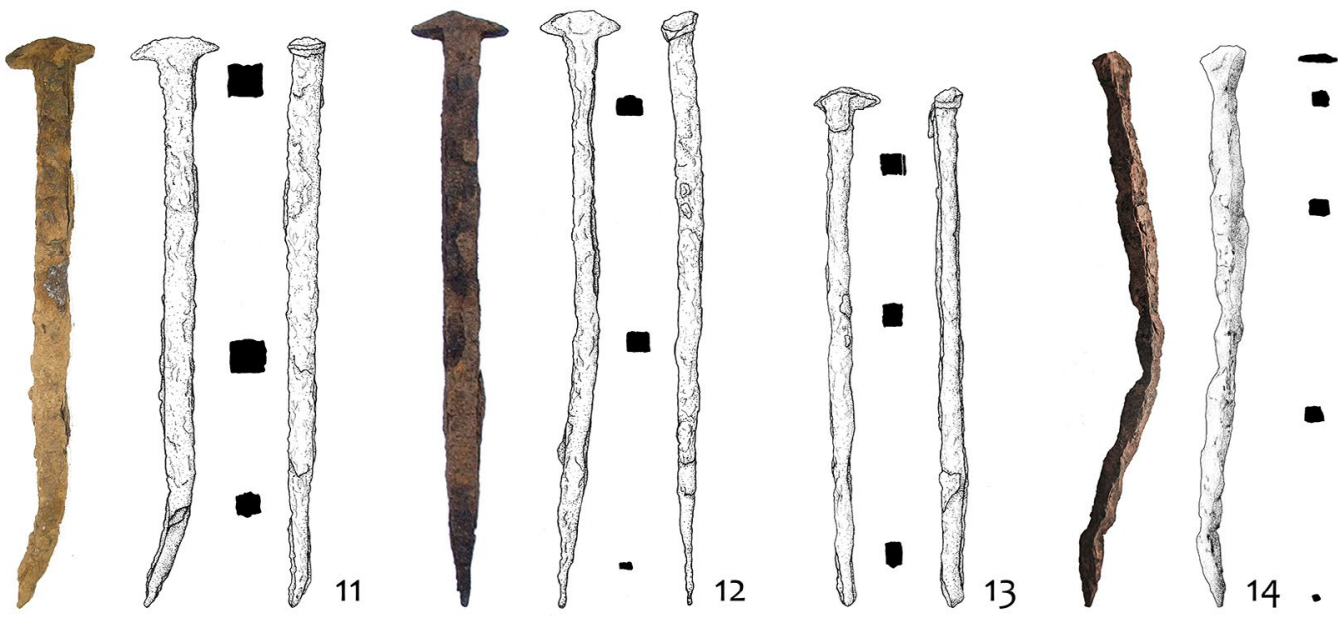

Figura 22: Materiales romanorrepublicanos obtenidos en el transcurso de la prospección. Clavos o piquetas de tienda (7-14)

Dentro de lo que podríamos definir como utillaje militar, materiales con diferentes funciones, pero que se interpretan como evidencias de la actuación del ejército romano en función de su hallazgo en contextos de campamentos o campos de batalla (Poux, 2008: 389) se encontrarían los 10 clavos de hierro que interpretamos como piquetas de tienda (Fig. 22: 7-14). Casi todas ellas responden al mismo modelo: largas clavijas de hierro, de unos $18 \mathrm{~cm}$ de longitud, con vástago de sección cuadrangular 0,7-0,9 cm y cabeza en ' $T$ ' de 1,3-2,5 $\mathrm{cm}$. Tres son algo más reducidas, de entre $12-13 \mathrm{~cm}$ de longitud (Gorges et al., 2009: 274, fig. 4; Morillo et al., 2011: 67, fig. 11; Morillo et al., 2021: 121, fig. 8, n. ${ }^{\text {os }} 12,13,26$ y 31$)$.

Por su morfología común, este tipo de materiales a menudo ha pasado casi desapercibo en la investigación como material militar romano, por lo que en algunos catálogos han recibido la simple denominación de "clavos", sin avanzar más sobre su homologación al módulo de las clavijas de tienda de otros tipos y asociándose a otros usos domésticos. No cabe duda que los clavos de hierro tuvieron diversas utilidades, en particular en el ámbito de la carpintería. Sin embargo, no se reflexiona acerca de que las obras de carpintería no debían ser especialmente frecuentes en campamentos de campaña, y que para los trabajos en madera en las obras defensivas y estructuras interiores en acantonamientos se prefiere la técnica del ensamblado en lugar de la clavazón para evitar que la corrosión del hierro por la humedad debilite la estructura (por ejemplo, en Osterburken, Huther, 2014: 89-112 y 235-255). Evidentemente, en contextos militares de campaña, dichos elementos no pueden explicarse de otra manera que en razón de su utilidad como elementos de sujeción de las tiendas de campaña.

Un simple repaso a la bibliografía científica ha permitido rastrear la variabilidad de los elementos metálicos de sujeción de las tiendas romanas (Morillo et al., 2021: 122-123). Dentro del criterio de máxima rentabilidad productiva y extremado pragmatismo de una campaña militar se sacrifica la estandarización en razón de la utilidad, recurriendo a todo aquello que pudiera servir para sujetar una tienda de campaña al menor coste y mayor rapidez de elaboración.

Por otra parte, clavijas de tienda de la misma tipología que las documentadas en El Pedrosillo ya se habían publicado con anterioridad en asentamientos con contextos arqueológicos militares romanos como 
Newstead, los campamentos numantinos o los recintos augusteos de La Loma y La Muela. Ejemplares del mismo tipo se conocen en los campamentos de Cáceres el Viejo y Aguilar de Anguita, clasificados como simples clavos de hierro a pesar de responder al mismo patrón y módulo que las piquetas de tienda, muy diferente al de otro tipo de clavos para construcción (Morillo et al., 2021: 123, con bibliografía de referencia).

En el caso del Pedrosillo contamos además con un análisis metalográfico de uno de estos clavos férricos, encargado en su día por J.-G. Gorges e inédito9 . En dicho informe se confirma que se trata de hierro puro con poco contenido en carbono con una estructura ferrítica muy resistente a la vez que muy plástica, concebido para soportar tensión. El mineral procede del reciclaje, como avala la abundante presencia de escorias. Respecto a su cronología, el informe certifica que se trata de un útil anterior a la época industrial.

La identificación en 2006 de 5 de estas piquetas en el pequeño recinto $\mathrm{C} 2$ del Pedrosillo ha confirmado sin lugar a dudas el empleo de dichos elementos para la sujeción de las cuerdas que tensaban el cuero de las tiendas (Gorges et al., 2009: 274-276, fig. 4). Todavía se encontraban clavadas in situ a intervalos regulares de entre 3,30 y 3,60 m (12-13 pies itálicos), lo que permitiría identificar el módulo aproximado de las tiendas de campaña, que coincidiría con los 10-12 pies (aprox. 3-3,60 m) de anchura de los papiliones según Higinio (1) (Figs. 23-24). En el campamento F2 de Masada las dimensiones de las tiendas son un poco menores (8-10 pies) (Richmond, 1962: 146). Todas las clavijas se encontraban alineadas a unos 5,40 m (aproximadamente 20 pies itálicos) de la cara interna del muro oriental y cerca de la esquina sudeste, lo que indica la anchura del intervallum, unos $6 \mathrm{~m}$ (22 pies itálicos) hasta la línea del caballete de la tienda, dispuesta perpendicularmente a la muralla como se detecta en el Campamento F2 de Masada (Richmond, 1962: 146, fig. 7). Como ocurre asimismo en este último yacimiento, la entrada de la tienda se encontraría en el lado contrario, abierto hacia el interior del recinto, aunque no sabemos si habría otros contubernia afrontados.

Otra posibilidad es que dicha alineación de clavijas correspondiera a la presencia de una hilera de mulas (una por contubernium) atadas con las riendas a dichas sujeciones. Van Driel Murray opina que la mayor parte de las piquetas de hierro se utilizaban para atar animales, mientras para las tiendas se emplearían estacas de madera (van Driel Murray, 2017: 7). Sin embargo, tanto la liviandad como la morfología de dichas piquetas descarta a nuestro juicio su empleo para dicha finalidad en el caso del Pedrosillo.

9. G. Renoux, F. Dabosi e Y. Thebault: Rapport préliminaire de l'étudde paléométallurgique effectuée sur un "piquet de tente" découvert à Pedrosillo (Espagne). Université de Toulouse, junio de 2007.

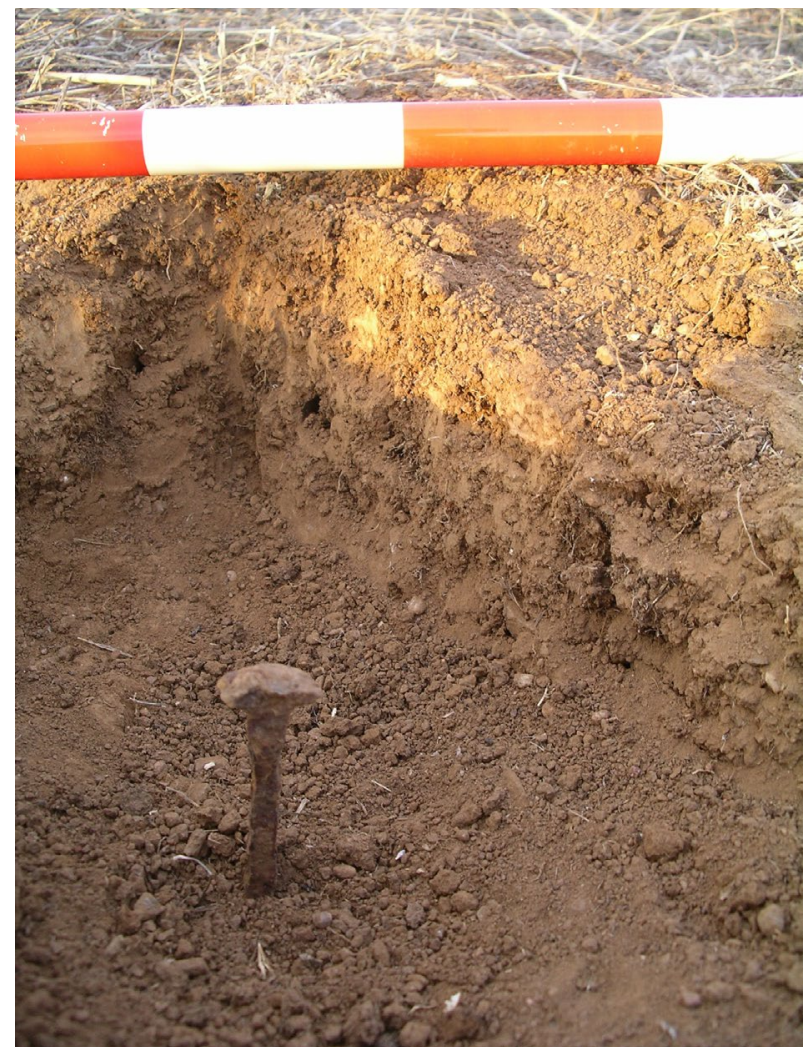

Figura 23: Microexcavación de una clavija de hierro in situ a partir de su hallazgo mediante detector de metales en el recinto pequeño (C2) durante la campaña arqueológica de 2006

La trascendencia del descubrimiento del Pedrosillo se ha visto reflejada ya como una novedad en la bibliografía específica (van Driel Murray, 2017: 7). Recientemente se han dado a conocer nuevos hallazgos del mismo tipo en contextos militares tardorrepublicanos en Hispania, como la Cabeza del Cid (Cerdeño y Gamo, 2016: 178: fig. 9, 3), o Baecula (Bellón et al., 2015: 248, 253, 309, fig. 18). También en el recinto altoimperial del Mouro (Belmonte-Grao, Asturias), han sido halladas estas mismas piezas por uno de los firmantes de este trabajo (E. Martín) y por el momento permanecen inéditas. En ellas se apunta ya el antecedente del Pedrosillo ${ }^{10}$.

También se han encontrado elementos de indumentaria personal, como un pasador de bronce en " $T$ " rematado con apéndices en forma de bellota, parcialmente conservado (Morillo et al., 2021: 123, fig. 8, n. ${ }^{\circ}$ 7) (Fig. 25: 15). Estos pasadores se interpretan como prendedores o sujeciones de cinturón a la manera de hebilla y derivarían, según Palol, de las fíbulas de La Tène. Se puede identificar con el tipo c de Palol (de Palol, 1955-56: 98-102). Se trata de una categoría muy abundante, con numerosas subvariantes tipológicas y con una larga cronología, aunque muy mal estudiada, ya que raramente se han publicado en

10. Sobre el empleo de clavijas para tiendas en los contextos militares republicanos v. Luik, 2002: 102 y Dobson, 2014. 


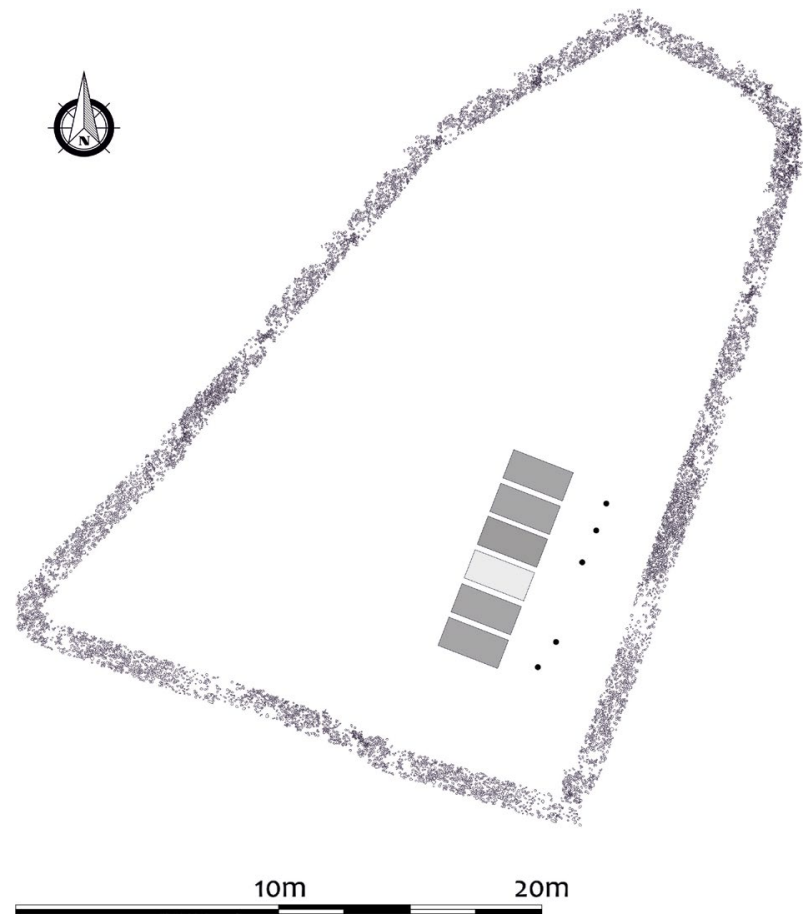

Figura 24: Recinto C2a. Modelización de la posición de la hilera de tiendas de campaña (papiliones) a partir de la localización de los clavos de sujeción in situ

contexto arqueológico, y cuyo origen se ha situado en el mundo ibérico. No podemos avanzar mucho más sobre este ejemplar, más allá de la cronología centrada en el periodo romanorepublicano y su vinculación con los contextos culturales meridionales.

Debemos mencionar también el hallazgo de un amuleto de plomo con forma de falo esquemático $(6,95$ $\mathrm{cm}$ de longitud, anchura máxima de 2,98 y mínima de
1,6; peso 119,50 gr), en el que se aprecia perfectamente por una de sus caras el glande y el tronco del órgano sexual masculino, delimitados por tres líneas incisas de separación. En la parte inferior adopta una forma circular, que representa sumariamente la bolsa escrotal

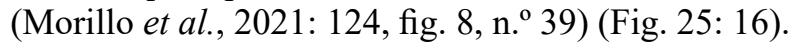

Aunque los más habituales dentro de los amuletos con forma fálica (fascinus), son los fabricados en bronce, también se conocen del mismo tipo en plomo, alguno de ellos muy semejante al que aquí presentamos (Galeano y Gil, 1998: 56-57, n. ${ }^{\text {os }} 4$ y 5). Es evidente su carácter apotropaico como talismanes contra el Mal de Ojo. Su asociación al plomo, metal con connotaciones mágicas relacionadas con divinidades y espíritus de ultratumba, refuerza el carácter supersticioso de ejemplares como éste (Morillo et al., 2021: 124-125).

La bibliografía se hace eco de la abundancia de amuletos fálicos en recintos militares de la frontera romana y en ámbitos civiles militarizados, lo que ha llevado a denominarlos incluso como Limesphalli (Oldestein, 1976: 158-159). Su abundancia en estos ambientes castrenses, donde la virilidad constituye una virtud inherente, y extremadamente supersticiosos, resulta lógica. Hasta la fecha no se había asociado directamente a un contexto militar en Hispania. Teniendo en cuenta su peso y la carencia de anilla de sustentación, este tipo de piezas debían ser llevados por su poseedor de otra manera o depositados en determinados lugares (Morillo et al., 2021: 124).

Sin duda los hallazgos numismáticos constituyen una de las evidencias más significativas de cara a la datación. En el pequeño fuerte poligonal se localizó en 2007 una moneda hispano-púnica (Fig. 25: 20), un quinto de bronce del tipo de Tanit y prótomo de caballo (Morillo et al., 2011: 66, fig. 9), emisión con una amplia
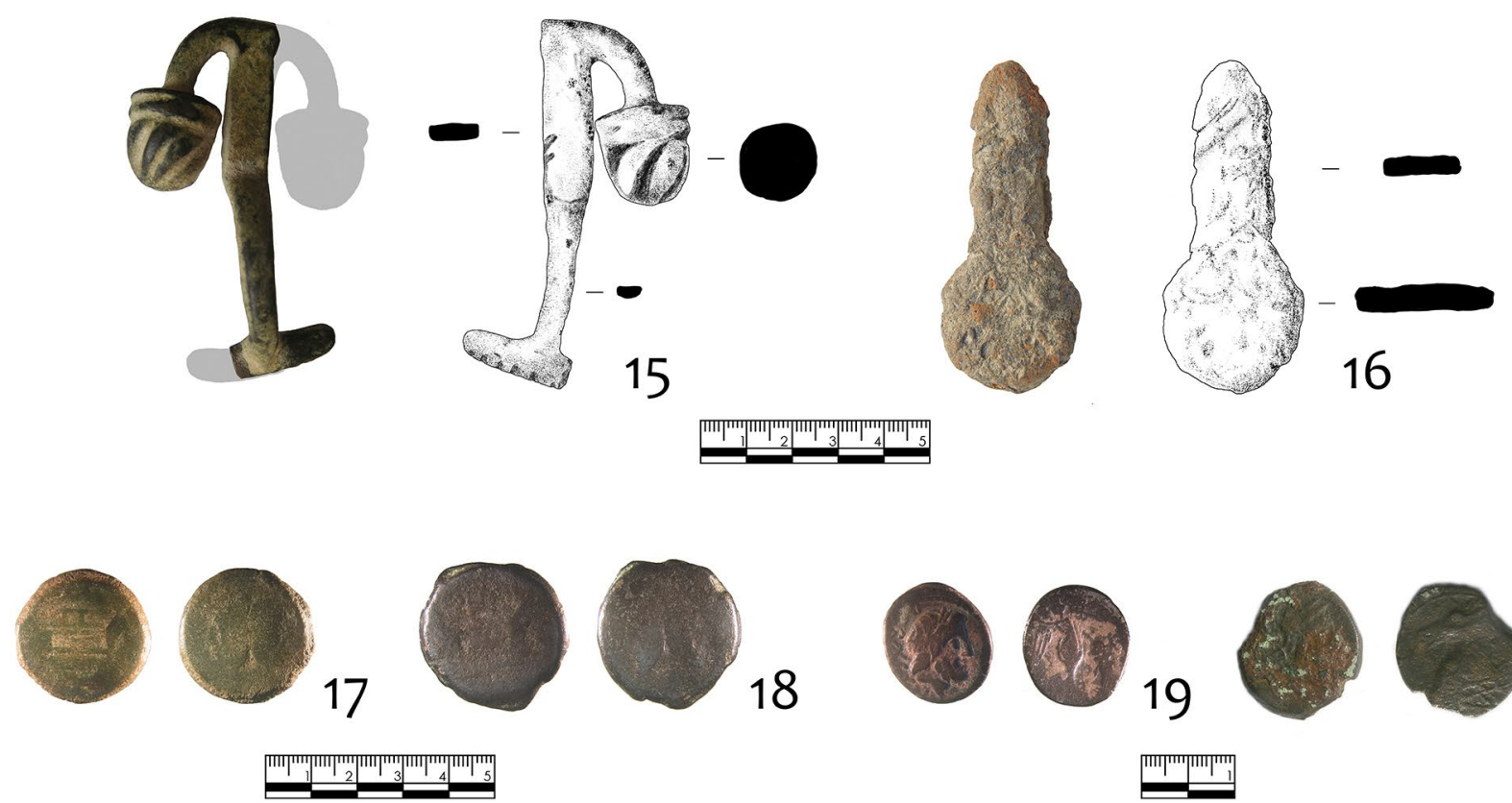

19
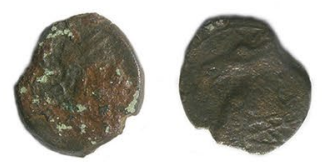

Figura 25: Materiales romanorrepublicanos obtenidos en el transcurso de la prospección: pasador en "T" (15), amuleto fálico (16) y hallazgos numismáticos (17-20) 
dispersión en el Levante y valle del Guadalquivir, con prolongaciones hacia el sur de Extremadura y la Meseta, que se acuñan entre el 221 y el 218 a. C., manteniéndose en circulación durante toda la siguiente centuria (Villaronga, 1973: 73-85 y 127-128, Clase VIII; Alfaro, 1997: 77-79, mapa 4; García-Bellido y Blázquez, 2001: 156-166, 9 C; Blázquez Cerrato, 2002: 251-253, nota 804).

Tres piezas más, en este caso romanorrepublicanas, se localizaron durante la campaña de 2010. La primera de ellas (Fig. 25: 19) es un victoriato forrado (RRC $53 / 1$ ), con cabeza laureada de Júpiter mirando hacia la derecha en anverso y victoria alada en pie coronando un trofeo en reverso, acuñado con posterioridad al 211 a. C. Los otros dos ejemplares son ases sextantales del tipo Jano bifronte laureado y proa de nave a la derecha, con ROMA en el exergo. El primero (Fig. 25: 17) pertenece a la acuñación RRC 56/2, que tuvo lugar entre el 211-206 a. C. La segunda pieza (Fig. 25: 18) pertenece al tipo RRC 162/3, acuñado en Roma entre 179-170 a. C. (Morillo et al., 2021: 116-117, fig. 6, n. ${ }^{\text {os }}$ $40,11$ y 54$)$.

Las fechas más antiguas las ofrecen el bronce hispano-púnico (221-218 a C.) y el victoriato (post. 211 a. C.), mientras que la datación post quem la proporciona el as sextantal RRC 162/3, acuñado entre el 179 y 170 a C. Los 4 ejemplares presentan un considerable desgaste, evidencia de un largo periodo de circulación. Este tipo de ejemplares son habituales en la mayoría de los contextos arqueológicos hispanos del siglo II a. C. ya que presentan una larga perduración en las estratigrafías (Morillo et al., 2021: 117). En el Occidente peninsular, las monedas de bronce romanorrepublicanas son muy escasas y corresponden además en su mayoría a las acuñaciones sextantales y semiunciales, emitidas entre el 189 y 158 a. C. (Blázquez Cerrato, 2010: 430; 2014: 417-419, fig. 3; 2014: 417). La moneda de bronce romanorrepublicana en una región escasamente monetizada como ésta, concentrada además en unas franjas cronológicas concretas, debe ponerse en relación con la presencia del ejército romano con vistas al control del territorio al norte de Sierra Morena (Blázquez Cerrato, 2014: 423).

Cuestión de enorme interés en relación con los objetos encontrados sería su dispersión espacial dentro del yacimiento. Los dos campamentos concentran la mayoría de las evidencias. En el recinto grande se localizaron 3 monedas romanorrepublicanas en la zona más meridional y 3 piquetas a poca distancia del muro perimetral oriental. En el sector septentrional aparecieron una glans plúmbea y un amuleto de plomo.

Del recinto menor proceden las 5 piquetas halladas in situ alineadas a unos 5,40 $\mathrm{m}$ de la la cara interna del muro oriental, junto a la esquina sudeste, además de una bala de plomo y una moneda hispanopúnica, en este caso junto al muro occidental. El pasador en " $T$ " se localizó entre ambos recintos.

La densidad de hallazgos es mucho menor en la ribera izquierda del arroyo. No obstante, se detecta una nueva concentración en el sector del posible recinto $\mathrm{C} 3$ y c17 y la construcción poligonal F2. Allí aparecieron dos piquetas de tienda, una glande y una punta de hierro identificada como un posible venablo. Un pilum catapultarium aislado aparece en esta misma ladera izquierda del arroyo, junto a uno de los muros rectilíneos aislados.

\section{EL CONJUNTO ARQUEOLÓGICO DEL PEDROSILLO. REFLEXIONES SOBRE SU IN- TERPRETACIÓN}

A través del análisis edilicio y arquitectónico de las estructuras constructivas hemos documentado la presencia de dos recintos campamentales de diferente tamaño además de fortines de distinto tipo y construcciones lineales aisladas en el terreno (Fig. 26). La cronología tardorrepublicana del conjunto se encuentra asimismo avalada tanto por los paralelos arquitectónicos como por la aparición de hallazgos metálicos que comparten una filiación militar.

La homogeneidad del registro arqueológico mueble e inmueble pone de relieve que estamos ante un proyecto planificado y ejecutado de manera coordinada y sincrónica en un emplazamiento cuidadosamente elegido. Afectó a las dos laderas que bajan con cierta pendiente hacia un pequeño arroyo en el que se encuentra tanto un manantial como un vado natural (Fig. 27). La intencionalidad se plasmó en el derribo y enrasamiento de las ruinas de las estructuras prehistóricas que existían en la orilla derecha del arroyo para construir un campamento legionario y un pequeño fuerte, este último en la zona más elevada, dominando visualmente buena parte del conjunto. Ambos recintos carecen de construcciones interiores, por lo que debemos pensar que su ocupación se realizó mediante estructuras perecederas y transportables, es decir, tiendas de campaña. La confirmación de esta hipótesis la proporcionó el hallazgo de varias piquetas de hierro en ambos campamentos. De hecho, el descubrimiento de varias de estas sujeciones para tiendas clavadas a distancias

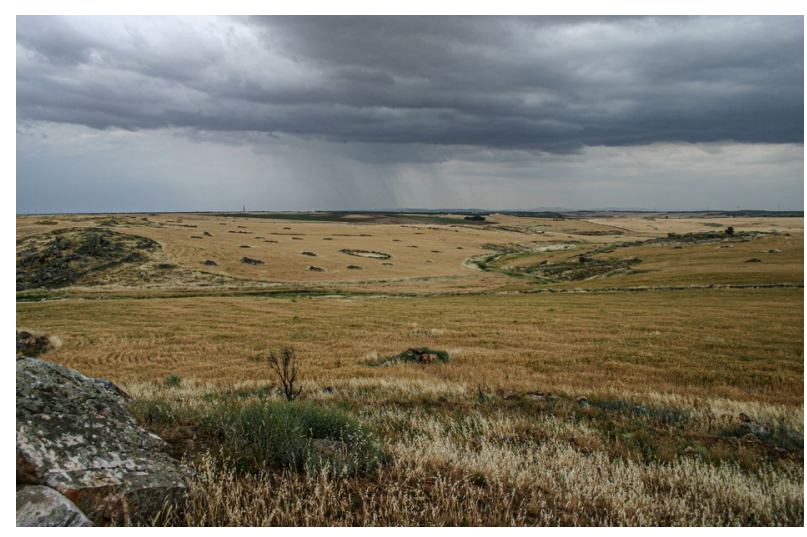

Figura 26: Vista general hacia el noreste del posible campo de batalla desde el muro perimetral oriental del recinto campamental C2 (primavera del 2005) 

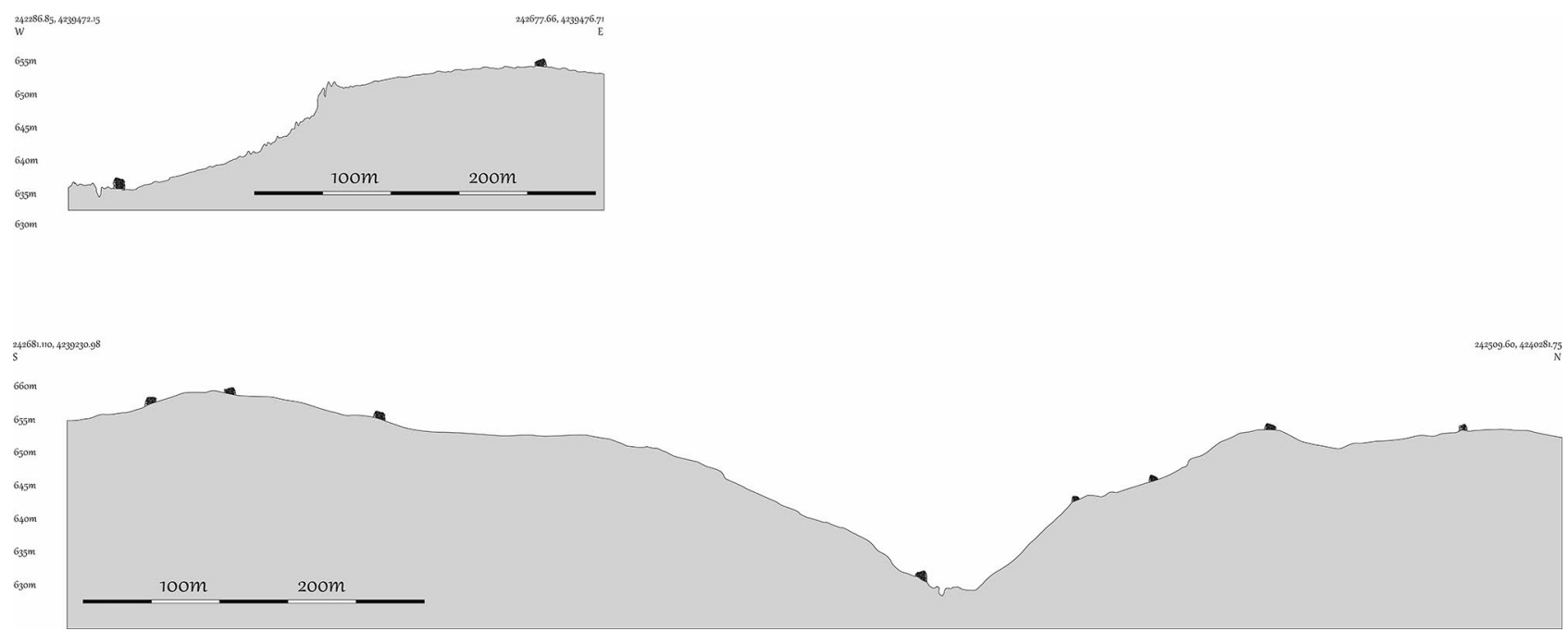

Figura 27: Secciones topográficas del complejo militar romano del Pedrosillo. En la parte superior la sección E-W en el sector del gran recinto $\mathrm{C} 2$, con la posición de sus muros perimetrales marcados en negro; en la parte inferior sección S-N, con los muros perimetrales de los recintos campamentales (C2a y C2) a la izquierda de la imagen, y el titulum excavado junto al arroyo (vertiente derecha del arroyo). En la ladera opuesta, a la derecha de la imagen, se aprecian diferentes tituli y fortines circulares ocupando eminencias del terreno

regulares en el pequeño fuerte $\mathrm{C} 2 \mathrm{a}$ fue concluyente en este sentido.

El resto de las estructuras menores se disponen a ambos lados del arroyo, en lo que parece constituir un dispositivo táctico para controlar y proteger el vado, siendo la función de los campamentos de la ribera meridional el apoyo a este esquema militar. Los fortines circulares, protegidos con parapetos y con un amplio dominio visual, parecen destinados al empleo de la artillería ligera (honda, venablos), mientras las fortificaciones lineales tendrían sentido precisamente para dificultar y retrasar entretanto el cruce del regato y hacer más vulnerable a cualquier enemigo a las descargas de proyectiles lanzadas. Precisamente la disposición intercalada tan particular de los tituli parece indicar que el enemigo dispondría de una fuerte caballería, y de ahí que sea necesario zigzaguear para cruzar el campo de obstáculos mientras se asciende una pronunciada ladera. Esto nos ha llevado a aventurar la hipótesis de que es un espacio preparado como campo de batalla (Figs. 28 y 29).

La baja densidad de monedas, militaria y elementos de utillaje e indumentaria personal, así como su lugar de localización también nos llevan a plantear algunas

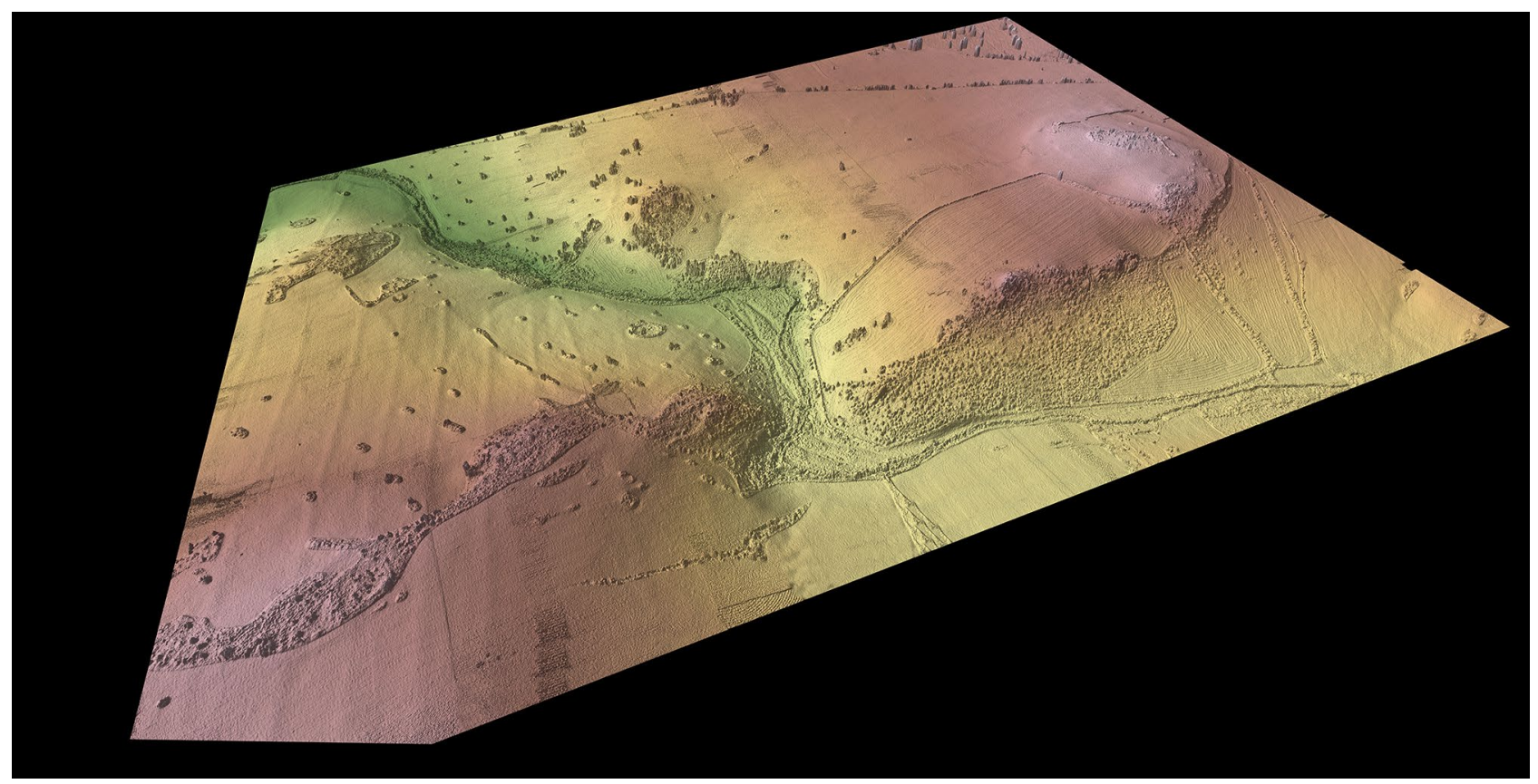

Figura 28: Modelo Digital de Terreno en relieve del complejo arqueológico del Pedrosillo generado a partir de la fotogrametría visto desde el noroeste. Se aprecian la disposición de estructuras en ambas vertientes del arroyo 


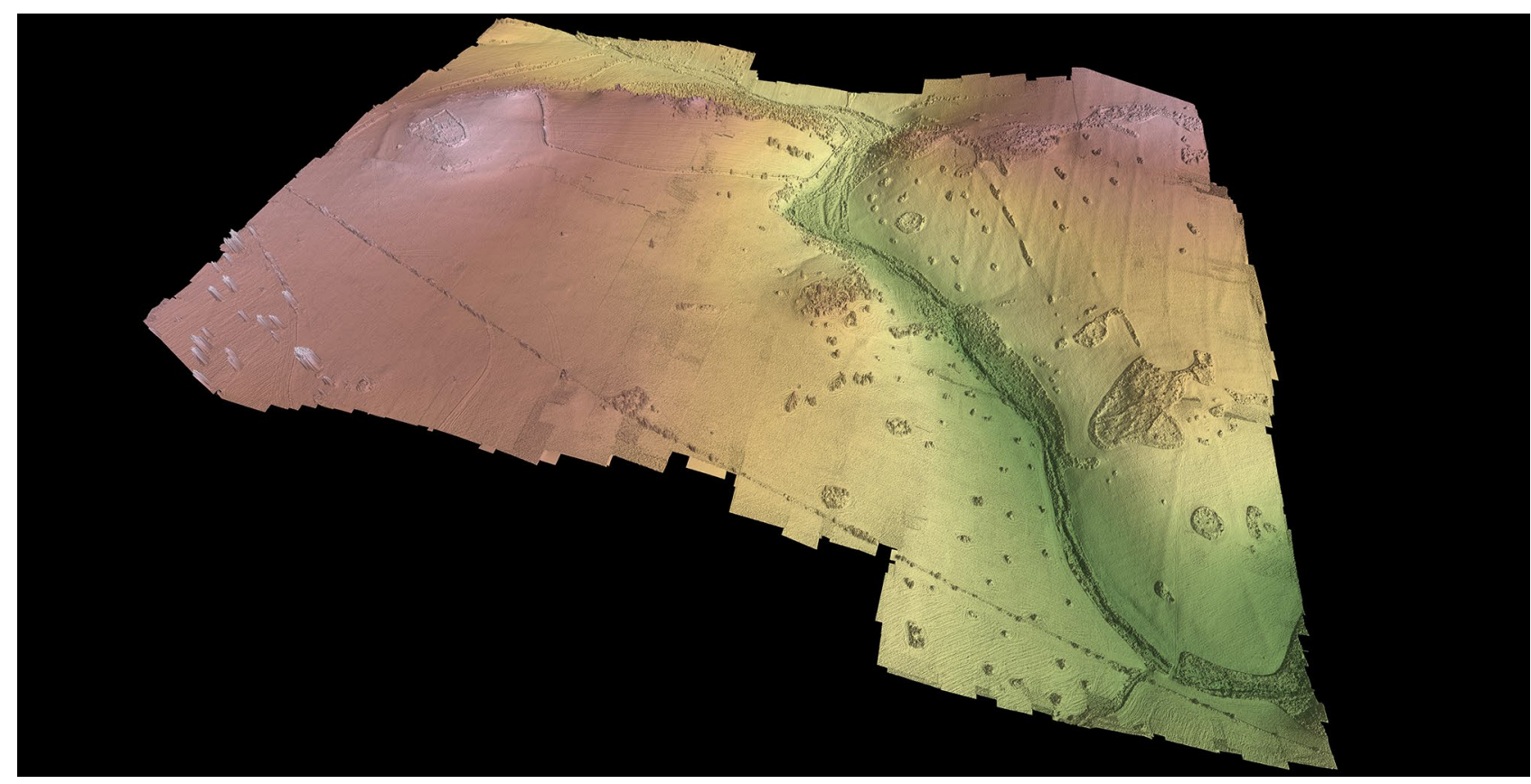

Figura 29: Modelo Digital de Terreno en relieve del complejo arqueológico del Pedrosillo generado a partir de la fotogrametría visto desde el noreste. Se aprecian la disposición de estructuras en ambas vertientes del arroyo

hipótesis. En su mayor parte se encontraron dentro de los dos campamentos, lo que indica su carácter de objetos perdidos de manera involuntaria u olvidados por parte de las tropas que se encontraban en su interior, generalmente de poco valor. Sin embargo, extramuros de dichos recintos y en todo el complejo los hallazgos son prácticamente inexistentes, lo que parece indicar que el enfrentamiento previsto, para el que se había adecuado todo este dispositivo, nunca sucedió. No parece haber existido una rebusca sistemática de militaria una vez concluido el enfrentamiento, que suele ser lo habitual en campos de batalla (Quesada et al., 2015: 316). Una excepción es la anómala concentración de materiales (piquetas de tienda, glande, pilum) en la ribera izquierda del arroyo, en el sector del recinto $\mathrm{C} 3$ y la construcción poligonal F2, lo que parece indicar una presencia más permanente de tropa en este lugar, sincrónica a la de los recintos castrenses, pero difícil hoy en día de tipificar, tal vez un puesto avanzado al otro lado del vado.

Quedarían aún muchas cuestiones por resolver. El tipo de materiales recuperado no permite dilucidar la identidad o el tipo de tropas, legionarias o aliadas (socii), aunque la existencia de un campamento de 10 ha podría indicar la presencia de contingentes de ciudadanos romanos (legionarios). Dicha interpretación podría verse reforzada por el tipo de armas localizadas, glandes y puntas de venablos que, como ya hemos señalado, se han asociado durante este periodo a las tropas legionarias.

Dilucidar el marco cronológico de este yacimiento sería uno de los objetivos primordiales, aunque no podamos pronunciarnos con rotundidad. La numismática nos indica claramente una datación post quem
179/170 a. C., pero la larga perduración de la moneda en circulación en este periodo no permite aquilatar de forma más precisa. No se encuentran evidencias de las abundantes acuñaciones del periodo sertoriano, lo que no indica que estamos sin duda ante el fondo de moneda circulante durante el siglo II o primeros compases del I a. C. Otro indicio indirecto, en este caso de carácter arquitectónico, sería la propia planta de los campamentos, anterior a la aparición de las plantas rectangulares a partir del conflicto sertoriano.

Este marco temporal, centrado en la segunda mitad del siglo II a. C., así como el ámbito geográfico, un lugar de la Beturia túrdula, a la salida de un camino natural que permite cruzar Sierra Morena sin grandes dificultades desde la Baetica, nos aproximaría al contexto de las Guerras Lusitanas (155-138 a. C.), conflicto que presenta notables dificultades de caracterización arqueológica (Berrocal, 2018). Las fuentes literarias (Apiano, Iber. 67-71) nos informan del papel clave desempeñado por la vertiente septentrional de Sierra Morena durante este momento. A este respecto, hay que señalar la relativa proximidad de Azuaga, que se suele identificar sin mucho motivo con la antigua Arsa, a 24 kilómetros al oeste. Aún más próxima hacia el mediodía se encuentra la antigua Regina, cuyo oppidum primitivo controlaba precisamente una de las más importantes vías de paso. Sin embargo, el oppidum más cercano, a unos $6 \mathrm{~km}$, es Las Dehesillas (Rodríguez Díaz e Iñesta, 1984), cuyo nombre antiguo se desconoce. Su posición al NW, justamente al norte de todo el dispositivo táctico organizado por el ejército romano a orilla del arroyo del Pedrosillo, podría indicar el posible enemigo contra el que se dispuso (Gorges y Rodríguez Martín, 2006: 667668). Se ha querido relacionar este complejo militar del 
Pedrosillo con la campaña del 140 a. C. de Q. Máximo Fabio Serviliano contra Viriato, que se saldó con el sitio de Erisana, de localización desconocida (Gorges y Rodríguez Martín, 2009: 381). No obstante, no podemos descartar su asociación con otros episodios del conflicto contra los lusitanos que tuvo lugar más tarde, entre el 114 y el 93 a. C., del que desconocemos muchos detalles ${ }^{11}$ (Moreno Sánchez, 2017: 63-64).

Ya, M. Reddé, después de sus intervenciones en Alesia apuntaba que "la arquitectura de los sistemas defensivos era mucho más diversa y variada de lo que suponemos habitualmente" (1995: 352). La arqueología, lejos de la aparente homogeneidad que transmiten las fuentes clásicas, demuestra en efecto una gran diversidad arquitectónica en los dispositivos militares de asedios y campos de batalla, que varían y se adaptan según las circunstancias del enemigo y el terreno, multiplicando casi siempre diferentes obstáculos de aproximación. No es posible establecer una regla general. En los últimos años, gracias en buena medida a los hallazgos de militaria con ayuda del detector de metales, se van dando a conocer yacimientos de este tipo cuyo registro material dista mucho de ser el "canónico" como Le Lampourdier (Deyber et al., 2018) o Chaussée-Tirancourt (Bayard, 2018).

El conjunto militar del Pedrosillo, con todas las limitaciones inherentes, constituye un hito fundamental para avanzar en el conocimiento de los modelos de planta y arquitectura defensiva que se emplearon en Hispania durante el periodo republicano, cuyo conocimiento ha avanzado muy significativamente en la última década ${ }^{12}$. Estos nuevos datos nos permiten además avanzar sobre la propia evolución de la técnica de castrametación romana y de su adaptación a circunstancias concretas en un momento crucial como es la segunda mitad del siglo II a. C.

\section{REFERENCIAS}

Adam, J. P. (1996). La construcción romana, materiales y técnicas. León: Celarayn.

Alfaro, C. (1997). Las emisiones feno-púnicas. En C. Alfaro, A. Arévalo, M. Campo, F. Chaves, A. Domínguez y P. P. Ripollès (Eds). Historia monetaria de Hispania Antigua (pp. 50-115). Madrid: Jesús Vico S. A.

11. Plutarco (Mario, 6); Apiano (Iber. 99-100); Eutropio (IV, 27); Valerio Máximo (VI, 9, 3); Obsequente (41, 42, 46).

12. Una simple comparación de trabajos de comienzos de esta temática de comienzos del siglo XXI (Luik, 1997; Morillo, 2003; Morillo y Aurrecoechea, 2006; Cadiou, 2008; Dobson, 2008) con otros de hace pocos años ilustran perfectamente este avance (p. e. Morillo y Adroher, 2014; Sala Sellés y Moratalla, 2014; Padrós y Ruiz de Arbulo, 2015; Pera y Vidal, 2016; Morillo, 2016; Morillo y Sala Sellés, 2019; Quesada, 2019; Vallorí et al., 2019).
Aquilué, X., Dupré, X., Massó, J. y Ruiz de Arbulo, J. (1991). La cronología de les muralles de Tarragona. Revista d'Arqueologia de Ponent, 1, 272-304.

Asensio Esteban, J. A. (2006). El gran aparejo en piedra en la arquitectura de época romana republicana en la provincia Hispania citerior: el opus siliceum y el opus quadratum. Salduie, 6, 117-159.

Bayard, D. (2018). L'occupation des oppida gaulois par l'armée romaine à la fin de la République. L'exemple du “camp César" de la Chaussée-Tirancourt (80). En M. Reddé (Dir). Les armées romaines en Gaule à l'époque républicaine. Nouveaux témoignages archéologiques (pp. 155-178). Bibracte, 28. Glux-en-Glenne: Bibracte, Centre archéologique européen.

Bellón, J. P., Ruiz, A., Molinos, M., Rueda, C. y Gómez, F. (Eds.). (2015). La Segunda Guerra Púnica en la Península Ibérica. Baecula, Arqueología de una batalla. Jaén: Universidad de Jaén.

Bernardini, F., Vinci, G., Horvat, A., de Min, A., Forte, E., Furlani, S.,... y Tuniz, C. (2015). Early Roman military fortifications and the origin of Trieste, Italy. Proceedings of the National Academy of Sciences of the United States of America. Anthropology, 16, E1520-1529. DOI: https://doi. org/10.1073/pnas.1419175112

Berrocal, L. (2018). The Lusitanian Wars, a faceless conflict from the Archaeology of the 2nd century BC. En N. Moreira, M. Derderian y A. Bissonnette (Eds). Fields on conflict. Conference/2018/PEQUOT Museum. Conference Proceedings 4 (pp. 50-60). Mashantucket (CT): Pequot Museum.

Blázquez Cerrato, C. (2002). Circulación monetaria en el área occidental de la península ibérica. La moneda en torno al "Camino de la Plata". Montagnac: Monique Mergoil.

Blázquez Cerrato, C. (2010). El proceso de monetización de Lusitania desde el siglo I a. C. al siglo I d. C. En J.-G. Gorges y T. Nogales (Eds). Naissance de la Lusitanie romaine (Ier av.-Ier ap. J.-C.)/Origen de la Lusitania Romana (siglos I a. C.-I d. C.) (pp. 405-435). Toulouse - Mérida: Museo Nacional de Arte Romano.

Blázquez Cerrato, C. (2014). Huellas militares numismáticas en el occidente peninsular. En F. Cadiou y M. Navarro (Eds.). La guerre et ses traces. Conflicts et Sociétés en Hispanie à l'époque de la conquête romaine (IIIe-Ier siècle av. J. C.) (pp. 415-428). Mémoires, 37. Bordeaux: Ausonius Éditions.

Blé Gimeno, E. (2012). Tormenta romana. Análisis morfológico y funcional de la artillería romana tardorrepublicana en el nordeste peninsular. Gladius, XXXII, 25-48. DOI: https:// doi.org/10.3989/gladius.2012.0002

Blood, K., Lax, A. y Welfare, H. (1999). Analytical survey of the fort and its environ. En P. Bidwell, M. Snape y A. Croom. Hardknott Roman Fort, Cumbria, including an account of the excavations by the late Dorothy Charlesworth (pp. 22-32). CWAAS, Research Series, 9. Kendal: Cumberland and Westmorland Antiquarian and Archaeological Society.

Braconi, P. (2001). Emplecton. Annali di Archeologia e Storia Antica, Nuova Serie, 8, 105-118. 
Cadiou, F. (2008). Hibera in terra miles. Les armées romaines et la conquête de l'Hispanie sous la République (218-45 av. J.-C.). Madrid: Casa de Velázquez.

Campbell, D. B. (2018). Fortifying a Roman Camp. The Liber munitionibus castrorum of Hyginius. Text, translation and brief introduction by. Glasgow: Bocca della Verita.

Castanyer, P., Santos, M. y Tremoleda, J. (2015). Una nueva fortificación de época republicana en Empúries. Una base militar para la conquista de Hispania. En M. Bendala (Ed.). Los Escipiones en Hispania (pp. 107-127). Alcalá de Henares: Museo Regional de la Comunidad de Madrid.

Cerdeño, M. ${ }^{\mathrm{a}}$ L. y Gamo, E. (2016). Estudio preliminar del campamento romano de La Cabeza del Cid. (Hinojosa, Guadalajara, España). Complutum, 27(1), 169-184. DOI: https:// doi.org/10.5209/CMPL.53221

Deyber, A., Zaaraoui, Y. y Buffat, L. (2018). Le Lampourdier. Un camp romain républicain témoin de la bataille d'Orange (6 octobre 105 av. n.è). En M. Reddé (Dir.). Les armées romaines en Gaule à l'époque républicaine. Nouveaux témoignages archéologiques (pp. 19-43). Bibracte, 28. Gluxen-Glenne: Bibracte, Centre archéologique européen.

Dobson, M. (2008). The Army of the Roman Republic. The second century BC, Polybius and the camps at Numantia, Spain. Oxford: Oxbow.

Dobson, M. (2013). No holiday Camp: The Roman Republican Army Camp as a fine-tuned instrument of war. En J. D. Evans (Ed.). A companion to the Archaeology of the Roman Republic (pp. 214-233). Malden-Oxford: Blackwell. DOI: https://doi.org/10.1002/9781118557129.ch14

Dobson, M. (2014). Tents, huts or houses? Soldiers' accommodation at Numantia. The work of Adolf Schulten and beyond. En F. Cadiou y M. Navarro Caballero (Eds). La guerre et ses traces. Conflits et société en Hispanie à l'époque de la conquête romaine (IIIe-Ier s. av. J.-C.) (pp. 57-87). Bordeaux: Ausonius.

Driel-Murray, C. van. (2017). Warm and dry: a complete Roman tent from Vindolanda. En Q. Mould (Ed.). Leather in Warfare: Attack, Defence and the Unexpected (pp. 1-16). Leeds: Royal Armouries Museum in Leeds.

Duncan-Jones, R. P. (1980). Length-Units in Roman Town Planning: The Pes Monetalis and the Pes Drusianus. Britannia, 11, 127-133. DOI: https://doi.org/10.2307/525675

Fassbinder, J. W. E., Sternberg, R., Zanier, W., Ebner, D. y Rägeth, J. (2014). Magnetic prospecting of the Roman military Camp at Septimer Pass (Switzerland). Open Journal of Archaeometry, 2(1), 25303. DOI: https://doi.org/10.4081/ arc.2014.5303

Gamer, G. y Ortego, T. (1970). Nuevas observaciones sobre el campamento romano de Almazán (Soria). Celtiberia, 39, 67-79.

Galeano Cuenca, G. y Gil Fernández, R. (1998). Sobre algunos bronces romanos del museo de Priego de Córdoba. Antiquitas, 9, 55-60.

García-Bellido, M. ${ }^{a}$ P. y Blázquez, C. (2001). Diccionario de cecas y pueblos hispánicos. Madrid: CSIC.
Gauthier, F. (2016). The Changing Composition of the Roman Army in the Late Republic and the So-Called MarianReforms. Ancient History Bulletin, 30, 103-120.

Gorges, J. G., Morillo, A., Rodríguez Martín, F. G. y Martín Hernández, E. (2009). Le campement romano-républicain du "Pedrosillo" (Casas de Reina, Badajoz, Espagne) à l'épreuve des sondages: premiers résultats de la campagne 2006. En Á. Morillo, N. Hanel y E. Martín Hernández (Eds.). Limes $X X$. Actas del XX Congreso Internacional de Estudios sobre la Frontera Romana (pp. 267-279). Anejos de Gladius, 13. Madrid. CSIC - Polifemo.

Gorges, J.-G. y Rodríguez Martín, F. G. (2004). De Lusitanie en Bétique: Regina et le réseau routier romain entre Guadiana et Sierra Morena. En J.-G. Gorges, E. Cerrillo y T. Nogales (Eds.). Las comunicaciones en Lusitania romana ( $V$ Mesa Redonda Internacional sobre Lusitania Romana, Cáceres, 2002) (pp. 61-108). Madrid: Ministerio de Cultura.

Gorges, J.-G. y Rodríguez Martín, F. G. (2006). Un probable complejo militar romano de época republicana en la Beturia túrdula: notas preliminares sobre el campamento del "Pedrosillo" (Casas de Reina, Badajoz). En Á. Morillo (Ed.). Arqueología Militar Romana en Hispania. Producción y abastecimiento en el ámbito militar (pp. 655-669) León: Universidad de León.

Gorges, J.-G. y Rodríguez Martín, F. G. (2009). Les guerres lusitaniennes entre mythe, histoire et réalité: réflexions autour du complexe militaire romain du "Pedrosillo" (Casas de Reina, Badajoz, Espagne). En J.-G. Gorges, J. d'Encarnação, T. Nogales y A. Carvalho (Eds.). Lusitânia romana. Entre o mito e realidade. Actas da IV Mesa Redonda Internacional sobre a Lusitânia Romana (pp. 349-380). Cascais: Câmara Municipal de Cascais.

Gorgues, A., Rubio Rivera, R. y Bertaud, A. (2014). La Cerca de Aguilar de Anguita (Guadalajara, Espagne): un camp militaire romain d'époque républicaine? L'apport des nouvelles fouilles. En F. Cadiou y M. Navarro (Eds.). La guerre et ses traces. Conflicts et sociétés en Hispanie à l'époque de la conquête romaine (IIIe-Ier s. a. C.). Memoires, vol. 15 (pp. 99-132). Bordeaux: Ausonius.

Harnecker, J. (2004). Arminius, Varus and the Battlefield at Kalkriese. An introduction to the archaeological investigations and their results. Bramsche: Rasch.

Hauschild, T. (1984-1985). Excavaciones en la muralla romana de Tarragona. Torre de Minerva (1979) y Torre del Cabiscol (1983). Butlleti Arqueològic, 6-7, 11-38.

Heras Mora, F. J. (2009). El Santo de Valdetorres (Badajoz, España). Un nuevo enclave militar romano en la línea del Guadiana. En Á. Morillo, N. Hanel y E. Martín (Eds.). Limes $X X$. Actas del XX Congreso Internacional de Estudios sobre la Frontera Romana (pp. 315-327). Anejos de Gladius, 13. Madrid: CSIC - Polifemo.

Huther, S. (2014). Der römische Weihebezirk von Osterburken III. 1. 2. Die Holzbauwerke. Text. Darmstadtt: Landesamt für Denkmalpflege im Regierungspräsidium Sttutgart Konrad Theiss verlag.

Joly, M. y Barral, Ph. (2001). Le castellum 11. En M. Reddé y S. von Schnurbein (Dirs.). Alésia. Fouilles et recherches franco-allemandes sur les travaux militaires romains autour 
du Mont-Auxois (1991-1997). 1. Les fouilles (pp. 285-288). Paris: De Boccard.

Jones, R. H. (2012). Roman camps in Britain. The Hill, Stroud: Amberley.

Kühlborn, J. S. (2008). Oberaden, Stadt Bergkamen, Kreis Unna, und Beckinghausen, Stadt Lünen, Kreis Unna. Römerlagen in Westfalen, 3. Münster: Merkur Druck GmbH \& CO. KG, Detmold.

Kühlborn, J. S. (2009). Anreppen, Stadt Delbrück, Kreis Paderborn. Römerlagen in Westfalen, 4. Münster: Merkur Druck GmbH \& CO. KG, Detmold.

Lugli, G. (1957). La Tecnica Edilizia Romana, con particulare riguardo a Roma e Lazio. Roma: Giovanni Bardi.

Luik, M. (1997). Die römischen Militäranlagen der Iberischen Halbinsel von der Zeit der Republik bis zum Ausgang des Princizipats. Ein Forchungüberblick. Jahrbuch des römisch-germanischen Zentalsmuseum Mainz, 44, 213-275.

Luik, M. (2002). Die Funde aus den römischen Lagern um Numantia im Römisch-Germanischen Zentralmuseum. Bonn: RGZM.

Martin, R. (1965). Manuel d'architecture grecque. Vol. 1. Matériaux et techniques. Paris: Picard.

Martínez Velasco, A. (2011). Conquista y romanización en La Mancha y el Campo de Montiel: el campamento romano de El Real (Campo de Criptana, CR). Revista Estudios Campo de Montiel, 2, 57-94.

Matherat, M. G. (1943): La technique des retranchements de César. D'après l'enseignement des fouilles de Nointel. Gallia, I(1), 81-127. DOI: https://doi.org/10.3406/galia.1943.1951

Menchón Bes, J. y Massó Carballido, J. (1999). Les muralles de Tarragona. Defenses i fortificacions de la ciutat (segles II a. C. $-X X d$. C.). Tarragona: Centre d'Estudis Històrics i Socials Guillem Oliver del Camp.

Miller, M. C. J. y Voto, J. G. de. (Eds.). (1994). Polybius and Pseudo-Hyginus: the fortification of the Roman camp. Chicago: Ares.

Monnier, J. (2001). La Montagne de Flavigny. En M. Reddé y S. von Schnurbein (Dirs.). Alésia. Fouilles et recherches franco-allemandes sur les travaux militaires romains autour du Mont-Auxois (1991-1997). 1. Les fouilles (pp. 233-248). Paris: De Boccard.

Morales Hernández, F. y Morillo, A. (2020). Nuevas aportaciones sobre el Campamento III de Renieblas (Soria) ¿castra de Nobilior o castra de Escipión? Cuadernos de Prehistoria y Arqueología Universidad Autónoma de Madrid, 46, 187-214. DOI: https://doi.org/10.15366/cupauam2020.46.007

Morillo, A. (2003). Los establecimientos militares temporales: conquista y defensa del territorio en la Hispania republicana. En Á. Morillo, F. Cadiou y D. Hourcade (Eds.) Defensa y territorio en Hispania de los Escipiones a Augusto (Espacios urbanos y rurales, municipales y provinciales) (pp. 41-80). León - Madrid: Universidad de León - Casa de Velázquez.
Morillo, A. (2008). Criterios de identificación de campamentos romanos. Salduie, 8, 77-97.

Morillo, A. (2014). Campamentos y fortificaciones tardorrepublicanas en Hispania. "Calibrando" a Sertorio. En F. Sala y J. Moratalla (Eds.). Las Guerras Civiles romanas en Hispania (pp. 35-49). Alicante: Universidad de Alicante.

Morillo, A. (2016). Campamentos y fortificaciones tardorrepublicanas en Hispania. Una nueva línea de investigación en arqueología militar romana. En J. Pera y J. Vidal (Eds.). Fortificaciones y control del territorio en la Hispania republicana (pp. 1-51). Zaragoza: Pórtico.

Morillo, A. y Adroher, A. (2014). Modelos de arquitectura defensiva e implantación territorial de los campamentos republicanos en Hispania. En R. Mataloto, V. Mayoral y C. Roque (Eds.). La Gestación de los paisajes rurales entre la protohistoria y el periodo romano. Formas de asentamiento y procesos de implantación (pp. 228-252). Anejos de Archivo Español de Arqueología, LXX. Mérida: CSIC.

Morillo, A., Adroher, A., Dobson, M. y Martín Hernández, E. (2020). Constructing the archaeology of the Roman conquest of Hispania: new evidence, perspectives and challenges. Journal of Roman Archaeology, 33, 36-52. DOI: https://doi. org/10.1017/S1047759420000902

Morillo, A. y Aurrecoechea, J. (2006). The Roman Army in Hispania. An archaeological guide. León: University of León.

Morillo, A., Martín Hernández, E., Durán Cabello, R. y Rodríguez Martín, F. G. (2021). El campo de batalla tardorrepublicano del Pedrosillo (Casas de Reina, Badajoz). Campaña de 2010. En C. Pereira, P. Alburquerque, Á. Morillo, C. Fabião y F. Chaves (Eds.). De Ilipa a Munda. Guerra e conflicto no Sul de Hispânia (pp. 107-131). Lisboa: Universidade de Lisboa.

Morillo, A. y Morales Hernández, F. (2015). Campamentos romanos de la Guerra de Numancia: la circunvalación escipiónica. En M. Bendala (Ed.). Los Escipiones en Hispania (pp. 275-297). Alcalá de Henares: Museo Regional de la Comunidad de Madrid.

Morillo, A., Morales Hernández, F. y Durán Cabello, R. (2017). Schulten y los campamentos romanos republicanos en Hispania: una mirada desde el siglo XXI. En E. Baquedano y M. Arlegui (Eds.). Schulten y el descubrimiento de Numancia (pp. 174-200). Alcalá de Henares: Museo Regional de la Comunidad de Madrid - Museo Numantino.

Morillo, A., Rodríguez Martín, F. G., Martín Hernández, E. y Durán Cabello, R. (2011). The Roman Republican Battlefield at Pedrosillo (Casas de Reina, Badajoz, Spain). New research (2007). Conimbriga, L, 59-79. DOI: https://doi. org/10.14195/1647-8657 503

Morillo, Á. y Sala Sellés, F. (2019). The Sertorian Wars in the conquest of Hispania: from data to archaeological assesment. En A. P. Fitzpatrick y C. Haselgrove (Eds.). The Archaeology of Caesar in Britain and Gaul. New archaeological perspectives (pp. 49-72). Oxford - Philadelphia: Oxbow.

Napoli, J. (1997). Recherches sur les fortications linéaires romaines. Collection l'École Française de Rome, 229. Roma: École Française de Rome. 
Noguera, J. (2008). Los inicios de la conquista romana de Iberia: Los campamentos de campaña del curso inferior del río Ebro. Archivo Español de Arqueología, 81, 31-84. DOI: https://doi.org/10.3989/aespa.2008.v81.39

Noguera, J., Blé, E. y Valdés, P. (2015). Metal detecting for Surveying Marching Camps? En L. Vagalinski y N. Sharankov (Eds.). Limes XXII. Proceedings of the 22nd International Congress of Roman Frontier Studies Ruse, Bulgaria (September 2012) (pp. 853-860). Sofia: National Archaeological Institute.

Ocharan, J. A. y Unzueta, M. (2002). Andagoste (Cuartango, Álava). Un nuevo escenario de las guerras de conquista en el norte de Hispania. En Á. Morillo (Coord.). Arqueología militar romana en Hispania. Anejos de Gladius, 5 (pp. 311 325). Madrid: CSIC - Polifemo.

Oldestein, J. (1976). Zur Ausrüstung römischer Auxiliareinheiten. Beriche Römisch-Germanische Commission, 57, 21-284.

Padrós, C. y Ruiz de Arbulo, J. (Eds.). (2015). Dossier: Castella i praesidia a la façana mediterrània de la Hispània tardorepublicana. Revista d'Arqueología de Ponent, 25 , 229-325.

Palol, P. de. (1955-56). Pasadores en T iberorromanos en la Península Ibérica. Ampurias, 17-18, 97-110.

Parrinello, S., Bercigli, M. y Bursich, D. (2017). From survey to 3D model and from 3d model to "videogame". The virtual reconstruction of a Roman camp in Masada, Israel. Disegnarecon, 10(19), 11.1-11.19.

Paton, W. R. (translation), Walbank, F. W. y Habicht, C. (translation) (2014). Polybius, The Histories. Volume 3, Books 5-8. Cambridge - London: Mass - Loeb Classical Library and Harvard University Press.

Pera, J., Rodrigo, E., Romaní, N. y Carreras, C. (2019). Puig Castellar de Biosca (Lleida). Una fortificación romana del siglo II a. C. en el noreste de la Hispania Citerior. Gladius, XXXIX, 19-43. DOI: https://doi.org/10.3989/gladius.2019.02

Pera, J. y Vidal, J. (Eds.) (2016). Fortificaciones y control del territorio en la Hispania republicana. Zaragoza: Pórtico.

Peralta, E. (1999). El asedio romano del castro de La Espina del Gallego (Cantabria) y el problema de Aracellium. Complutum, 10, 195-212.

Peterse, C. L. J. (1984). Der oskische Fuss in pompejanischen Atrien. Bulletin Antieke Beschaving, 59, 9-30.

Peterse, C. L. J. (1985): Notes on the design of the house of Pansa (VI,6,1) in Pompeii. Mededelingen van het Nederlands Instituut te Rome, 16, 35-55.

Pöppelmann, H., Deppmeyer, K. y Steinmetz, H. D. (Eds.). (2013). Roms vergessener Feldzug. Der Schlacht am Harzhorn. Veröffentlichungen des Braunschweigischen Landesmuseum, 115. Darmstadt: Braunschweigischen Landesmuseum.

Poux, M. (2008). L'empreinte du militaire tardo-républicain dans les faciès mobiliers de La Tène finale. En M. Poux (Ed.)
Sur les traces de César. Militaria tardo-républicains en contexte gaulois (pp. 299-432). Bribacte, 14. Glux-en-Glenne: Bibracte, Centre archéologique européen.

Prados Martínez, F. (2007). La edilicia pública y su reflejo en la arquitectura ibérica: materiales, aparejos y técnicas constructivas. Pallas, 75, 9-35.

Prados Martínez, F., Jiménez Vialás, H., León Moll, M. ${ }^{a}$ J., Nicolás Mascaró, J. C., Adroher Auroux, A. y Torres Gomariz, O. (2020). Entre Cartago y Roma. Son Catlar y el impacto púnico en Menorca. En S. Celestino y E. Rodríguez (Eds.). IX Congreso Internacional de Estudios Fenicios y Púnicos / International Congress of Phoenician and Punic Studies (pp. 969-979). Mytra, 5. Mérida: Instituto de Arqueología de Mérida.

Prevot, Ph. (2008). Cinq mesures romaines graduées en bois de la colonie romaine d'Arausio/Orange (Vaucluse): étude de leurs applications à l'artisanat du petit mobilier. Gallia, 65, 327-353. DOI : https://doi.org/10.3406/galia.2008.3347

Quesada Sanz, F. (2008). La Arqueología de los campos de batalla. Notas para un estado de la cuestión y una guía de investigación. Salduie, 8, 21-35.

Quesada Sanz, F. (2019). El ejército romano republicano en la Península Ibérica: nuevos hallazgos y líneas de investigación (1977-2017) (I): generalidades, revisiones de excavaciones clásicas, campos de batalla. Índice Histórico Español, 132, 121-167.

Quesada Sanz, F., Gómez, F., Molinos, M. y Bellón, J. P. (2015). El armamento hallado en el campo de batalla de las Albahacas-Baecula. En J. P. Bellón, A. Ruiz, M. Molinos, C. Rueda y F. Gómez (Eds.). La Segunda Guerra Púnica en la península ibérica: Baecula: arqueología de una batalla (pp. 311-396). Textos CAAI, 7. Jaén: Universidad de Jaén.

Quilici, L. y Quilici Gigli, E. (Eds.). (2001). Fortificazioni antiche in Italia. Roma: Quasar.

Raepsaet, G. (2019). La civitas Tungrorum, le pes Drusianus et le statut foncier des terres conquises. Revue Belge de Philologie et d'Histoire / Belgisch Tijdschrift voor Filologie en Geschiedenis, 97, 67-94. DOI: https://doi.org/10.3406/ rbph.2019.9260

Rageth J., Zanier W. y Klein, S. (2010). Crap Ses und Septimer: Archäologische Zeugnisse der römischen Alpen eroberung 16/15v.Chr.aus Graubünden. Germania, 88, 241-183.

Reddé, M. (1995). Titulum et Clavicula. A propos des fouilles récentes d'Alésia. Revue Archéologique de 1 'Est et du Centre-Est, 46, 349-356.

Reddé, M., Schnurbein, S. von, Barral, Ph., Bénard, J., Brouquier-Reddé, V., Goguey, R.,... y Petit, Ch. (1995). Fouilles et recherches nouvelles sur les travaux de César devant Alésia (1991-1994). Neue Ausgrabungen und Forschungen zu den Belagerungswerken Caesars um Alesia (1991-1994). Bericht der Römisch-Germanischen Kommission, 76, 73-158.

Richmond, I. A. (1962). The Roman Siege-Works of Masada, Israel. Journal of Roman Studies, 52, 142-155. DOI: https:// doi.org/10.2307/297886 
Rodríguez Díaz, P. e Iñesta, J. (1984). “Las Dehesillas”. Un yacimiento prerromano en el término municipal de Higuera de Llerena (Badajoz). Materiales de superficie. Norba, 5, 17-28.

Romeo Marugán, F. (2021). El sistema ofensivo y campo de batalla del entorno de la ciudad antigua del Cabezo de Alcalá de Azaila (Teruel). Primeros resultados. Gladius, 41, 67-89. DOI: https://doi.org/10.3989/gladius.2021.04

Rost, A. y Wilberts-Rost, S. (2012). Kalkriese 6. Verteilung der Kleinfunde auf dem Oberesch in Kalkriese. Kartierung und Interpretation der römischen Militaria unter Einbeziehung der Befunde. Römisch-Germanische Forschungen, 79. Mainz: Philipp von Zabern.

$\mathrm{RRC}=$ Crawford, M. H. (1974). Roman Republican Coinage. Cambridge: Cambridge University Press.

Sala Sellés, F. (2014). Romans contra romans. Sertori i les guerres civils en el sud-est d'Hispània. Alicante: Museo Arqueológico de Alicante MARQ.

Sala Sellés, F. y Moratalla, J. (2014). (Eds.). Las guerras civiles romanas en Hispania. Una revisión histórica desde la Contestania. Alicante: Universidad de Alicante - Museo Arqueológico de Alicante MARQ.

Salgado Carmona, J. A. (2020). Consolidación y adecuación de yacimiento arqueológico de Cáceres el Viejo (Cáceres). Informe preliminar. Cáceres.

Sáez Abad, R. (2006). Artillería y poliorcética en el mundo grecorromano. Anejos de Gladius, 8. Madrid: CSIC - Polifemo.

Sánchez Moreno, E. (2017). Las Guerras Celtibérico-Lusitanas (114-93 a. C.) y su dimension geopolítica. En J. Principal, T. Naco, M. Durán e I. Mestres (Eds.). Roma en la Península Ibérica presertoriana. Escenarios de implantación militar provincial (pp. 59-77). Col. Instrumenta, 56. Barcelona: Universidad de Barcelona.
Schnurbein, S. von. (2001). Camps et castella. En M. Reddé y S. von Schnurbein (Dirs.). Alésia. Fouilles et recherches franco-allemandes sur les travaux militaires romains autor du Mont-Auxois (1991-1997). 1. Les fouilles (pp. 507-513). Paris: De Boccard.

Schulten, A. (1927). Numantia. Die Ergebnisse der Ausgrabungen 1905-1912. III. Die Lager des Scipio. München: von F. Bruckmann A. -G.

Schulten, A. (1929). Numantia. Die Ergebnisse der Ausgrabungen 1905-1912. IV. Die Lager bei Renieblas. München: von F. Bruckmann A. -G.

Schulten, A. (1933). Masada: Die Burg des Herodes und die Römischen Lager, mit einem Anhang; Beth-Ter. Sonderdruck aus der Zeitschrift des Deutschen Palästina-Vereins, 56. Leipzig: J. C. Hinrich'sche Buchhandlung.

Ulbert, G. (1984). Cáceres el Viejo. Ein spätrepublikanisches Legionslager in Spanish-Extremadura. Madrider Beitrage, XI. Mainz: Philipp von Zabern.

Unzueta, M. y Ocharan, J. A. (1999). Aproximación a la conquista romana del Cantábrico oriental: el campamento y/o campo de batalla de Andagoste (Cuartango, Álava). En J. M. Iglesias y J. A. Muñiz Castro (Eds.). Regio Cantabrorum (pp. 125-142). Santander: Caja Cantabria.

Vallorí Márquez, B., Rueda, C. y Bellón Ruiz, J. P. (Eds.). (2019). Accampamenti, guarnigioni e assedi durante la Seconda Guerra Púnica e la conqusita romana (secoli III-I a. C.): prospettive archeologiche. Roma: Quasar.

Völling, Th. (1990). Funditores im römischen Heer. Saalburg Jahrbuch, 45, 24-58.

Villaronga, L. (1973). Las monedas hispano-cartaginesas. Barcelona: Sección Numismática del Círculo Filatélico y Numismático.

Walbank, F. W. (1979). A Historical Commentary on Polybius. Vol. 3, Commentary on Books XIX-XL. Oxford: Clarendon Press. 